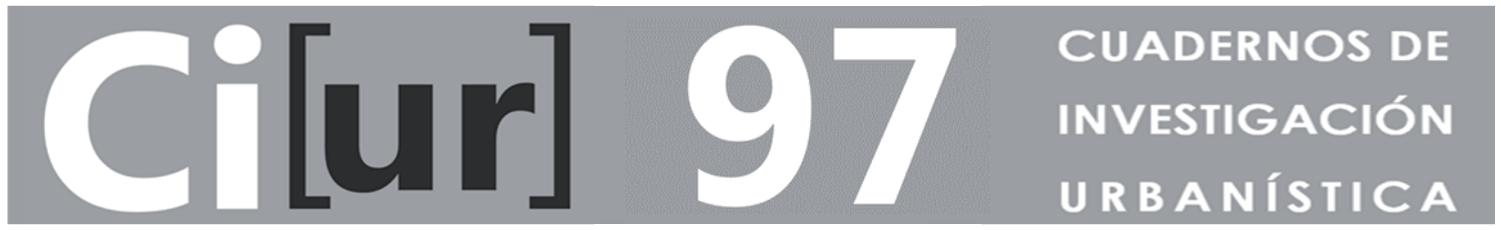

\title{
ANTECEDENTES Y FORMACIÓN DEL PLAN GENERAL DE VALENCIA DE 1966
}

\author{
JUAN RAMÓN SELVA ROYO \\ Doctor Arquitecto
}

Este documento es un extracto de la tesis doctoral "29+1. La ordenación urbanística metropolitana de Gran Valencia (1947-1986)", dirigida por el profesor José María Ezquiaga Domínguez y leída por su autor el día 9 de enero de 2013, en la Escuela Técnica Superior de Arquitectura de la Universidad de Navarra.

Noviembre / Diciembre 2014 


\section{Director: José Fariña Tojo}

\section{Consejo de Redacción:}

Director Ester Higueras García

Jefe de redacción María Emilia Román López

Vocales Julio Alguacil Gómez (Univ. Carlos III de Madrid), Pilar Chías Navarro (Univ. Alcalá de Henares, Madrid), José Antonio Corraliza Rodríguez (Univ. Autónoma de Madrid), Alberto Cuchí Burgos (Univ. Politécnica de Cataluña), José Fariña Tojo (Univ. Politécnica de Madrid), Agustín Hernández Aja (Univ. Politécnica de Madrid), Mariam Leboreiro Amaro (Univ. Politécnica de Madrid), Rafael Mata Olmo (Univ. Autónoma de Madrid), Fernando Roch Peña (Univ. Politécnica de Madrid), Carlos Manuel Valdés (Univ. Carlos III de Madrid)

Consejo Asesor:

Ma Teresa Arredondo (Directora de Relaciones con Latinoamérica, Univ. Politécnica de Madrid), Luis Maldonado (Director de la Escuela Superior de Arquitectura, Univ. Politécnica de Madrid), Antonio Elizalde, Julio García Lanza, Josefina Gómez de Mendoza, José Manuel Naredo, Julián Salas, Fernando de Terán

Comité Científico: Antonio Acierno (Univ. Federico II di Napoli, Nápoles, ITALIA), Miguel Ángel Barreto (Univ. Nal. del Nordeste, Resistencia, ARGENTINA), Luz Alicia Cárdenas Jirón (Univ. de Chile, Santiago de Chile, CHILE), José Luis Carrillo (Univ. Veracruzana, Xalapa, MÉXICO), Marta Casares (Univ. Nal. de Tucumán, ARGENTINA), María Castrillo (Univ. de Valladolid, ESPAÑA), Mercedes Ferrer (Univ. del Zulia, Maracaibo, VENEZUELA), Fernando Gaja (Univ. Politécnica de Valencia, ESPAÑA), Alberto Gurovich (Univ. de Chile, Santiago de Chile, CHILE), Josué Llanque (Univ. Nal. S. Agustín Arequipa, PERÚ), Angelo Mazza (Univ. Federico II di Napoli, Nápoles, ITALIA), Luis Moya (Univ. Politécnica de Madrid, ESPAÑA), Joan Olmos (U. Politécnica de Valencia, ESPAÑA), Ignazia Pinzello (Univ. degli Studi di Palermo, Palermo, ITALIA), Julio Pozueta (Univ. Politécnica de Madrid, ESPAÑA), Alfonso Rivas (UAM Azcapotzalco, Ciudad de México, MÉXICO), Silvia Rossi (Univ. Nal. de Tucumán, ARGENTINA), Adalberto da Silva (Univ. Estadual Paulista, Sao Paulo, BRASIL), Carlos Soberanis (Univ. Francisco Marroquín, Guatemala, GUATEMALA), Carlos A. Torres (Univ. N ${ }^{\text {al }}$. de Colombia, Bogotá, COLOMBIA), Graziella Trovato (Univ. Politécnica de Madrid, ESPAÑA) Carlos F. Valverde (Univ. Iberoamericana de Puebla, MÉXICO), Paz Walker (Univ. de la Serena, Santiago de Chile, CHILE), Fernando N. Winfield (Univ. Veracruzana, Xalapa, MÉXICO)

Maquetación: Antonio Jesús Antequera Delgado: ciur.urbanismo.arquitectura@upm.es

Distribución: Mairea Libros: distribucion@mairea-libros.com

\section{(C) COPYRIGHT 2014}

JUAN RAMÓN SELVA ROYO

I.S.S.N. (edición impresa): 1886-6654

I.S.S.N. (edición digital): 2174-5099

Año VII, Núm. 97, noviembre-diciembre 2014, 68 págs.

Edita: Instituto Juan de Herrera

Imprime: FASTER, San Francisco de Sales 1, Madrid 


\title{
DESCRIPTORES:
}

\author{
Plan General / Área Metropolitana / Gran Valencia
}

\section{KEY WORDS:}

General Urban Management Plan / Metropolitan Area /Great Valencia Conurbation

\section{RESUMEN:}

La Adaptación del Plan General de Ordenación Urbana de Valencia y su Comarca a la Solución Sur, aprobada el 30 de junio de 1966, es sin duda uno de los proyectos más polémicos y trascendentales del urbanismo metropolitano valenciano. Un plan denostado -a menudo descalificado con el escueto epíteto de desarrollista- pero del que curiosamente no se ha llegado a publicar ningún documento original: la bibliografía especializada no le prestó atención a la intrahistoria proyectual, centrándose más bien en los razonamientos sociopolíticos que justificaron su derogación. Pareciera que, en el fondo, nadie quiso nunca plantearse las preguntas correctas, incluyendo aquella que explicara cómo los arquitectos redactores de la Corporación Administrativa Gran Valencia (tres de los mejores profesionales de su generación) pudieron llegar a ser responsables de un Plan General supuestamente tan desastroso. El amplio período que separó la aprobación ministerial de los trabajos de la Comisión Técnica Especial (22 de julio de 1958) de la aprobación definitiva del Plan General -ocho años decisivos- exige, pues, ser analizado en profundidad para obtener una adecuada comprensión de este último. Tal es el propósito del presente artículo, ofreciendo un análisis crítico respaldado por los interesantes e inéditos trabajos previos a su redacción final.

\section{ABSTRACT:}

There is no doubt in asserting that the Adaptation of the Valencia and its Country General Urban Management Plan to the South Settlement, approved on June 30, 1966, has become one of the most controversial and transcendental projects referred to the Valencian metropolitan urbanism. A reviled planning, often labeled as a developmentalist one, despite the fact that any of its original documents was never published: specialized literature paid no attention to the intra-history, focusing instead in the sociopolitical reasons which led to its revocation. It could ultimately seem that no one wanted to ask the right questions, like how could it be possible that Greater Valencia Administrative Corporation architects (three of the main experts of their generation) answered for such a supposedly calamitous Town Planning. Thus, in order to achieve right insight, it's necessary to carefully analyze the wide period -eight decisive years- between the ministerial approval of the Special Technic Commission conclusions (July 22, 1958) and the finally adoption of the Plan. Such is this paper's aim, enabling a proper comprehension supported by the interesting and unpublished drawing up of its previous studies. 


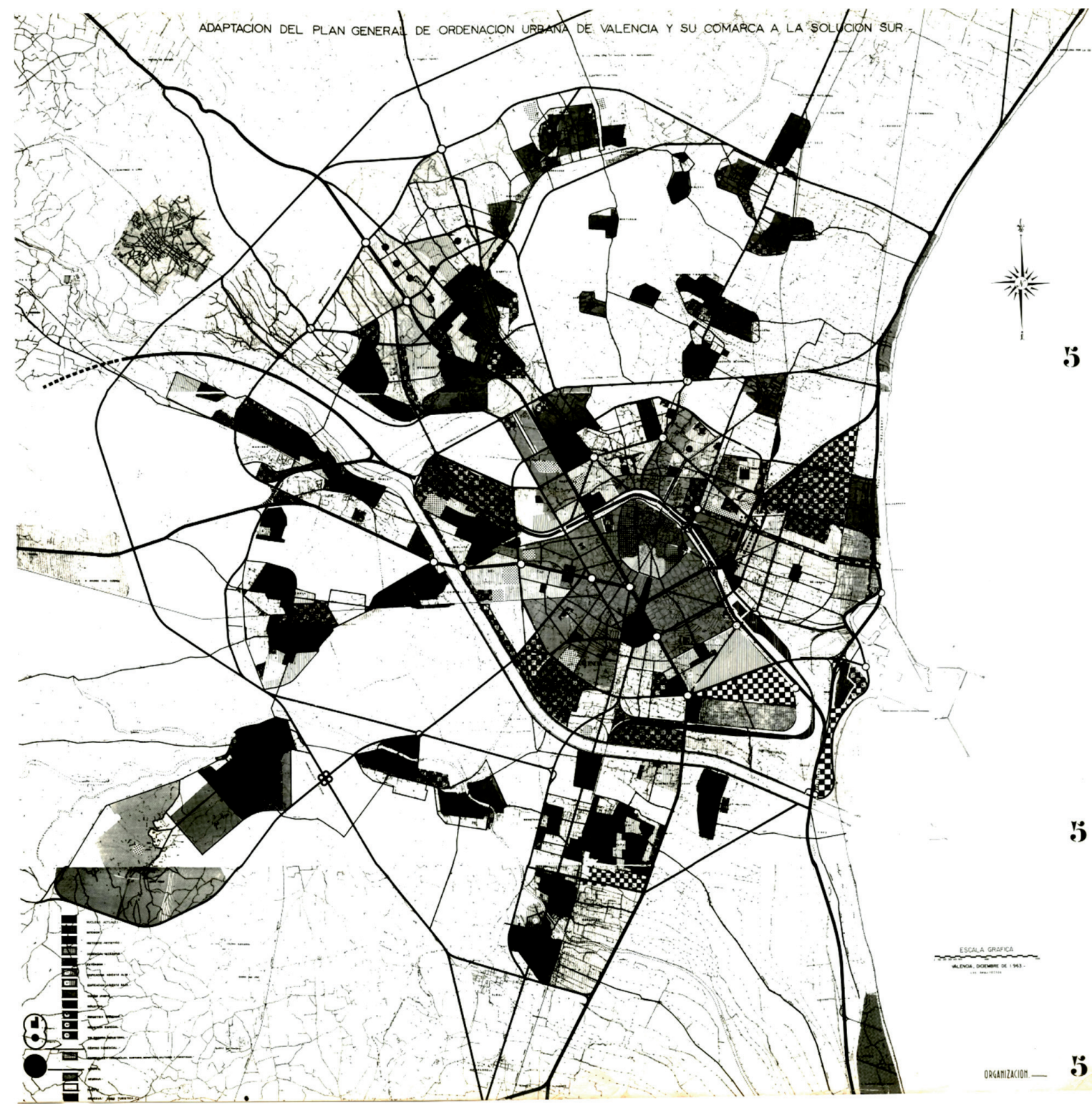

Figura 0. Adaptación del Plan General de Ordenación Urbana de Valencia y su Comarca a la Solución Sur. Reproducción fotográfica del Plano 5. Organización (Zonas verdes). Diciembre 1963. Escala gráfica: hoja de $71 \times 71 \mathrm{~cm}(1: 10.000$ en el original)

Fuente: Archivo de Planeamiento del Ayuntamiento de Valencia

\section{CONSULTA DE NÚMEROS ANTERIORES/ACCESS TO PREVIOUS WORKS:}

La presente publicación se puede consultar en color en formato pdf en la dirección: This document is available in pdfformat and full colour in the following web page: http://www2.aq.upm.es/Departamentos/Urbanismo/institucional/publicaciones/ciur/ 


\section{ÍNDICE}

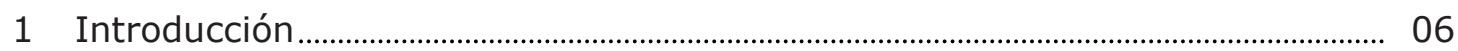

2 La Ordenación de Valencia (1959): un Plan General desconocido........................ 06

2.1 Incertidumbre y preparativos en la Gran Valencia.............................................. 06

2.2 El Plan de Adaptación de la capital ........................................................................ 11

2.3 Tramitación fallida y renuncia de García Ordóñez .............................................. 20

3 El Plan General de Valencia y su Comarca adaptado a la Solución Sur............ 32

3.1 El área metropolitan como referente..................................................................... 32

3.2 Plan General del Sector Burjasot, Benimanet, Paterna, Godella y

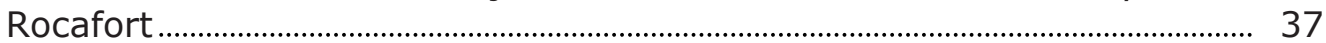

3.3 La primera redacción de la adaptación (1963) …….......................................... 40

3.4 Cesiones y compromisos: hacia la versión definitiva........................................... 46

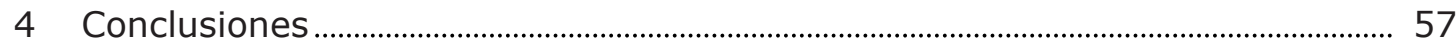

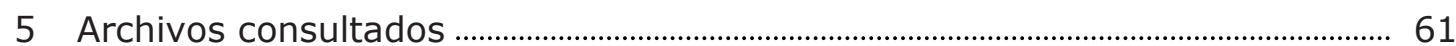

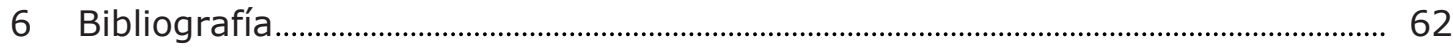




\section{INTRODUCCIÓN}

En los últimos años -sobre todo a raíz del cincuentenario de la doble riada que sufrió la ciudad de Valencia en 1957- han visto la luz diversos artículos sobre el cambio de rumbo que experimentó esta urbe. Algunos de ellos son simplemente conmemorativos; otros, en cambio, sacan a la luz interesantes antecedentes y razones técnicas de la publicación Valencia - Ordenación Técnica de la Ciudad y su Comarca, el documento que concretó el desvío del río Turia a un nuevo cauce ${ }^{1}$.

Todas estas investigaciones, sin embargo, desarrollan aspectos relacionados con la inicialmente denominada Solución Sur, pero sin conexión directa con el Plan General de Ordenación Urbana que finalmente se aprobó ocho años más tarde, en 1966. La cuestión clave de por qué ese plan llegó a ser como fue, tan distinto de los planteamientos de la Comisión Técnica Especial, tiene más bien que ver con los eslabones perdidos de los que se hablará a continuación.

Se ha tomado como punto de partida cronológico la publicación antes mencionada. Este documento fue editado por la Delegación del Gobierno en 1958 para dar a conocer las conclusiones del equipo interdisciplinar que abordó cómo solucionar definitivamente el problema histórico de las riadas.

A partir de ahí, resulta necesario destacar la figura del arquitecto Fernando M. García-Ordóñez ${ }^{2}$, coordinador urbanístico de la Comisión Técnica Especial por designación directa del Director General de Urbanismo, Pedro Bidagor Lasarte. Además, es preciso introducir al menos la mención de la Corporación Administrativa Gran Valencia, entidad político-técnica que desde 1947 se encargaba de supervisar el urbanismo metropolitano de la capital levantina ${ }^{3}$. Estos dos protagonistas son fundamentales a la hora de entender los acontecimientos que seguirán.

\section{LA ORDENACIÓN DE VALENCIA (1959): UN PLAN GENERAL DESCONOCIDO}

\subsection{Incertidumbre y preparativos en la Gran Valencia}

En enero de 1958, al poco de constituirse la citada Comisión, García-Ordóñez ya había perfilado cuál iba a ser el futuro de la comarca en el tercer artículo que

\footnotetext{
1 Es el caso, por ejemplo, de LLOPIS ALONSO, Amando (2010), "El Jardín del Turia: otros tiempos, otros proyectos, otras imágenes", en Historia de la ciudad VI. Proyecto y complejidad. Valencia: ÍCARO (Colegio Territorial de Arquitectos de Valencia); o del libro VV.AA. (2007), La riuà que canvià València. Valencia: Adonay, catálogo de la exposición homónima.

2 Fernando Martínez García-Ordóñez (n.1922), arquitecto y urbanista, ha sido recientemente reconocido por la crítica arquitectónica. Destaca la distinción de Mestre Valencià d'Arquitectura que el Colegio Oficial de Arquitectos de la Comunidad Valenciana le otorgó en 2007. Puede obtenerse más información sobre su figura en el libro digital SELVA ROYO, Juan Ramón (2013), FMGO, Fernando M. García-Ordóñez, Arquitecto. 1954-1983, o bien en su entrada biográfica en Wikipedia.

3 Para una adecuada comprensión de este organismo, puede consultarse, por ejemplo, SELVA ROYO, Juan Ramón (2014), 29+1. La ordenación urbanística metropolitana de Gran Valencia (1947-1986). Tesis doctoral sin publicar. Director: José María Ezquiaga Domínguez. Universidad de Navarra, Escuela Técnica Superior de Arquitectura. De hecho, el presente artículo es deudor directo de la citada investigación.
} 
publicó en la revista Nuestro Tiempo ${ }^{4}$. Bajo el título de "Un Plan Regional: nueva Valencia", trataba de las directrices que se estaban aplicando en la coordinación de los trabajos de la Oficina Técnica para la Ordenación de Valencia y su región circundante. Más tarde, con la aprobación en julio de los trabajos de la Solución Sur, los criterios básicos en el orden urbanístico, a modo de resumen, fueron expuestos en lo que entonces se vino a denominar Esquema Director ${ }^{5}$.

Una vez que se contó con la aprobación del Consejo de Ministros, y tras dejar ultimada durante el mes de agosto los detalles de la citada publicación de la Delegación del Gobierno (tarea que recayó en la Comisión Técnica Especial), Bidagor autorizó a la Oficina Técnica de Gran Valencia para que comenzara los trabajos del Plan General adaptado a la Solución Sur. Este departamento técnico estaba integrado entonces por los arquitectos valencianos Mauro Lleó Serret (Arquitecto Jefe), Víctor Bueso Bellot y Antonio Gómez Llopis. A la vez, se confió a Fernando Martínez García-Ordóñez -que había intervenido en los trabajos anteriores pero no pertenecía a dicha Oficina- su dirección y coordinación para esta tarea concreta.

En efecto, el acta no 101 de la Comisión Ejecutiva de la Gran Valencia, de 19 de septiembre de 1958, refleja que también en despacho extraordinario, la Presidencia (que todavía recaía en el Alcalde Tomás Trénor, forzado a dimitir el 8 de octubre siguiente) se ocupa de la labor que ha de realizar la Oficina Técnica de Gran Valencia para la rectificación y adaptación del Plan General de Ordenación Urbana, así como también para verificar estudios de emplazamiento de algunos polígonos, estimando que esta Oficina podría ser ampliada con el nombramiento de un Arquitecto de los que han formado parte de la Oficina Técnica de la Comisión Técnica Especial, y concretamente propone que D. Fernando Martínez y GarcíaOrdóñez entre a formar parte de la Oficina Técnica de Gran Valencia, entendiendo que su cargo no forma parte de la plantilla, y que el nombramiento se hace con carácter temporal. Las propuestas de la Presidencia se aprueban por unanimidad.

En el Archivo Histórico de la Generalitat Valenciana se conserva una carta del día 15 de septiembre, firmada por el Secretario de la Corporación Administrativa, Rafael Ariño, y dirigida a Manuel Muñoz Monasterio (el Arquitecto que, desde Madrid, ejercía de supervisor -Arquitecto Director- de la Oficina Técnica de Gran Valencia), que concluye requiriendo la presencia de éste para la referida sesión de la Comisión Ejecutiva, y aludiendo a una misiva del alcalde Tomás Trénor a Bidagor en referencia a unos asuntos sobre Gran Valencia que no se explicitan (se supone que relacionados con el inicio de la redacción de la Adaptación).

Es probable que estos asuntos trataran sobre la significativa petición que el propio Director General de Urbanismo haría pocos días más tarde a Rafael Ariño: el arquitecto Emilio Larrodera, Jefe de Planeamiento del Ministerio, había informado del poco cuidado que los técnicos de Gran Valencia ponían en la redacción de los planes que remitían para aprobación de la Comisión Central (pues omitían

\footnotetext{
4 GARCÍA-ORDÓÑEZ, Fernando M. (1958), "Un plan regional: nueva Valencia", Nuestro Tiempo, no 45, Pamplona.

5 Véase GARCÍA HEREDIA, Antonio (2008), "Principio y fin del área metropolitana de Valencia. De la autarquía a la democracia", en Historia de la ciudad V. Tradición y progreso. Valencia: ÍCARO (Colegio Territorial de Arquitectos de Valencia). Se remite a dicho artículo para repasar textualmente los puntos del citado Esquema.
} 
documentación requerida por la recién aprobada Ley del Suelo), ante lo cual Bidagor decidió tomar cartas en el asunto ${ }^{6}$.

En cualquier caso, la incorporación de García-Ordóñez con la aquiescencia del Ministerio significó de hecho el inicio de un período de dos años en los que el Ayuntamiento -y por extensión, Gran Valencia- se vio desplazado en las tareas urbanísticas metropolitanas en favor de un desconocido arquitecto foráneo, hecho que no dejó de levantar suspicacias y supondría un verdadero problema más adelante.

Tras la riada de octubre de 1957 (aunque con algo de retraso sobre la iniciativa ministerial), desde la Comisión Ejecutiva había reclamado la necesidad de una instancia que coordinase a los organismos afectados, y que quizá la Corporación había de efectuar tal papel. En ese sentido apuntaba un escrito del alcalde de la capital dirigido al Consejo General de Gran Valencia, de 30 de diciembre de 1957:

(...) La catástrofe ocurrida en Valencia el pasado octubre a causa de las inundaciones producidas por el río Turia, ha tenido como consecuencia la necesidad de reconsiderar el Plan de Ordenación urbana de la misma.

Aparece como problema primordial el destino que haya de darse al actual cauce del río; se tienen noticias de que organismos dependientes del Ministerio de Obras Públicas están procediendo al estudio de posibles soluciones, y que ha sido suprimida indefinidamente la ejecución de las obras de modificación del trazado del ferrocarril Valencia a Tarragona. Como consecuencia de este ambiente formado, parece ser que se está estudiando, de una manera oficiosa, la posibilidad de modificar el Plan General de Ordenación urbana de Valencia y su comarca.

Todo ello es absolutamente lógico, ya que el estudio del problema del río bajo el aspecto hidráulico exclusivamente es incompleto, puesto que lleva aparejado otros dos aspectos, como son los enlaces ferroviarios y el urbanístico, ya que según sea la solución que se dé al río, será distinta también la solución urbana de la zona en contacto con el mismo, e incluso del conjunto de la Ciudad.

A juicio de esta Comisión Ejecutiva, el estudio de esos problemas que enunciamos y la modificación de planes y proyectos en ejecución, no deben efectuarse de una manera aislada por los distintos organismos afectados, sino que debe ser consecuencia de un estudio general de los efectos que las pasadas inundaciones han producido.

La dificultad que puede representar coordinar las iniciativas de los distintos organismos que han de ejecutar obras en la zona afectada por el Plan General de Ordenación de Valencia y su comarca, queda superada con la intervención del Consejo General de la Corporación Administrativa Gran Valencia, ya que por estar

\footnotetext{
${ }^{6}$ Entre otras cosas, Bidagor le remitió al secretario de Gran Valencia el oficio del Jefe de Planeamiento, en el que se decía: La vigente Ley sobre Régimen de Suelo señala, en sus artículos 9 y 10, la documentación que debe integrar los Planes generales y parciales. Estos extremos son omitidos por lo general en los proyectos remitidos por Gran Valencia, que en algunos casos se limita a enviar Proyectos que se reducen a un plano sin memoria justificativa. Así mismo, la modificación de planes parciales, como el caso de Tabernes Blanques y Plan Parcial 12-B carecen de los antecedentes y memoria necesarios para poder enjuiciar el alcance de la modificación propuesta, pues no se señala en ellos las características del Plan vigente ni se acompaña memoria detallada. Oficio de la Dirección General de Urbanismo, de fecha 16 de septiembre de 1958.
} 
integradas en este organismo todas las representaciones de los distintos órganos que intervienen de alguna manera en las obras que han de realizarse en Valencia y su comarca, es el más idóneo para proponer las directrices que han de seguirse en los proyectos que afectan a su comarca, impidiendo que la actuación de los organismos existentes sea aislada de cada uno sin contacto ni conexión con los demás.Por todo ello, la Comisión Ejecutiva de la Corporación Administrativa Gran Valencia, ha estimado conveniente someter a la consideración de su Consejo General la siguiente propuesta:

10. Que se considere de nuevo el Plan General de Ordenación de Valencia y su Comarca, para estudiar las enseñanzas que las pasadas inundaciones han traído consigo y las modificaciones que la realidad aconseja introducir en el referido Plan.

20. Que estando en curso de ejecución importantes obras que afectan a la zona incluida en el Plan General de Ordenación de Valencia y su comarca, tales como la canalización del río Turia, los accesos a la Ciudad por carretera, la desviación de la línea de Tarragona, etc., debe el Consejo General estudiar de nuevo estos proyectos a la luz de las enseñanzas producidas por la pasada riada, para dar su autorizada opinión sobre los mismos y proponer las modificaciones que deben introducirse en los mismos, al objeto de que se lleven a cabo con arreglo a un plan armónico y no se produzca la paralización indefinida de obras cuya iniciación han necesitado esfuerzo de las autoridades valencianas en su labor de muchos años.

El Consejo General, no obstante, resolverá con su mejor criterio lo que estime oportuno.

Como ya se ha visto, la realidad es que Gran Valencia quedó apartada de esa coordinación que reclamaba para sí, pues la intervención desde Madrid la relegó a un segundo plano, a la espera de los acontecimientos hasta el momento oportuno. En esos momentos críticos, incluso se había llegado a plantear la oportunidad de la existencia de la Corporación. Para empezar a recabar información, y con vistas a la confección de los Presupuestos del bienio 1958/59, hasta se le requirió que enviara relación nominal detallada del personal que prestaba sus servicios en ella.

El entonces alcalde de Valencia, Tomás Trénor Azcárraga, Marqués del Turia, se dedicó desde finales de 1957 a buscar soluciones que permitieran hacer operativo el Decreto de Adopción de Valencia por parte del Caudillo concedido tras la riada (emitido por el Ministerio de la Vivienda el 23 de diciembre de 1957), todavía sin dotación económica. Fue el comienzo de una serie de enfrentamientos con las autoridades del Gobierno, que desembocaron en su destitución el 8 de octubre del año siguiente, y que tuvieron su punto culminante en su famoso discurso de 19 de junio de 1958 ante el pleno del Ayuntamiento ${ }^{7}$.

\footnotetext{
7 Véase PÉREZ PUCHE, Francisco (1997). Hasta aquí llegó la riada. Valencia: Ayuntamiento de Valencia. Ahí se recoge el discurso íntegro, tal y como fue difundido por el Ateneo Mercantil de Valencia (su difusión en prensa estuvo prohibida por el Gobierno Civil), a raíz de una nueva riada ese mismo mes, que vino a evidenciar la falta de recursos que se seguía padeciendo.
} 
Como se ha visto, a las pocas semanas de incorporar a García-Ordóñez a la Oficina Técnica, el alcalde Trénor fue destituido, y su lugar fue ocupado por Adolfo Rincón de Arellano. Entonces, por disposición de la Dirección General de Urbanismo, la Corporación Administrativa -cuya Comisión Ejecutiva presidía el alcalde de Valencia- recuperó las competencias con vistas a la revisión del Plan, y se emprendió la elaboración del mismo.

García-Ordóñez, en una entrevista concedida al arquitecto Juan Cano, llega a decir que Rincón de Arellano, que sucedió al Marqués del Turia, le encargó que actualizara los planos de la parte Sur de la ciudad, que venían afectados por el desvío. Seguramente este encargo fuera a propuesta de Bidagor, pues el Alcalde estaba recién llegado a la primera línea de acción municipal, y posiblemente en esta decisión pesó la cuestionada eficiencia de la Oficina Técnica de Gran Valencia, a raíz del episodio ya visto de la documentación incompleta y la protesta de Larrodera. En cualquier caso, a los pocos meses ya se habían intensificado los trabajos de Adaptación del Plan (de eso se trataba, de situar exactamente el nuevo cauce en el Plan General de Valencia y corregirlo con las actuaciones asociadas al desvío), y así lo prueba la numerosa correspondencia que -desde enero de 1959- se conserva entre García-Ordóñez (al frente de la Oficina Técnica en Valencia) y Muñoz Monasterio o el propio Bidagor (dando su visto bueno desde Madrid).

En la citada entrevista, el arquitecto asturiano recuerda que trabajó durante tres o cuatro meses en la oficina de la Gran Valencia, con unos delineantes, tratando de situar el cauce Sur y los posibles nudos, en coordinación con Gómez-Perreta, y de ahí salió el polígono industrial de Vara de Cuart, para trasladar la industria. Hubo una discusión durante toda la redacción del Plan Sur: "yo tenía una obsesión, que la ciudad no se expandiera hacia abajo, hacia la Albufera. El cordón del río era muy importante, había que hacer dos calzadas, y -no sé por qué- querían llevar el ferrocarril por la margen Sur. Y yo estaba en contra porque el ferrocarril siempre sería un foco de infección industrial. Llevémoslo por arriba, puesto que así aseguramos el crecimiento entre la ciudad y el margen." Costó mucho, pero al final se consiguió proteger el espacio natural de la Albufera. Seguramente, GarcíaOrdóñez no precisó bien la duración de su trabajo al frente de Gran Valencia, pues hasta verano de 1959 consta su puesto de coordinador en la correspondencia archivada (ese Plan Marco ${ }^{8}$ ya estaba listo en primavera, al menos en lo tocante a la capital).

En abril de ese año, con los trabajos de Adaptación ya muy avanzados, quedaría reforzada finalmente la necesidad de Gran Valencia como entidad coordinadora, tras presentar Rincón de Arellano un escrito al Ministerio, razonando los términos de la propuesta de subsistencia, adaptación, modificación, fusión con otra entidad estatal

\footnotetext{
8 Así lo denomina García-Ordóñez en la entrevista del arquitecto Juan Cano: El plan Sur era como un Plan Madre. Es importante saber esto. Nunca se había hecho un proyecto tan ambicioso en España y yo creo que tampoco en Europa. Era ambicioso, no porque quisiera serlo, sino porque para actuar había que tocar una barbaridad de cosas. Y la prueba es que la oficina técnica se montó para que hubiera una representación de los distintos organismos que se encontraban afectados: Agricultura (sobre todo Riegos), Obras Públicas, Carreteras y Ferrocarriles, Obras Hidráulicas, la Confederación Hidrográfica del Júcar, Puertos, el problema urbano de la ciudad, todos los espacios industriales (como el polígono Fuente del Jarro), áreas de expansión (como La Fe o como la del puerto). Con esto se dibujó lo que podía ser un Plan Marco.
} 
autónoma o incorporación al presupuesto del Estado de los servicios actualmente encomendados a la Entidad ${ }^{9}$.

\subsection{El Plan de Adaptación de la capital}

Con respecto a las propuestas técnicas de los trabajos de revisión del Plan de Valencia, la Oficina Técnica estudió en primer lugar lo referente al municipio de Valencia (en concreto, la situación de los Polígonos para vivienda de Renta Limitada proyectados a raíz de la ley de 1955 y la zonificación general) para pasar a continuación -ese era el plan inicial previsto- al estudio de la comarca ${ }^{10}$.

A tal fin, se requirió del arquitecto municipal de urbanismo, Camilo Grau Soler, preparar el plan completo de urbanización del Polígono de la Avenida de Castilla -el único que de momento se iba a iniciar en Valencia-, ya que el Director General de Urbanismo era partidario de subastar las obras necesarias. El plano de Zonificación (III, a escala $1: 10.000$ ) ya estuvo preparado el 1 de abril, pues una semana antes Monasterio se había llevado una copia a Madrid con el fin de preparar el plan de etapas. También se estaba dedicando desde la capital a la redacción de las normas urbanísticas, en coordinación con García-Ordóñez.

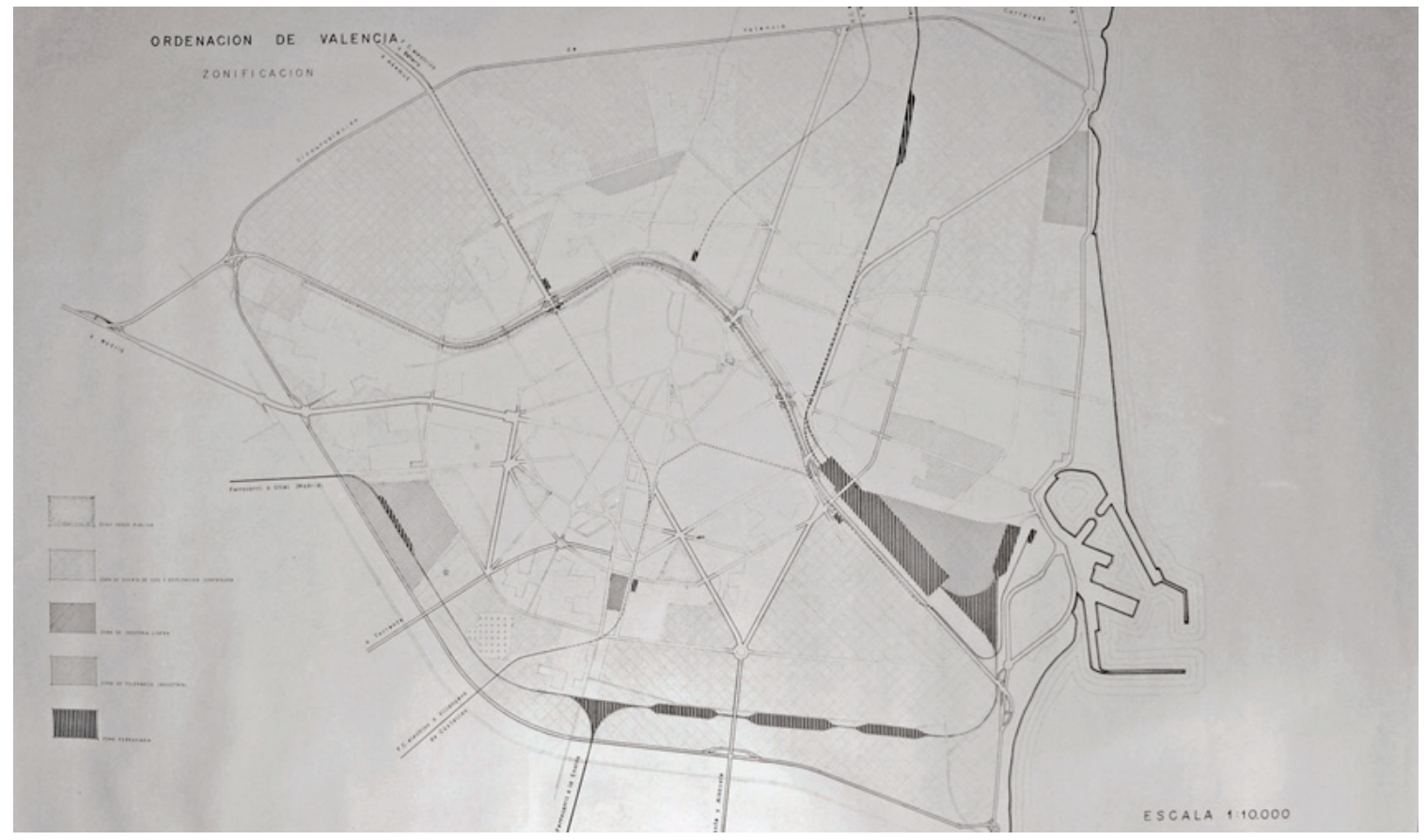

Figura 1. El plano III, de Zonificación a escala 1:10.000, elaborado por García-Ordóñez en marzo de 1959 como documento integrante de la revisión del Plan General. Este plano ha permanecido inédito hasta hoy.

Fuente: Archivo Histórico Municipal del Ayuntamiento de Valencia

${ }_{9}^{9}$ Escrito de 7 de abril de 1959, del Presidente de la Comisión Ejecutiva, incluido como Anexo nº II en informe requerido por el Ministerio de la Vivienda.

10 Así lo atestiguan varias cartas de Manuel Muñoz Monasterio a Fernando M. García-Ordóñez, que se conservan en el Archivo Histórico de la Generalitat Valenciana. Véanse, por ejemplo, las de 21 de febrero y 1 de abril de 1959. 
Se tomó como referencia la Memoria, Normas, Ley y Reglamento del Plan de Ordenación Urbana de Barcelona y su Comarca, que la Comisión de Urbanismo remitió el 6 de mayo por carta de Manuel Teixidor. También se solicitaron a la Dirección General de Urbanismo (en escrito dirigido al Jefe de Planeamiento, Emilio Larrodera) modelos de ordenanzas para zona industrial y para zona de tolerancia industrial, pidiendo las instrucciones precisas para redactar las que habrían de plantearse en Valencia.

La Ordenación de Valencia quedó, pues, lista enseguida. En el Archivo de Planeamiento del Ayuntamiento de Valencia se conserva un documento hasta ahora inédito, fechado en marzo de 1959, y que -sin estar firmado- hay que atribuir sin ninguna duda a García-Ordóñez.

Se trata del Plan de Adaptación Urbana a la Solución Sur de desvío del Río Turia, y comprende una extensa y razonada relación de las medidas que habían de adoptarse para ello, describiéndose aquellos que en el actual desarrollo a mayor escala han sufrido ciertas modalidades o decisiones. No obstante, debe entenderse que el programa desarrollado en los planos que se acompañan, no puede tener sentido de detalle. Su interés se deriva de un enfoque conjunto de la ciudad. En él se podrá encontrar el espíritu general que debe presidir el desarrollo de cada plano parcial. Son estos los que definirán las excepciones cuando las haya y aquellos aspectos típicos de cada área.

Este Plan de Adaptación -que sirvió de referencia textual para la Memoria del Plan de 1966- comienza indicando que la readaptación de todos los proyectos parciales urbanísticos aprobados previamente o en vía de estudio, se basaba en gran parte en su encaje con los trazos definitivos de los proyectos hidráulico y ferroviario. A falta de otros accidentes naturales, se procuró que ambos trazados se constituyeran en lindes naturales de la futura urbe en el estado de máxima expansión. Estas áreas Sur y Suroeste eran las más atractivas para la expansión, pero no las más aconsejables: al Norte y Noroeste, la ciudad, libre de trabas, podrá extenderse con mayor libertad hasta ciertos límites prefijados.

Luego, continuaba detallando cómo quedaba el nuevo dispositivo ferroviario desde el punto de vista urbanístico, así como los accesos por carretera y circunvalaciones. En el primer caso, a propósito de la faja de terreno comprendida entre el nuevo cauce y las vías -con un destino previo de vivienda o tolerancia industrial-, introducía la necesidad de las compensaciones o gravámenes que habrían de efectuarse con los cambios de zonificación y expropiaciones correspondientes. Con respecto a la red viaria, comenzaba aclarando que, por responder a exigencias técnicas menos rígidas, apenas ofrece dificultades. E incluso ha sufrido muy pocas modificaciones con relación al trazado existente anteriormente. Se habla de los nuevos ramales y bifurcaciones en los accesos de la ciudad, además del necesario desvío del trazado primero para la entrada desde Barcelona (por la Avenida de Aragón), exponiendo las siguientes razones:

a)Existen múltiples construcciones de nueva planta en el eje previsto

b)Los terrenos para esta variante, menos costosos, eran además en su mayoría cedidos gratuitamente por los Ayuntamientos de paso 
c)Las autoridades locales eran partidarias de que la carretera discurriese próxima a la costa. Estas razones aconsejaron, de acuerdo con la Oficina Provincial de Obras Públicas, conectar el tramo ya ejecutado en la desembocadura del Carraixet con una línea próxima a la costa.

También se introdujeron dos nuevos ramales: el acceso de Torrente desde el nudo situado en el último Tránsitos se bifurca en dos direcciones. La primera se vierte en la Plaza de Castilla. Anteriormente lo hacía unos doscientos metros más allá. Parecía más lógico el encuentro con la Avenida de Castilla en dicha Plaza, y no en la angostura de un cruce sin posibilidades de protección. El segundo ramal, apoyándose en el ferrocarril de Villanueva de Castellón, se orienta hacia el centro urbano, situado en los terrenos de la actual Estación del Norte. Tiene esto dos objetos: en primer término, hace más cortas y menos interferidas las circulaciones que se dirigen al interior de la ciudad, y la segunda, porque conecta a éste con el polígono industrial del suroeste.

El acceso de Alicante tiene otra bifurcación en su encuentro con el último Tránsitos, que ya aparecía en el anteproyecto de la Oficina Técnica Especial. El nuevo ramal fue motivado por la necesidad de apartar del centro urbano las circulaciones de tránsito Barcelona-Alicante. Se pasaba luego a describir los nuevos polígonos de edificación, verdaderas unidades vecinales delimitadas por la malla fundamental de accesos y circunvalaciones. Además, se categorizaban zonas mediante los denominados polígonos de edificación impuesta, terrenos expropiados y proyectados con unidad de conjunto donde la edificación adquiría la máxima categoría, sirviendo de base a nuevas áreas comerciales.

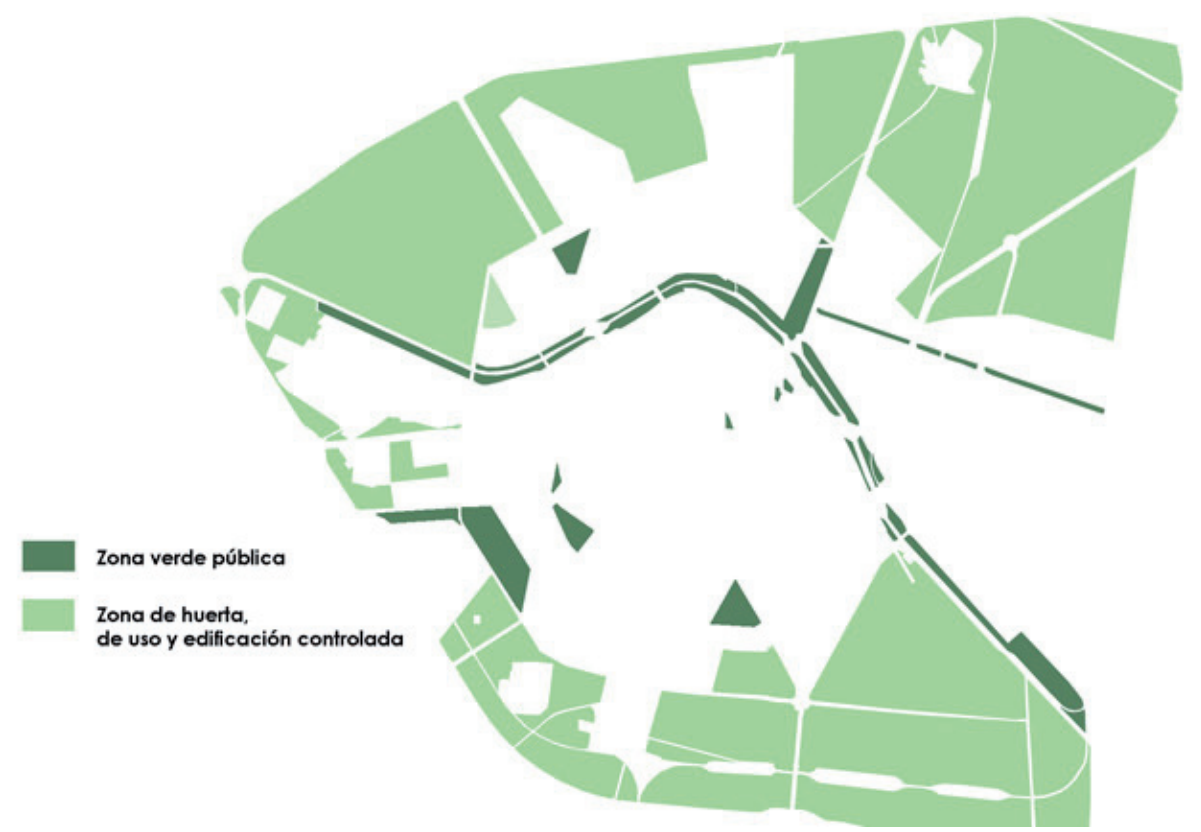

Figura 2. Esquema de zonas verdes previstas en la zonificación del Plan General de 1959 elaborado por Gran Valencia, entre espacios públicos (verde oscuro) y zona de huerta protegida, con uso y edificación controlada.

Fuente: Elaboración propia 
Pero quizá lo más llamativo -y la novedad mayor desde el punto de vista de la investigación- sea constatar la congelación del crecimiento prevista para los núcleos periféricos, aquellos poblados situados fuera del Camino de Tránsitos (Mislata, Benicalap, Torrefiel, Benimaclet y barrios urbanos situados en la carretera de Albacete).

En efecto, los terrenos de huerta comprendidos entre dichos núcleos y los nuevos límites urbanos (el nuevo cauce por el Sur y la circunvalación de poblados por el Norte) se protegían con un uso agrícola especialmente controlado tanto para los cultivos como la edificación: interesa sólo que dichos terrenos de huerta próximos a la ciudad sean residenciados por sus colonos o braceros, y en modo alguno por otro tipo de población. Con este fin deberán limitarse las licencias de construcción en torno a los actuales caseríos, al cupo estricto necesario para cubrir el incremento demográfico o la renovación de viejas viviendas. En contraste con las actuaciones recientes de la Corporación Administrativa, García-Ordóñez quiso proteger especialmente la cintura agrícola, ya entonces muy amenazada por las numerosas solicitudes presentadas para la construcción de industrias ${ }^{11}$.

El Plan de Adaptación incluía consideraciones sobre las nuevas áreas comerciales, los usos especiales y los polígonos industriales, diferenciando entre distintos grados de tolerancia y justificando la elección del emplazamiento para todos ellos.

Por último, la Memoria del Plan venía acompañada de un interesante documento titulado Información sobre los polígonos actualmente aprobados, en el que se actualizaba la vigencia de todos los Planes Parciales de desarrollo del Plan General de Valencia y su Comarca. El documento anexo se componía tanto de un informe escrito como de un plano al efecto. En referencia a los planes desarrollados con anterioridad por Gran Valencia, este informe ratificaba su aprobación definitiva (con su fecha rotulada a mano, en rojo $)^{12}$.

11 El propio Arquitecto Jefe, Mauro Lleó, había avalado una modificación (que no prosperó, puesto que el Ministerio de Vivienda denegó la solicitud) de la Ordenanza especial que regula las edificaciones en zona de huerta que no sean para fines exclusivamente agrícolas, por considerarla excesivamente rigurosa: la presión sobre la huerta cada vez era más grande, y desde la Oficina Técnica se propuso suprimir el artículo 40, que obligaba a que los terrenos tuviesen diez veces más superficie que la requerida para la edificación. Informe de la Oficina Técnica de Gran Valencia, de fecha 8 de julio de 1958.

12 La transcripción del documento, incluyendo las anotaciones en rojo (transcritas entre paréntesis), es la siguiente:

Plano Parcial no I.- Avenida de Castilla. Excepto la zona limitada por paramento Sur de la futura Plaza de Castilla, calle no 29, cruce de la calle 29 con el Ferrocarril de Utiel. Camino viejo de Torrente, cruce del co viejo de Torrente con la calle no 16, cruce de la calle no 16 con el nuevo acceso de Torrente y calle no 31 hasta la Plaza de Castilla. El nuevo acceso de Torrente conservará su anchura de 40 m hasta su cruce con el Ferrocarril de Utiel. (15-3-50) (I-A)

Plano Parcial no II.- Cuarte Extramuros. Únicamente el co de las Tres Cruces en su tramo comprendido entre la Avda. de Castilla y el Río será prolongación recta del tramo anterior. Quedan por tanto afectados solamente los terrenos que ocupan la Cárcel Modelo y Zona Verde entre C. de Cuarte y Río. Las líneas existentes en el Proyecto Parcial no II correspondientes al paramento Oeste del mencionado tramo del Co de Tres Cruces subsisten. (15-3-50)

Plano Parcial no III.- Co Real de Madrid. Queda sin aprobar la zona comprendida entre la calle no 53 (Salvador Perles), calle no 62, Ferrocarril Madrid-Valencia, Prolongación de Concepción Arenal, Plaza en proyecto, Concepción Arenal, Carretera Real de Madrid, calle no 68 y límite del Plano hasta la calle no 53 (Salvador Perles). La línea de circunvalación prevista en el Plan Sur, se adaptará a la faja anteriormente destinada al acceso al Puerto y Zonas Verdes marginales que figura en este Plano Parcial. 
Sin embargo, no había ninguna referencia al Proyecto Parcial de Desarrollo no 2 del Sector Burjasot-Godella-Benimamet (Valencia), íntegramente desarrollado sobre suelo municipal. Además, se encuentran señalados -con posterioridad, lógicamente- la fecha de aprobación de muchos de los polígonos referidos, incluidos los realizados por el INUR (inicialmente Ilamado Gerencia de Urbanización).

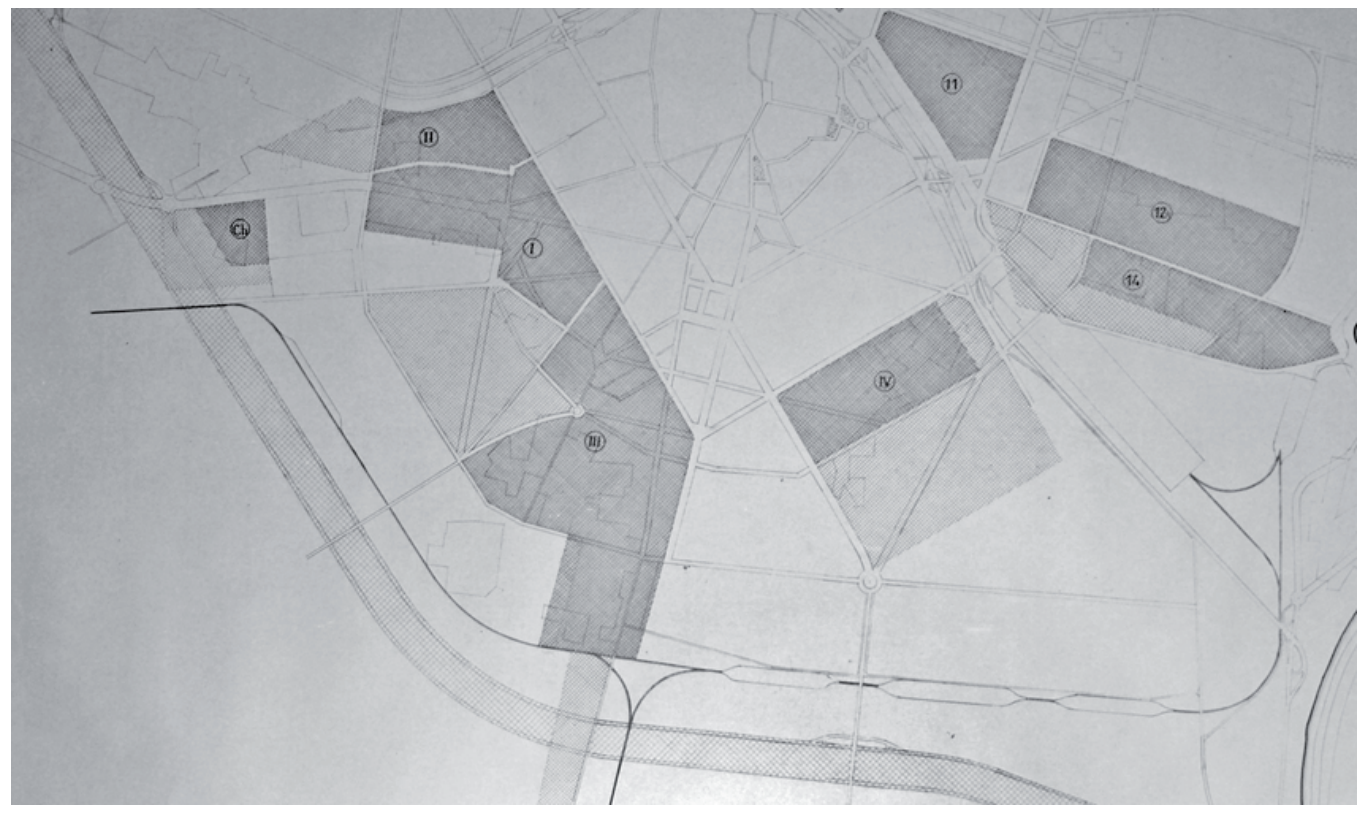

Figura 3. Fragmento del plano I. Ordenación de Valencia. Información sobre los polígonos actualmente aprobados, elaborado por García-Ordóñez en 1959 como documento del Plan General de Valencia. Se hace referencia a varios Proyectos parciales elaborados por Gran Valencia, el I, II, III, IV y el Barrio Residencial no 2 (con las letras Ch, en alusión a Chirivella). De menor a mayor intensidad en el rayado, la leyenda indicaba: 1) Zonas en que se suspenden licencias de construcción y obras en curso; 2) Polígonos aprobados y en ejecución. Se suspenden; y 3) Polígonos aprobados y en ejecución. Subsisten.

Fuente: Archivo Histórico Municipal del Ayuntamiento de Valencia

En la sesión ordinaria del pleno del Ayuntamiento de Valencia de 8 de julio de 1959, se procedió a la aprobación por unanimidad -con carácter de Plan General de Ordenación del término municipal de Valencia- del nuevo Plan de Ordenación de Valencia y su Comarca adaptado a la Solución Sur de desviación del Río Turia, redactado por la Oficina Técnica de la Gran Valencia ${ }^{13}$. La propuesta del Teniente de Alcalde Pedro Ribera Sala -él además presidía la Comisión de Urbanismo- se había

Dentro de lo exceptuado queda aprobado el Polígono comprendido entre el futuro Río y la carretera aneja, que limita la Ciudad del Aprendiz por el Sur, calle no 37, calle no 54, Camino Real de Madrid, calle no 63 y calle no 52 hasta el futuro Río, punto de partida. Quedan sin aprobar las alineaciones de la calle de Venezuela, que comienza en la calle de Gaspar Aguilar y se prolongará sin quiebro hasta su encuentro con la calle del Ferrocarril, aconsejándose para su anchura treinta metros. (23-2-54)

Plano Parcial no IV.- Monteolivete. Queda aprobada la zona limitada por Camino de Tránsitos hasta la calle prolongación de Císcar, esta calle hasta su encuentro con la calle paralela a la de Tránsitos que limita el polígono de ejecución "Fuente de San Luis", dicha calle hasta su encuentro con Carrera de Encorts y calle diagonal hasta encuentro con Tránsitos en la plaza hoy circular que tendrá un diámetro de $160 \mathrm{~m}$. (24-1-53)

13 Se daba luz verde para su tramitación reglamentaria hasta su definitiva aprobación por los Organismos superiores (permitiendo la modificación del Plan anterior, aprobado por Ley de 18 de diciembre de 1946, tras trece años de vigencia). 
sometido a votación con fecha 2 de mayo, lo que confirma que, para entonces, los trabajos de ordenación de García-Ordóñez ya habían concluido (al menos en lo referente a la capital). El escrito hacía referencia a una Moción anterior que había quedado a la espera del desarrollo del Plan de Ordenación. En cuanto éste estuvo listo, y dada su trascendencia, la Comisión se apresuró a formular la propuesta de aprobación.

En palabras del propio escrito, dos son los objetivos concretos de esta Moción: el someter a conocimiento y aprobación de la Corporación los planos que integran el nuevo Plan de Ordenación y el proponer las zonas en que debe prohibirse temporalmente la construcción, para no hipotecar prematuramente el desarrollo de detalle del nuevo Plan. En cuanto al primer objetivo, se acordó su aprobación de acuerdo con la definición de Plan General sostenida en el artículo 9 de la nueva Ley de Ordenación del Suelo de $1956^{14}$. Se ratificaba, además, el carácter generalista del plan, que fijaba únicamente el esquema de estructura urbana y definición de los usos y destinos de las distintas zonas, sin pretender una interpretación exacta e invariable del trazado y anchura de vías y calles. Para el desarrollo de los planes parciales pertinentes, se propuso el refuerzo de la Oficina Técnica Municipal de Urbanismo, insinuando así el fin de la participación de Gran Valencia en dichos trabajos referentes a la capital.

El segundo objetivo apuntado motivó una enconada discusión en cuanto a la oportunidad de autorizar la suspensión temporal de licencias en los sectores sujetos a modificaciones. Se recelaba de la inminencia de las obras del desvío del cauce (aún no se había aprobado la ley que financiaría su ejecución), por lo que el debate se centró en si era llegado o no el momento de aprobarla. Tras diversas consideraciones sobre el Plan de Estabilización (iniciado en 1959) que vivía el país, el alcalde Rincón de Arellano señaló el posicionamiento reciente de Bidagor respecto de la Solución Sur, para apuntalar el compromiso de su próxima puesta en marcha.

También se dio cuenta de un dictamen de 6 de mayo en el que la Comisión manifestaba su intención de aprobar los nueve planos de que constaba el nuevo Plan, modificando puntualmente el plan de etapas propuesto. Finalmente, en el punto cuarto de este dictamen se indicó la intención de expresar a la Corporación Administrativa Gran Valencia la felicitación del Ayuntamiento por el concienzudo y detallado trabajo que ha desarrollado su Oficina Técnica, toda una declaración de agradecimiento a la dirección ejercida por García-Ordóñez.

Como prueba de la satisfacción del avance de los trabajos de la Adaptación del Plan a la Solución Sur, García-Ordóñez viajó a Barcelona en noviembre de 1959 para asistir al Primer -y único- Congreso Nacional de Urbanismo ${ }^{15}$. Del 2 al 8 de ese mes viajó junto con el Arquitecto Jefe de la Oficina Técnica de Gran Valencia Mauro Lleó Serret (entonces también al frente del Servicio Técnico de la Delegación del Ministerio de la Vivienda), y los también arquitectos Vicente Valls Abad y Joaquín García Sanz.

14 Véase el Acta de la Sesión Ordinaria del Excmo. Ayuntamiento Pleno celebrada el día 8 de julio de 1959, en primera convocatoria. Archivo Histórico Municipal de Valencia.

15 A este respecto, véase la interesantísima publicación LARRODERA LÓPEZ, Emilio; GARCÍA ORDÓÑEZ, Fernando (1962), "Planes Generales con aplicación al Plan General de Valencia", Sesión de estudio para el $1^{\text {er }}$ Congreso Nacional de Urbanismo 'La Gestión Urbanística', Barcelona, 1959. Madrid: Ministerio de la Vivienda, Secretaría General Técnica. 
Para dicha ocasión redactó junto con Emilio Larrodera López una de las Sesiones de Estudio: Planes Generales con aplicación al Plan General de Valencia, que se incluyó en la posterior publicación-resumen del Ministerio, titulada "La Gestión Urbanística". Larrodera era, a la sazón, un joven urbanista, Jefe de Planeamiento en la Dirección General, que había asistido a los cursos impartidos por Gaston Bardet en el Instituto Superior e Internacional de Urbanismo Aplicado de Bruselas, por lo que la sintonía con García-Ordóñez en cuanto a la identificación de la ciudad como estructura jerárquica compleja estaba servida.

En el archivo personal de García-Ordóñez se conserva un borrador de lo que estuvo destinado a ser una comunicación para este congreso, en respuesta a la interesante ponencia sobre los instrumentos de planeamiento que dirigió Gabriel Alomar. Era ésta una figura nacional de referencia, que acababa de publicar en 1955 el libro 'Comunidad planeada', continuación de 'Teoría de la ciudad. Ideas fundamentales para un urbanismo humanista', de 1947.

En cualquier caso, el texto de García-Ordóñez pudo aprovecharse más tarde en forma de manifiesto programático titulado Carta a los Urbanistas, siendo publicado en marzo de 1960 en la revista portuguesa Binário. En ella se encuentran, entre otras, unas consideraciones que revelan la influencia tanto de Bardet (crítica explícita al funcionalismo lecorbuseriano) como de Alomar (referencias al carácter orgánico de la institución humana que sustenta el urbanismo moderno):

"Le Corbusier, figura señera del urbanismo contemporáneo, ha volcado toda su elocuente personalidad en la exaltación del funcionalismo práctico y descarnado de la máquina; su sentido del hombre llegó a ser eminentemente dinámico. Califica a las viviendas de "máquinas para vivir"; sus planificaciones urbanas adolecen de la misma capacidad despersonificadora de la sociedad marxista. Pierre Vago afirma que 'Le Corbusier retrasa la eclosión del verdadero urbanismo'. Le Corbusier es una víctima genial de la trepidante civilización mecanicista. Frank Lloyd Wright, por citar otro ejemplo clásico, siempre fiel a sus convicciones democráticas, fue, por el contrario, a lo largo de toda su vida un furibundo detractor de las integraciones masivas de tipo colectivista. En cambio, abogó decididamente a favor de la "casa orgánica" o la "ciudad orgánica", por entender que "orgánico" es lo mismo que viviente. 'La estructura viviente -afirma- es un concepto en virtud del cual los rasgos o partes están organizados de tal manera, en forma y substancia, como para resultar, si se les aplica a un propósito, eminentemente interesantes. Todo lo que vive es por tanto orgánico. Lo inorgánico, lo desorganizado, no puede vivir'. Wright está pensando en la "democracia", prototipo de sociedad "orgánica" y en la "libertad" tal como él la disfrutó en las praderas del Far West. Rousseau hubiera sido el mejor cliente de Frank Lloyd Wright".

No se ha podido precisar el momento exacto en que García-Ordóñez quedó desvinculado de la coordinación de los trabajos de revisión del Plan General. Sí que consta, en cambio, que fue por decisión personal, ante la oposición que se despertó a su alrededor, pero ha de datarse mucho después de su participación en el citado congreso (posiblemente con ocasión de la Ley del Plan Sur), pues la publicación que recogió las ponencias y escritos del mismo -editada en 1962- se refería a él como el director del trabajo de revisión. 
En efecto, García-Ordóñez redactó la parte de la primera Sesión de Estudio correspondiente al Plan General de Valencia. Previamente, Larrodera había hecho una introducción del alcance y material documental que había de recoger un plan general, por lo que se entiende que el caso valenciano (en contraste con las quejas de poco tiempo atrás) constituía un ejemplo modélico. Antes de exponer los antecedentes y el planteamiento -tanto estático como dinámico- del nuevo plan (haciendo un buen resumen de su propio Plan de Adaptación), en el apartado de Gestión previa, el arquitecto asturiano dejó escrito que:

(...) aunque no pertenezco a dicha Oficina por haber intervenido en los trabajos anteriores, se me confirió la dirección del trabajo, con la colaboración de los compañeros Bueso y Gómez, asesorados por Muñoz Monasterio y el ingeniero señor Oñate.

El plan fue aprobado finalmente por el Ayuntamiento, procediéndose rápidamente a la suspensión de licencias de construcción en todas las áreas afectadas por los nuevos proyectos.

Recientemente fueron sacados a concurso nacional entre arquitectos varios polígonos de urgente realización.

En una publicación municipal de finales de $1961^{16}$ todavía se acompañaban las medidas urbanísticas en marcha con planos elaborados bajo la coordinación de García-Ordóñez, confirmando así la vigencia del mismo y el apoyo que el Ayuntamiento de Valencia había hecho del planeamiento redactado y aprobado en 1959.

Es el caso del plano de zonificación que se adjuntaba bajo el título de "Plano general de urbanización" (y que se correspondía con el IV. Ordenanzas de zonificación). En él se pueden apreciar claramente las distintas áreas urbanas acomodadas al nuevo viario, así como los terrenos reservados para usos especiales. El área de huerta seguía protegida, sin incluir nuevos polígonos de edificación previstos en sus terrenos, lo que permite hacerse una idea de la inicial aceptación de dichos planteamientos de contención del crecimiento urbano por parte del Ayuntamiento de Valencia: la ciudad tenía ya perfectamente definida su morfología definitiva más conveniente.

Se puede apreciar una gran relación con respecto al plano antes reproducido: por un lado los usos continúan diferenciados, distinguiendo entre núcleos actuales o periféricos, zona interior, zona de ensanche, ensanches futuros (con tolerancia industrial o sin ella), edificación abierta (contemplando dos categorías), polígonos de ordenanza especial, e incluso quedando señalada la zona industrial y la zona universitaria; pero se han omitido los círculos que identificaban las áreas y modificado la dimensión de las letras $\mathrm{R}$ de las zonas de reserva, operaciones todas dirigidas a su reproducción a un tamaño más pequeño.

Con respecto al plano general de zonificación (el no III), el característico viario se enriquece con numerosas rotondas, lo que apunta a una evolución en el estudio de las necesidades del tráfico. De todas formas, a la hora de analizar la red viaria

16 Boletín de Información Municipal del Ayuntamiento de Valencia, no 32 (no 13 Segunda Etapa). Valencia, cuarto trimestre 1961. 
propuesta, es necesario acudir al completísimo juego de hojas de la base catastral, con el nuevo viario superpuesto, que se ha conservado en el Archivo de Planeamiento. Esta red viaria propuesta sería recogida en el Plan de Accesos, grafiada en una colección de hojas de la base catastral a escala 1:4.000 (y que se ha conservado, aunque incompleta, en el Archivo de Planeamiento del Ayuntamiento de Valencia). En ellas aparece el nuevo viario superpuesto, con trazos grises sobre el dibujo del parcelario. Su autoría es, sin duda, la de García-Ordóñez, a tenor de las indicaciones incluidas en el Plan de Adaptación de marzo de 1959.

Creo que merece la pena recoger alguno de estos valiosos documentos, como botón de muestra de la colección completa, porque se aprecia en ellos la contenida relevancia de las secciones viarias previstas (en comparación, sobre todo, con la Red Arterial de 1966), donde el cauce no es masivamente invadido por las autopistas que más tarde harán su aparición. De hecho, estas hojas se combinan perfectamente con los planos de ordenación de volúmenes en los terrenos recuperados de los que se hablará más adelante.

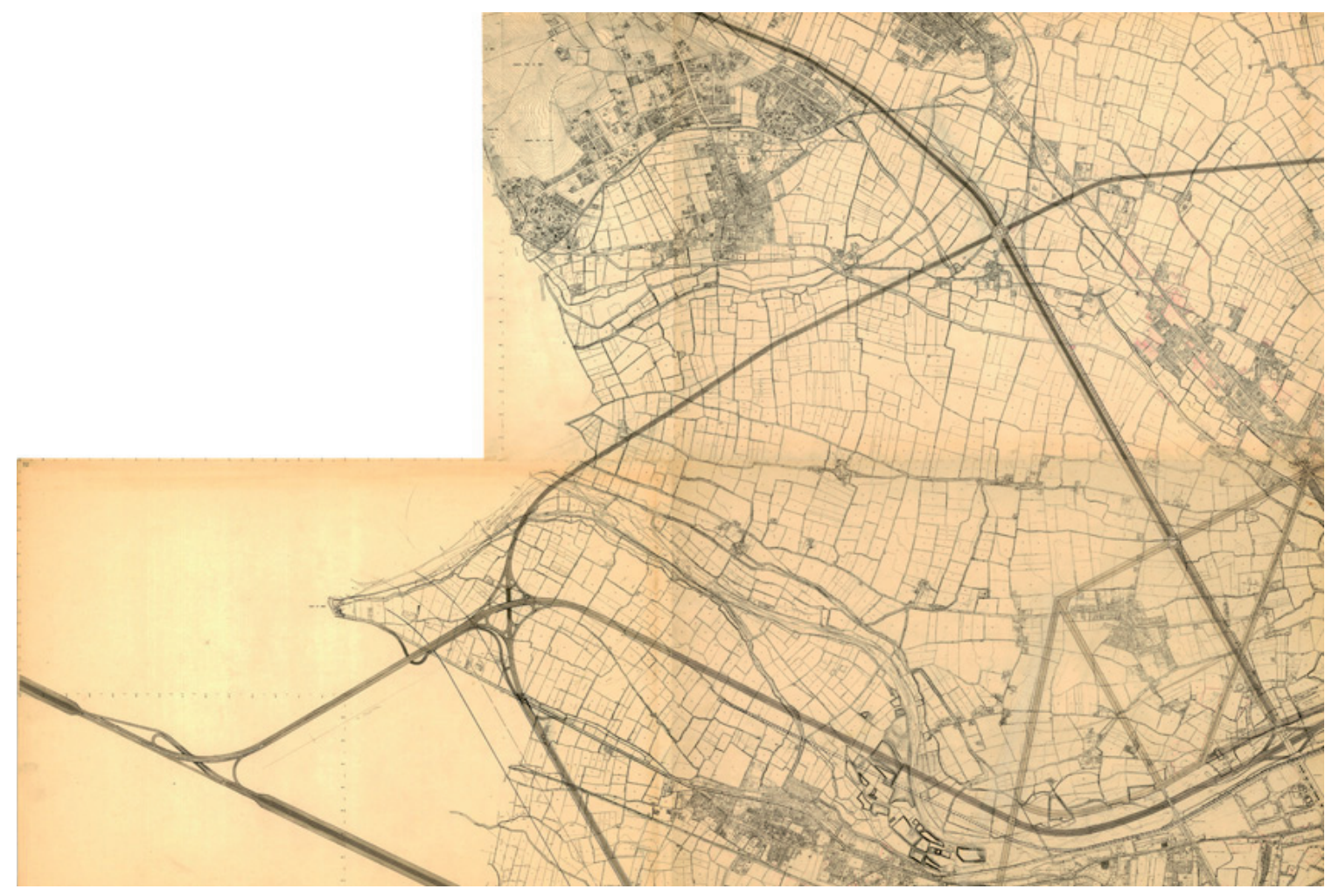

Figura 4. Montaje de varias de las hojas a escala 1:4.000 correspondiente al sector Noroeste del término de Valencia, en la que se recoge, sobre la base catastral, la solución viaria de García-Ordóñez para Valencia. Las hojas no llevan fecha ni firma, pero hay que datarlas sin duda hacia 1959.

Fuente: Elaboración propia a partir de originales del Archivo de Planeamiento del Ayuntamiento de Valencia

Es una pena que la colección esté incompleta, pues no he podido localizar en la carpeta correspondiente las hojas 14, 19, 20, 21, 23, 28 y 29. Sobre todo se echan de menos la 14 y la 19 (quizá las más importantes), referidas al tramo central del cauce desalojado y la conexión de la ciudad con el Puerto, respectivamente. Como 
muchos otros documentos de esta investigación, hay que suponer que fueron extraviados o sustraídos en algún momento, debido tanto a la dispersión del material en varios archivos como a la falta de medios para su conservación.

Sorprendentemente, a pesar del consenso político y técnico (en el que estuvieron implicados todos los arquitectos de la Oficina Técnica de Gran Valencia) de que gozó inicialmente el Plan General aprobado en 1959, tras la aprobación del Plan Sur a finales de 1961 se replantearon muchos de sus elementos. En concreto, el nuevo estudio de la red viaria, confiado a la Oficina Regional de Proyectos (dependiente del Ministerio de Obras Públicas), resulta especialmente llamativo si se tienen en cuenta estos antecedentes tan comedidos.

\subsection{Tramitación fallida y renuncia de García-Ordóñez}

Antes de apuntar los motivos que hicieron fracasar a este concienzudo Plan, conviene volver al plano de zonificación en una de sus versiones finales. Al no continuarse con los trabajos comarcales, ha de tomarse este documento como el corolario del trabajo realizado, así como el punto final de una etapa frustrada.

Ya en el Plan de Adaptación para la ciudad de Valencia, de mayo de 1959, se indicaba que aunque en la presente etapa no se ha previsto ningún estudio detallado sobre el área comarcal, se ha tenido en cuenta ésta tanto en lo que respecta al sistema de carreteras como en la distribución demográfica e industrial. Basándonos en las ideas preestablecidas por la Oficina Técnica Especial planificadora del proyecto base, se ha considerado la ciudad y su área de influencia comarcal como un todo estructural con unidad de funciones.

Dos meses después, en su visita de julio, Muñoz Monasterio trató con GarcíaOrdóñez sobre el inicio efectivo de los trabajos de ordenación de la comarca. El Plan de Revisión Comarcal parece, no obstante, haberse iniciado antes, a comienzos de año, como atestigua una carta de 19 de enero. Monasterio habría incoado esos trabajos a la par que García-Ordóñez acometía el estudio de la capital, con el fin de refundir después las conclusiones de ambos.

Un punto que seguramente resultó clave para el proceso de defenestración interna que sufrió García-Ordóñez por esa época, fue la adjudicación por parte del Ayuntamiento de Valencia del Polígono Industrial de la Avenida de Castilla (Polígono Industrial de Servicio, Ilamado comúnmente de Vara de Cuart), tras concurso fallado el 30 de octubre de 1959, al equipo que él mismo formaba junto con el arquitecto Juan María Dexeus Beatty y el ingeniero Claudio Gómez-Perretta. Precisamente, a dicho concurso es al que había hecho referencia el propio GarcíaOrdóñez en su conferencia en el Congreso de Barcelona.

La firma de la aceptación del encargo para la redacción de este polígono (el no 3, según el nombre de la convocatoria) tuvo lugar el 29 de diciembre. Días atrás, el 4 del mismo mes, había comparecido él mismo en persona -acompañado de Dexeus y Gómez Perretta- para aceptar el nombramiento.

En efecto, por acuerdo del consistorio municipal de 8 de julio, se había aprobado la creación de un concurso para optar a desarrollar determinados polígonos en las zonas de expansión de Valencia. La Mesa constituida conforme al pliego de 
condiciones aprobado para el concurso recibió 48 propuestas de participación, de las cuales cuatro de ellas tuvieron lugar fuera de plazo, por lo que finalmente se contó con 44 solicitudes, ya fuera individualmente o en grupo, para las cinco áreas propuestas.

Pero ya desde el principio, no fue bien visto por todos que se sacaran a concurso polígonos de ordenación sin haberse presentado anteproyectos, basándose sin más en los nombres de los arquitectos particulares y el conocimiento que de ellos se pueda tener (ni siquiera se tomaban en cuenta los méritos de los participantes) ${ }^{17}$. El Ayuntamiento, no obstante, echaba en falta -como se pudo comprobar en el pleno de julio de 1959- personal en su Oficina Técnica municipal de Urbanismo, y optó en agosto por la contratación externa de equipos, encomendándoles el desarrollo de sectores enteros de la ciudad.

El Teniente de Alcalde Salvador Pascual Gimeno lideró la oposición a la adjudicación, por considerarlo no conveniente a los intereses municipales, así como por su difícil y justa resolución. Apuntaba que durante el período de presentación ya se comentaba si no estaría previamente adjudicado, extremo que había tenido que negar repetidamente, pero que no dejaba de deslizarse en la opinión pública. Proponía, en lugar de fallar por el nombre (muchos arquitectos presentados estaban incluso recién salidos de la Escuela, compitiendo en desigualdad de condiciones con otros profesionales más consagrados), realizar un Concurso de Planeamiento Parcial de los Polígonos, al igual que se hizo en Erandio (Bilbao) ${ }^{18}$, entre todos los arquitectos que quieran presentarse o limitado solamente a los que han intervenido en el que nos ocupa y objeto de este dictamen.

La falta de tiempo y la urgencia de la situación urbanística (se habían suspendido licencias en el mes de julio pasado, y aún no se habían encargado los polígonos) pesó más a la hora de llevar a término unas bases de concurso atípicas, que por otra parte nadie había impugnado en su día $)^{19}$.

17 Véase el Acta de la Sesión Ordinaria del Excmo. Ayuntamiento Pleno celebrada el día 30 de octubre de 1959, en primera convocatoria. Se trata del Expediente relativo al Concurso convocado para la contratación de los Servicios de Arquitectos particulares, para el desarrollo de planes y proyectos urbanísticos de determinados Polígonos en las zonas de extensión de la Ciudad. Archivo Histórico Municipal de Valencia.

18 Se refería al Concurso de ideas del polígono de Astrabudúa, convocado en enero de 1958 por la Dirección General de Urbanismo para construir viviendas de Renta Limitada. ARQUITECTURA, no 4. Madrid, abril de 1959, pp. 9-17.

19 Por 19 votos a 2 se resolvió favorablemente la cuestión, siendo finalmente los adjudicatarios:

10 Parte del polígono de Monteolivete comprendida entre la calle del Escultor Capuz y el actual Río Turia: al equipo formado por D. Luis Pérez-Mínguez Villota, D. Luis Laorga Gutiérrez y D. José López Zanón (solicitud número 37).

20 Resto del polígono de Monteolivete: al equipo formado por D. José María Pagola de la Puente, D. Luis García Camarero y D. Luis Martínez Lebrato (solicitud número 38).

30 Polígono Industrial de la Avenida de Castilla: al equipo formado por D. Fernando M. García Ordóñez, D. Juan María Dexeus Beatti y D. Claudio Gómez Perreta (solicitud número 26).

40 Polígono de Campanar: conjuntamente a los equipos siguientes:

a) D. Vicente Valls Abad y D. Manuel Blanch Díaz (solicitud número 24), y

b) D. Camilo Grau García, D. Joaquín García Sanz y D. Juan Luis Gastaldi Albiol (solicitud número 30).

50 Plano número nueve: al equipo formado por D. Pablo Navarro Alvargonzález, D. Julio Trullenque San Juan, D. Juan Luis Gastaldi Albiol y D. Jaime García Matarredona (solicitud número 44).

60 Prolongación del Paseo de Valencia al Mar:a D. Fernando Moreno Barberá (solicitud número 23). 
Finalmente, a pesar del equívoco nombre inicial (Polígono Industrial de la Avenida de Castilla), el Polígono no 3 fue recibido por el Ayuntamiento de Valencia como Polígono Industrial o de Vara de Cuart, y así pasó a la Gerencia de Urbanización. Su aprobación inicial tuvo lugar el 5 de mayo de 1961, la definitiva (por la que se fijaba el Plan Parcial) el 10 de julio, y fue entregado por Gran Valencia al Ministerio de la Vivienda en noviembre de ese año ${ }^{20}$.

Este plan constituyó una de las primeras experiencias españolas en el ámbito de los polígonos industriales programados, resultando de una gran aceptación tanto técnica como social. Sin embargo, fue visto por algunos como el inicio de una operación de acumulación de encargos privados por parte de García-Ordóñez, a costa de los arquitectos y urbanistas locales, y aprovechándose de su posición al frente de la Comisión Técnica Especial y la Oficina Técnica de Gran Valencia.

Efectivamente, poco tiempo después Bidagor le encargaría, desde la Gerencia de Urbanización recientemente creada en el Ministerio de la Vivienda, el desarrollo de los polígonos de Baladre, en Puerto de Sagunto (Valencia), y de La Moleta, en La Vall d'Uxò (Castellón), así como el de Fuente de San Luis (en Valencia, junto con Luis García Camarero) y San Blas (Alicante). En la redacción de los primeros participaron también, contratados por GO-DB -acrónimo del estudio profesional de García-Ordóñez y Dexeus Beatty-, dos jóvenes arquitectos que más tarde tendrían gran relevancia en el urbanismo comarcal: Antonio García Heredia y Joaquín Arnau Amo.

La circunstancia de la pertenencia del arquitecto asturiano al Opus Dei complicó la situación, mezclando de manera injusta las supuestas ambiciones políticas con su vinculación a esta institución católica. Recuérdese que hacía poco de la entrada en el Gobierno de algunos de estos políticos, sin una orientación ideológica concreta (es decir, muchos de ellos ajenos al pensamiento de la Falange), pero que fueron tachados despectivamente de tecnócratas con el fin de englobarlos a todos bajo el mismo supuesto grupo de poder (extremo absurdo como el que resultaría de denominar a estos servidores de lo público, por ejemplo, con el nombre de políticos madridistas, si tal hubiera sido el caso de su afiliación deportiva $)^{21}$.

\footnotetext{
20 Se habían previsto un total de 52 parcelas industriales. Tras la delimitación de la expropiación el 15 de noviembre de 1962 , se fijó un justiprecio de 60.162.811 pesetas. El polígono tenía una extensión de 47,92 hectáreas (479.200 metros cuadrados), con una posibilidad de ampliación de 16,83 Ha: en total, unas $65 \mathrm{Ha}$, para las que se acordó fijar los honorarios -a razón de quince mil pesetas la unidaden 987.600 pesetas.

21 Desde el falangismo primeramente, y más tarde también desde ámbitos de izquierda marxista, se quiso ver en el Opus un aparato coherente, gracias al cual unos hombres nuevos, sin tradición política, alcanzaron puestos destacados de la noche a la mañana. Se puede consultar LOPEZ RODÓ, Laureano (1990). Memorias. Barcelona: Plaza \& Janes, donde se da una respuesta sosegada a tales afirmaciones gratuitas. En él se añade: También se propaló el infundio de que los miembros del Opus Dei que intervenían en la política formaban un grupo homogéneo. Es patente que, como consecuencia lógica de la plena libertad política, eran muy diversas sus posturas y opiniones. A título de ejemplo, recordemos que Fernando Herrero Tejedor, Javier Domínguez Marroquín y José Ramón Herrero Fontana eran falangistas; Juan María de Araluce Villar y Pedro Mendizábal Uriarte, tradicionalistas; Mariano Navarro Rubio, sindicalista; Hermenegildo Altozano Moraleda, Antonio Fontán Pérez y Florentino Pérez Embid pertenecían al Consejo Privado del Conde de Barcelona y, en cambio, Gregorio López Bravo de Castro, Vicente Mortes Alfonso y yo mismo fuimos partidarios de la restauración de la Monarquía en la persona de Don Juan Carlos de Borbón; Alberto Ullastres Calvo y Juan José Espinosa San Martín eran políticos independientes; por último hubo quienes se hallaban en la oposición al Régimen, cuya figura más destacada fue Rafael Calvo Serer.
} 
Es muy posible que esta maniobra de desplazamiento tomara fuerza aprovechando la ausencia de García-Ordóñez en Valencia durante los tres primeros meses de 1960, debido a un viaje del que interesa dar cuenta en estos momentos por la trascendencia que tendrá más adelante.

En efecto, a finales de 1959 había tenido lugar su designación por parte de la Dirección General de Urbanismo para viajar a Estados Unidos al año siguiente en el ámbito de un programa formativo. Se cumplía así un sueño profesional, pues el país americano ya venía siendo considerado por García-Ordóñez como referencia urbanística desde largo tiempo atrás. Se puede recordar la ordenación del Back Bay Center de Boston, o la cita de su artículo para el Boletín del Ateneo Mercantil de mayo de 1959 (con ocasión del Cincuentenario de la Exposición Regional de 1909), refiriéndose al plan de renovación urbana de Baltimore: "just, what Baltimore needs, but i'll have long grey beard when I see it22".

La beca otorgada por la Dirección General de Urbanismo le dio acceso -a él y a siete arquitectos más- al viaje arriba comentado, con objeto de realizar un estudio urbanístico bajo el título de City and Regional Planning. El equipo completo estaba constituido por Enrique de Bonilla, Enrique Piqué, Félix Llano, Ángel Hernández, Pedro Méndez, Luis Alustiza, Manuel Baldrich y el propio Fernando Martínez ${ }^{23}$.

El periplo americano comenzó el 8 de enero de 1960, y se alargaría por el espacio de seis semanas. Tras aterrizar en Washington, visitaron -entre otras- las ciudades de Nueva Orleans, San Antonio, El Paso, Phoenix, Los Ángeles y San Francisco, para terminar en Nueva York el 7 de marzo. El certificado acreditativo de la estancia, otorgado por la Housing and Home Agency, está fechado en Washington el 24 de febrero de 1960.

El viaje se desarrolló al amparo del Programa de Cooperación Técnica -Technical Cooperation Program- , entre el Gobierno de los EE.UU. y España firmado el 26 de septiembre de 1953, siendo la International Cooperation Administration la encargada de sufragar los gastos ${ }^{24}$. Por esta razón, los arquitectos fueron tratados como 'huéspedes del Gobierno Federal' (estuvieron acompañados en todo momento por un funcionario federal y un traductor), disfrutando de un trato de preferencia en sus desplazamientos. Pudieron así tener un conocimiento de primera mano de la planificación regional en el entorno de Knoxville, de una factoría de viviendas

\footnotetext{
22 Véase GARCÍA-ORDÓÑEZ, Fernando M. (1959). "La renovación urbana en Valencia", en Boletín Informativo y cultural del Ateneo Mercantil. Valencia.

${ }_{23}$ Enrique de Bonilla y Mir ostentaba el cargo de Arquitecto Delegado Provincial del Ministerio de la Vivienda en Jaén; Enrique Piqué Marco era Arquitecto Técnico Municipal y de la Comisión de Urbanismo de Barcelona; Félix Llano Goiburu, Jefe de la Oficina Técnica del Plan de Ordenación Urbanística de Guipúzcoa; Ángel Hernández Morales era el Arquitecto de la Diputación Provincial de Santander; Pedro Méndez Cuesta, Arquitecto Secretario Técnico de la Comisaría General de Ordenación Urbana de Madrid; Luis Alustiza Garagalza ejercía su actividad profesional en San Sebastián; Manuel Baldrich Tibau era el Arquitecto Jefe de los Servicios Técnicos de la Diputación de Barcelona; y Fernando M. García-Ordóñez figuraba como Arquitecto de la Oficina de Planeamiento de Valencia.

24 Los programas de ayuda de los Estados Unidos contaban por entonces con muchos años de experiencia previa. El Plan Marshall, pensado para la reconstrucción de Europa tras la II Guerra Mundial, había comenzado en 1948. El acuerdo firmado con España se incluía dentro de la nueva política de expansión de la ayuda a otros países en desarrollo (predecesora de las agencias USAID), que abarcó los años 1953-60. La International Cooperation Administration gestionó estos programas desde el 1 de julio de 1955 al 3 de noviembre de 1961.
} 
prefabricadas de hormigón en Puerto Rico, o del funcionamiento del Departamento de Tráfico de la ciudad de Los Ángeles, por citar algunas experiencias reseñables.

No cabe duda de que para García-Ordóñez fue una experiencia profesional enriquecedora, más por el modo como hacían las cosas, que por las cosas en sí mismas, que eran muchas. El viaje resultó también notorio en el ámbito de la arquitectura, pues tuvo la oportunidad de visitar obras de Gropius y Mies van der Rohe $^{25}$ (en referencia casi segura a los neoyorquinos Pan Am Building (ahora Met Life)-todavía en fase de proyecto en 1960- y Seagram Building de Mies, finalizado dos años antes).

Finalmente, el programa formativo, que había comenzado en Washington con la entrega a los participantes de una cartera repleta de documentos, todos ellos sellados con el lema Adapt, don't adopt, concluyó en la misma ciudad con la redacción de un informe detallado de las experiencias adquiridas, dirigido a la Dirección General de Urbanismo. En el capítulo siguiente analizaré las consecuencias para el estudio urbanístico de Valencia que supuso este viaje, pues la doctrina metropolitana estaba por aquel entonces mucho más adelantada en el país americano que en España.

De vuelta en España, hay que destacar también, como uno de los trabajos de García-Ordóñez al frente de Gran Valencia, la ordenación de los volúmenes en varios de los Polígonos de Ordenanza Especial, como se señalaba en el plano IV. Ordenanzas de zonificación. Estos polígonos se correspondían con aquellas zonas singulares que habrían de ordenarse de manera cuidadosa, vinculadas a los centros comerciales del área urbana, según se había indicado en el Plan de Adaptación Urbana a la Solución Sur de Desvío de Río Turia, de marzo de 1959, elaborado por él mismo.

Allí se hacía referencia a cinco zonas comerciales (Avenida de Castilla; terrenos frente a la futura Estación Central, en la prolongación de Jacinto Benavente; la actual Estación del Norte; Acceso de Ademuz; y -aunque no lo cita expresamente, pero se echa de menos al no figurar la quinta anunciada- los terrenos recuperados al río Turia), cuya puesta en marcha puede realizarse por etapas, con arreglo al desarrollo de las obras hidráulicas, ferroviarias y de carreteras.

Sobre el ubicado en los terrenos ferroviarios existentes, se pueden leer las siguientes consideraciones:

Este centro queda dentro del gran Polígono residencial que comprende todos los terrenos recuperados y aun otros próximos que se deben expropiar para la perfecta conformación del mismo.

Está muy relacionado con el comercio del centro urbano, al cual quedará unido por de una Avenida axial asentada sobre el eje del actual dispositivo ferroviario.

Esta zona comercial, por estar conectada con los accesos de Torrente y Alicante, y con el ferrocarril eléctrico de Villanueva de Castellón, podrá acoger y absorber una gran mayoría de compradores procedentes de los populosos núcleos urbanos del Sur y Suroeste, descongestionando así el área central.

${ }^{25}$ Citas extraídas de GARCÍA-ORDÓÑEZ, Fernando M. (2006), "Memorias profesionales", sin publicar. Valencia. 
En el Archivo Histórico de la Generalitat Valenciana se conserva un plano de ordenación de los Terrenos recuperados en la Estación del Norte, con la misma tipografía que la empleada por Gran Valencia mientras García-Ordóñez estuvo a su cabeza. La disposición de las edificaciones no es exactamente la misma que la empleada en la maqueta que realizara la Comisión Técnica Especial -una maqueta que, en palabras del asturiano, hubo que realizarla a toda prisa-, pero puede observarse una cierta relación de continuidad.
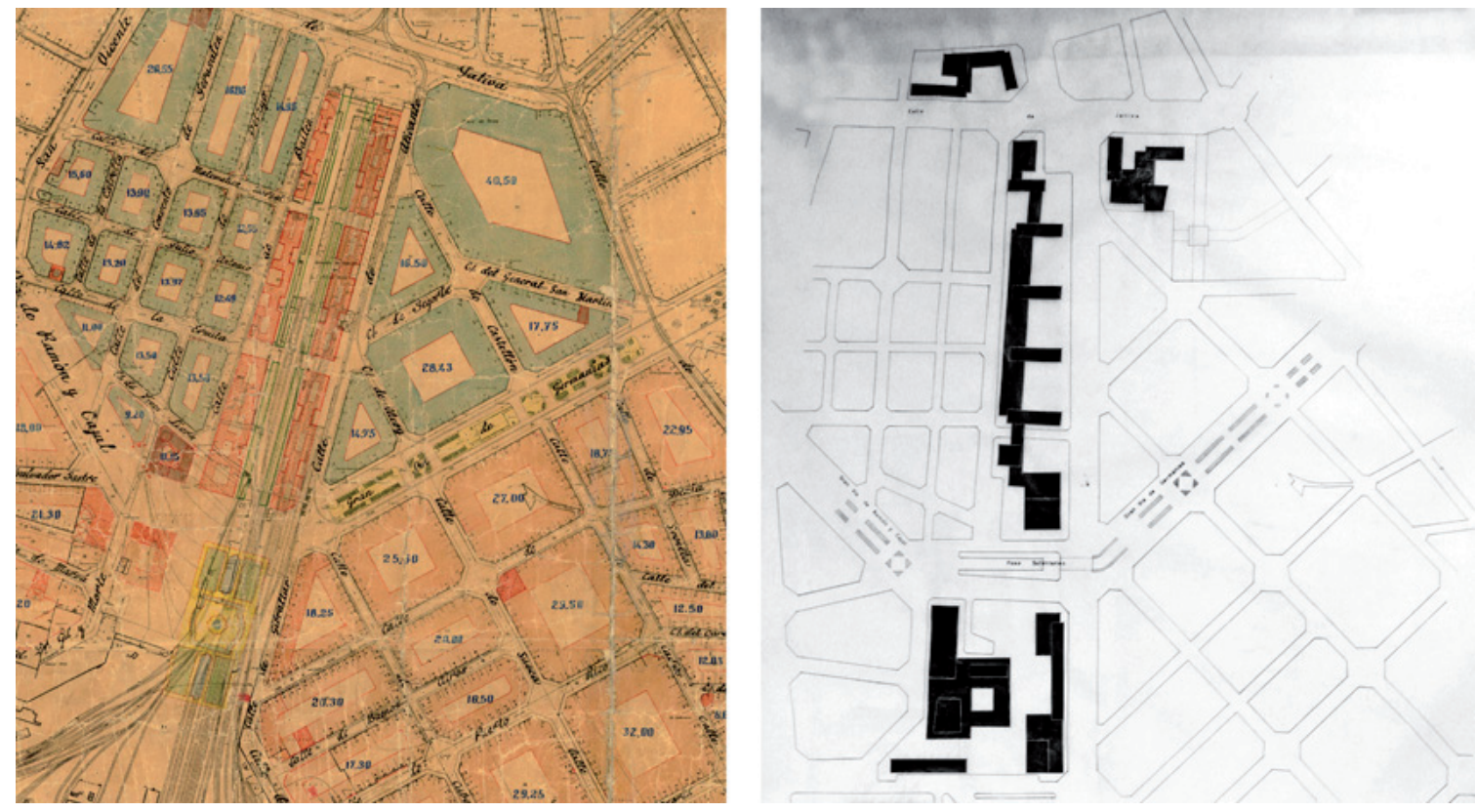

Figura 5. Comparación del proyecto incluido en la documentación del Plan de 1946 para el aprovechamiento de los terrenos de la Estación del Norte, grafiado sobre el plano de la Hoja no 5 de desarrollo del Plan (aprobado el 15 de marzo de 1950), con la propuesta de García-Ordóñez de 1959

Fuente: Archivo de Planeamiento del Ayuntamiento de Valencia y Archivo Histórico de la Generalitat Valenciana

Sí que se aprecia algo más de complejidad, sobre todo en la variadísima tipología de edificación abierta, interviniendo incluso al otro lado de la calle Játiva e incluso en sustitución de la Plaza de Toros (hecho vinculado a una operación de permuta que incluía los terrenos del antiguo Hospital, en la que estuvo implicada la Diputación Provincial de Valencia). Por otro lado, la calle Alicante se veía prolongada, quedando la playa de vías partida -junto con una calle perpendicular que hacía de diagonalen cuatro grandes cuadrantes triangulares.

Esta propuesta, basada en edificación abierta, recuerda además a un trabajo anterior al incluido en el Plan de Ordenación Urbana de 1946: el anteproyecto de Pecourt y Sancho premiado en el primer concurso del Colegio de Arquitectos de la Zona de Valencia (publicado en su Boletín no 9, de 1935), con motivo de la reordenación de los terrenos que debían haberse quedado libres tras el traslado de la Estación del Norte. Como ha puesto de manifiesto Pérez Igualada ${ }^{26}$, este proyecto

26 Cita extraída de PÉREZ IGUALADA, Javier (2012). La introducción de la edificación abierta en Valencia. Del Plan General de 1946 al Plan Sur de 1958. Cuaderno de Investigación Urbanística no 85. Madrid. Enrique Pecourt Betés fue un arquitecto tempranamente interesado en temas urbanísticos, 
puede considerarse como la primera propuesta de cierto alcance urbano basada en la edificación abierta realizada en Valencia: dos bloques lineales de distinta altura, unidos en planta baja, flanquean un nuevo eje urbano.

La ordenación incluida posteriormente en el Plan de 1946, elaborada bajo la supervisión de Valentín-Gamazo ${ }^{27}$, quedó reflejada en la Hoja no 5 de desarrollo del Plan de Ordenación de Valencia y su Comarca, elaborado por la Oficina Técnica Municipal y aprobado definitivamente por la Comisión Central de Sanidad Local en 15 de marzo de 1950 (junto con los Proyectos Parciales no I y II). Se conserva el plano original con la diligencia del Secretario de Gran Valencia, en el que aparece también la firma de Javier Goerlich Lleó dando su visto bueno como Arquitecto Mayor de Valencia. No aparece, sin embargo, la edificación que rodeaba inicialmente la plaza rectangular situada en el encuentro de las Grandes Vías: dos bloques simétricos y una iglesia de gran tamaño cerrando la perspectiva (quizá por exceder el ámbito de la Hoja y reservarse para un proyecto especial). Sólo permaneció grafiada el ajardinamiento del espacio público previsto.

Por supuesto, resulta obvio añadir que ninguno de estos tres proyectos -los de Enrique Pecourt, Valentín-Gamazo y García-Ordóñez- se llevaron nunca a cabo. Quedaron como testimonio de la voluntad de aprovechar un sector urbano de emplazamiento excepcional, conectando únicamente en ese sentido con el reciente proyecto de Gustafson para el Parque Central, y cuyo desarrollo final, por cierto, no está tampoco muy claro que vaya a tener lugar.

También se han conservado varios planos referentes a los terrenos recuperados al río. El que se reproduce aquí (el juego completo puede consultarse en el Anexo de la tesis) corresponde a la quinta zona comercial descrita en el Plan de Adaptación de marzo de 1959. Realizado a la misma escala 1:500, refleja un esponjamiento de la construcción mayor, disponiendo diferentes edificaciones singulares en el lecho del río entre el puente del Mar y las Torres de Serranos.

Con esta ordenación del antiguo río -y remarcando siempre la recuperación de terrenos-, García-Ordóñez se reafirmaba en combinar dos estrategias históricas del urbanismo europeo: el Ring de Viena y las marginales del Sena ${ }^{28}$. La operación resultaba una clara ganancia para la cota de la ciudad, como había sucedido en la capital austrohúngara tras el derribo de sus murallas, si bien aquí se combinaba con la necesaria vialidad de tráfico rápido -incluido el metropolitano (mencionado expresamente en la publicación de la Comisión Técnica Especial)- que se diseñó en París.

como lo refleja su ponencia -redactada junto a Luis Costa Serrano- "El cinturón verde de las ciudades", presentada al II Congreso de la Federación de Urbanismo y de la Vivienda (Barcelona, 1942).

27 El Plan incluía un Anteproyecto de prolongación de la Avenida del Marqués de Sotelo y enlace de las Grandes Vías, generando un nuevo centro urbano en el espacio de la Estación del Norte. Incorporaba una planta y dos perspectivas urbanas (una de ellas bastante general). Véase GIMÉNEZ BALDRÉS, Enrique (1996). Parcelaciones Residenciales Suburbanas. La formación de la periferia metropolitana de Valencia. Valencia: Generalitat Valenciana, COACV y Universidad Politécnica de Valencia.

${ }_{28}$ Coincido plenamente con esta apreciación del arquitecto Luis Perdigón Fernández, con quien me he entrevistado numerosas veces en el Archivo de Arquitectura y Urbanismo de la ETSAV. 


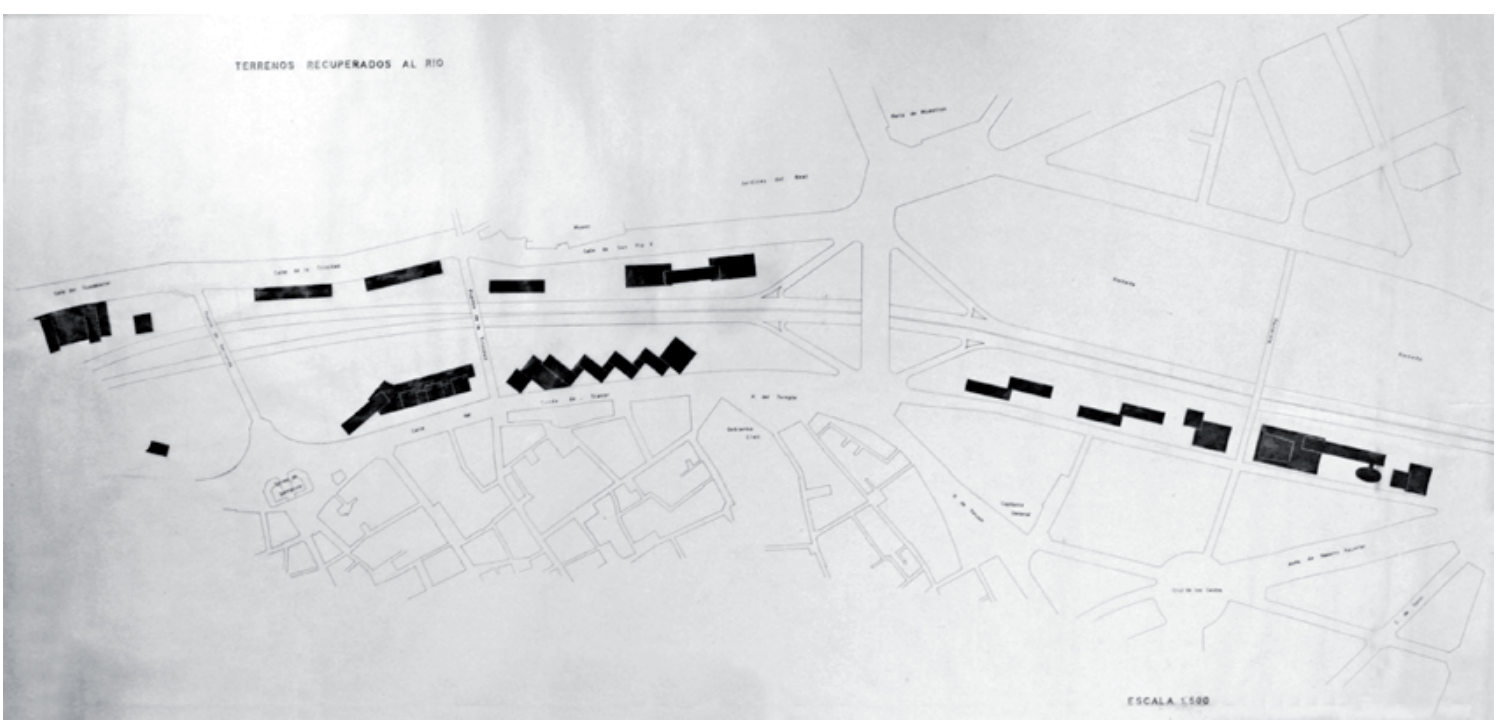

Figura 6. Plano sobre la ordenación de los Terrenos recuperados al Río, sin fecha ni firma. Escala 1:500. Fuente: Archivo Histórico de la Generalitat Valenciana

Es cierto que la influencia de los Estados Unidos estuvo también presente (la revista Arts \& Architecture le sirvió de inspiración gráfica a García-Ordóñez, además de manejar otros referentes teóricos), avalando la necesidad de resolver el tráfico mediante ese eje este-Oeste, al estilo de las vías de alta capacidad de las ciudades americanas. Con los años, los referentes externos para los urbanistas valencianos fueron reduciéndose exclusivamente a las experiencias estadounidenses, desechando los modelos europeos, y asumiendo así conceptos -aun perteneciendo a culturas tan dispares- como el Center Business District (muy utilizado tras la aprobación del Plan de 1966).

Otra labor de ordenación que afrontó la Oficina Técnica en este período fue la reforma interior puntual, que venía a entroncar con las famosas y polémicas propuestas del que fuera Arquitecto Mayor del Ayuntamiento de Valencia, Javier Goerlich Lleó. Entre ellas destaca la reurbanización de los terrenos liberados por el Viejo Hospital de Valencia, en pleno centro de Valencia, en la que la Diputación estuvo directamente relacionada ${ }^{29}$. Ahora, sin embargo, interesa hablar sobre una operación de reforma interior del Barrio del Carmen, cuyo plano -sin firma ni fechase conserva en la sección Gran Valencia del Archivo Histórico de la Generalitat. En efecto, parece que la Oficina Técnica estuvo relacionada con una propuesta destructiva, en la que la trama original del barrio quedaba reorganizada por la nueva edificación abierta. El sector afectado estaba comprendido entre las calles de Cuarte, Salvador Giner, Na Jordana y Guillem de Castro. Pueden apreciarse bloques en $\mathrm{H}$ similares a los utilizados en la maqueta de la Solución Sur en el sector de la Ciudadela (aunque eran ya bastante populares a raíz de su utilización por Vicente Vives en el Grupo Las Torres de Castellón, en 1955), y otras tipologías utilizadas en las propuestas de recuperación de terrenos.

29 Todavía estaba reciente la operación del traslado de la Plaza de Toros, que la Oficina Técnica había asumido como un punto de partida (recuérdese la propuesta de recuperación de terrenos de la Estación del Norte). 
También se conservan copias de propuestas realizadas para este barrio, en enero de 1960, por el Arquitecto Municipal de Urbanismo. En concreto, se trata del sector del Plan Parcial no 1-3-4, desarrollado a escala 1:1.000, y en el que la edificación abierta ha dejado paso a la regularización mediante manzanas: solamente adquiere protagonismo en la rectificación de alineaciones de la calle Alta, una gran cicatriz en el tejido urbano. A partir de este plano, la Oficina Técnica elaboró una propuesta de ordenación para el centro de la ciudad, perteneciente a la colección de planos -por tipografía y formato- realizados a raíz de la necesaria recuperación de terrenos de la Solución Sur. Sorprende encontrarse con este tipo de propuestas en el archivo de Gran Valencia, aunque quizá existiera algún tipo de compromiso de continuidad con la labor realizada por Javier Goerlich. Lo cierto es que conforme fue pasando el tiempo, la Oficina Técnica dejó de trabajar con la escala pequeña de la intervención urbana (algo más propio de los técnicos municipales), y apuntó cada vez de manera más decidida a la realidad metropolitana.

De hecho, durante esos años la labor del propio García-Ordóñez estuvo centrada fundamentalmente en la difusión de los contenidos de la Solución Sur, enfocados desde un punto de vista tanto metropolitano como humanístico, y no tanto centrados sobre determinados proyectos técnicos. Así lo refleja la charla Valencia, una ciudad con futuro, incluida en el ciclo de conferencias El futuro de Valencia organizado por el Ateneo Mercantil a lo largo de 1959. En él se puede leer que los problemas de la ciudad y su hinterland desbordan el ámbito local, superan los confines comarcales y trascienden al espacio nacional, siendo citada también una de las conclusiones del $\mathrm{V}$ Congreso de la Unión Internacional de Arquitectos, celebrado en Moscú en julio de 1958: una planificación regional es indispensable para el estudio urbanístico de toda ciudad. Por su periferia, la ciudad está en contacto con la región (en alusión al necesario cambio de escala que había que acometer).
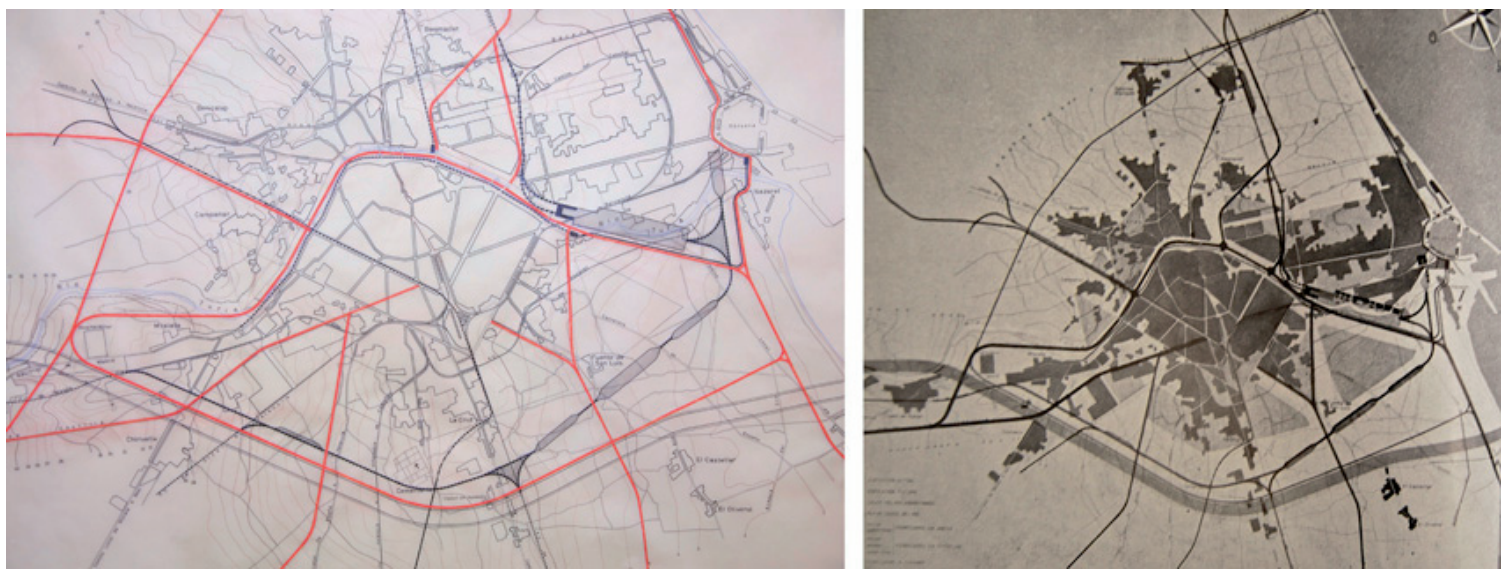

Figura 7. Fragmento de un plano sin título, con indicación de curvas de nivel y red viaria propuesta, que hay que fechar antes de octubre de 1958 (el Norte girado y la inclinación de la zona ferroviaria de la Fuente de San Luis lo hacen anterior a las propuestas de Adaptación del Plan de la primera mitad de 1959). A la derecha, esquema urbano preparado para la exposición en el Ayuntamiento de Valencia de octubre de 1958, conforme apareció publicado en el Boletín de Información Municipal del cuarto trimestre de 1958.

Fuente: Archivo Histórico de la Generalitat Valenciana. 
Finalmente, y volviendo a ese urbanismo territorial de Gran Valencia, hay que decir algo sobre la fallida tramitación de la modificación del Plan General de Valencia, antes de cerrar este epígrafe. Tras la tardía exposición pública de los acuerdos tomados por el Ayuntamiento, se presentaron tres alegaciones idénticas, firmadas por tres particulares, que, antes que señalar objeciones técnicas a los planos de ordenación, más bien impugnaban jurídicamente la validez del procedimiento legal. Los argumentos esgrimidos apuntaban a la necesidad de la aprobación por parte del Consejo de Ministros para una modificación del vigente Plan de Ordenación (según lo prescrito en el Decreto de 14 de octubre de 1949), además de la falta de aprobación de la Solución Sur, por lo que solicitaba la nulidad de todo lo actuado ${ }^{30}$.

Una vez emitidos los informes del Negociado de la Sección Administrativa de Urbanismo, y del Letrado Jefe de la Asesoría Jurídica Municipal, se desestimaron los fundamentos jurídicos aportados, al entender que la Ley del Suelo de 1956 facultaba a los Ayuntamientos a emprender la revisión de sus planes generales (derogando en ese punto $-y$ no en lo tocante a la pervivencia de la Corporación Administrativa - lo previsto por el Decreto del 49), y subrayando que los trámites no contaban aún con la aprobación definitiva de la Superioridad.

El 2 de diciembre de 1960, el pleno del Ayuntamiento ratificó la legalidad de las actuaciones encaminadas a la Adaptación. En enero se remitió el expediente y la documentación técnica a la Corporación Administrativa Gran Valencia, a los efectos del preceptivo informe y posterior tramitación, para su aprobación por la Superioridad. Con un año y medio de retraso se retomaba, pues, el camino emprendido en julio de 1959, todavía sin estar aprobada por parte del Gobierno la ejecución y financiación de las obras del Plan Sur (lo que añadía un punto de incertidumbre creciente conforme pasaba el tiempo).

Gran Valencia, por su parte, movió ficha para activar definitivamente el nuevo marco urbanístico que necesitaba la comarca. Primero mostró por carta ante el Director General de Arquitectura el agradecimiento de la Corporación por la eficiencia y rapidez con que se llevan a cabo las obras correspondientes al Plan de Adopción de Valencia decretado con motivo de la riada del año 1957. No estaba de más ganarse el apoyo del Ministerio ${ }^{31}$.

A continuación se dispuso que, por las Oficinas Técnicas propia y del Ayuntamiento de Valencia, se formulara un estudio de los Planes Parciales que quedaran subsistentes y aquellos que habrían de ser modificados a la vista de la Solución Sur. El 20 de julio de 1961 la Comisión Ejecutiva informó favorablemente ese estudio, que había sido anteriormente encomendado a los arquitectos Mauro Lleó, Víctor Bueso, Julio Bellot y Fernando Martínez García-Ordóñez.

El Consejo General, en sesión de 3 de agosto, ratificó dicho informe, pero recordando la vigencia del Plan General de Ordenación Urbana de Valencia y su Comarca declarado preceptivo por Ley de 18 de diciembre de 1946, y señaló

\footnotetext{
30 Las tres alegaciones poseían idéntica composición hasta en la mecanografía, siendo firmadas por Víctor Albalat Morte, Desamparados Bou Llorca y Santiago Bauzá Ortíz. Están firmadas el 29 de julio de 1960. La publicación de la modificación del Plan había tenido lugar un mes antes, el 29 de junio de 1960, en el número 153 del Boletín Oficial de la Provincia de Valencia (una información pública que llegaba con bastante retraso con respecto a su aprobación en el mes de julio del año anterior).

31 Oficio con fecha de registro en el Ministerio de la Vivienda 16 de junio de 1961, firmado por el Gobernador Civil de Valencia. Archivo General de la Administración, Alcalá de Henares (Madrid).
} 
además los Planes Parciales de desarrollo de dicho Plan que subsistían teniendo en cuenta el desvío previsto del Turia (indicados por el referido informe). Los acontecimientos estaban tomando, pues, un nuevo rumbo: no parece que en ningún momento se llegara a remitir la tan deseada Adaptación del Plan de la capital al Ministerio. Además, la aprobación de la Ley sobre el Plan Sur de Valencia el 23 de diciembre de 1961 -publicada en el no 309 del Boletín Oficial del Estado cuatro días después-, si bien tranquilizó a los valencianos confirmando la solución diseñada para la desviación del río, paralizó definitivamente la tramitación anterior al introducir un nuevo marco legal ${ }^{32}$.

Hasta entonces, se contaba únicamente con el acuerdo del Consejo de Ministros del 22 de julio de 1958 (que había aprobado la esquemática Solución Sur desarrollada por la Comisión Técnica Especial), junto con los distintos planes de enlaces (viario y ferroviario). Además, en octubre de 1958 había sido aprobado provisionalmente, mediante una Orden del Ministerio de Obras Públicas, el Anteproyecto de Defensa de Valencia contra las Avenidas del Río Turia - Solución Sur, el cual entró definitivamente en vigor (aunque sin mecanismos de financiación) en febrero de 1960.

Los planos de este anteproyecto recogían -además del nuevo cauce- numerosos colectores de aguas pluviales, como el que acompañaba a la pista de circulación rápida prevista para el cauce desalojado, o el colector Sur que partía del Camino de Tres Cruces: todos ellos iban a desaguar al final del nuevo cauce o a la dársena del Puerto. Además, se dibujaban unas defensas, como la grafiada en el barranco de Andolsa, al Noroeste de la capital.

La existencia de copias en los archivos de Gran Valencia evidencian la coordinación que el Ministerio de Obras Públicas mantenía con la Corporación Administrativa. Además, ésta se dedicó durante esos años a rehacer las redes urbanas más afectadas por la futura construcción del nuevo cauce, desarrollando numerosos planos ${ }^{33}$ (muchos de ellos son reconocibles, entre otros motivos, por tener girado el Norte conforme a los primeros esquemas generados por GarcíaOrdóñez en la Solución Sur).

La ley del Plan Sur vino a dotar de recursos la construcción de las obras, incorporando -si bien de una manera no muy exhaustiva ${ }^{34}$ - la faceta hidráulica de la Solución Sur, junto con las previsiones del Plan de Accesos y Carreteras y sus enlaces aprobado por el Ministerio de Obras Públicas el 7 de octubre de 1959 (y que resultaba una fiel traslación del plano $V$. Accesos y circulaciones principales de la Adaptación del Plan), así como la reforma ferroviaria promovida por la Ordenación

\footnotetext{
32 Con el Plan de Estabilización en marcha desde 1959, parecía que nunca fuera a llegar el momento de dotar económicamente a las obras previstas, pero Rincón de Arellano finalmente lo consiguió, no sin contar con la inestimable complicidad del Ministro de Hacienda Mariano Navarro-Rubio (se llegó incluso a incluir la aprobación en el Consejo de Ministros con posterioridad a que éste se hubiese cerrado). Véase PÉREZ PUCHE, Francisco (1997). Hasta aquí llegó..., ob. cit.

33 En uno de ellos, fechado en junio de 1962, y referido a la red de saneamiento de la zona Oeste de la capital, aparecen incluso los típicos rótulos de Gran Valencia, con la indicación de Arquitectos e Ingeniero de Caminos.

34 Por ejemplo, en un primer momento no se incluyeron las partidas correspondientes a los puentes sobre el nuevo cauce, dejando previsto el acceso desde Madrid con una solución de cruce en vado. Básicamente lo que se aprobaba -eso sí, de una manera definitiva- era el denominado Plan Sur como solución para llevar a cabo el proyecto de desviación del río Turia a su paso por la ciudad de Valencia.
} 
Técnica de Valencia (el Plan de Enlaces Ferroviarios de Valencia, adaptado a la Solución Sur, aprobado el 28 de noviembre de 1959).

Estos tres documentos aprobados por el Consejo de Ministros (Ley del Plan Sur, Plan de Accesos y Plan de Enlaces) constituían la única referencia legal cierta para la ordenación metropolitana. Las disposiciones contenidas en el artículo $11^{\circ}$ de la Ley 81/1961 de 23 de diciembre, además, requerían ahora que el Plan General de Ordenación Urbana de Valencia y su Comarca (seguía vigente el de 1946, tal y como había ratificado el Consejo General) fuese adaptado en su totalidad. En concreto, se apuntaba que los terrenos del cauce natural del río Turia que terminadas las obras de su desviación queden liberados, y los ocupados por las estaciones, vías y servicios ferroviarios que, trasladados a sus nuevos emplazamientos y trazados, quedan disponibles se desvinculan del carácter de dominio público por el que estaban afectados, y se adscriben a los nuevos destinos señalados en el Proyecto de la Solución Sur de Desviación del Río Turia y en el Plan General de Ordenación Urbana de Valencia, revisado y adaptado a dicha Solución.

Después de tantas vueltas, y aunque el texto de la ley no parecía echar por tierra los trabajos realizados hasta ese momento, se optó por dejar sin efecto la Adaptación del Plan General de Valencia estudiada por Gran Valencia, con lo que, en la práctica, se vino a dar la razón a los tres particulares, quienes -pretendiendo declarar nulo el trabajo realizado- habían alegado que la iniciativa habría de ser refrendada por el Consejo de Ministros.

Quizá aprovechando esta circunstancia -y ante la inusitada pero creciente oposición a su persona- García-Ordóñez, considerada terminada su misión, aprovechó para renunciar a su labor de coordinación al frente de la Oficina Técnica de Gran Valencia comunicándoselo por carta al Director General de Urbanismo, su buen amigo Pedro Bidagor ${ }^{35}$. Una manera discreta de abandonar la escena pública, dispuesto a retomar su vocación de urbanista con su estudio GO-DB (dentro de un proyecto más tarde llamado Plan Hábitat, para el que quiso crear un equipo multidisciplinar ${ }^{36}$ ), pero que no deja de resultar trascendental a la vista de los acontecimientos que estaban por llegar.

El Ayuntamiento, en su sesión del 21 de noviembre de 1961, acordó por aclamación concederle a título individual la Medalla de la Gratitud de Valencia, como expresión de agradecimiento por sus esfuerzos, sacrificios, trabajos y afanes, y como imperecedero reconocimiento de la Ciudad. De esta forma Rincón de Arellano cerraba el círculo, otorgando una salida digna a García-Ordóñez poco antes de emprender el planeamiento más ambicioso que la comarca tuvo que afrontar en el siglo pasado.

\footnotetext{
35 He tenido conocimiento de esta carta gracias a una entrevista personal con José Luis de los Ángeles, el que fuera trabajador de GO-DB (administrativo especializado) desde 1958 hasta diciembre de 1979. 36 En febrero de 1964 salieron convocadas las plazas de arquitectos urbanistas para integrarse en el Plan Hábitat (la oficina que pretendía dirigir García-Ordóñez). Antonio García Heredia y Joaquín Arnau Amo, todavía estudiantes en Madrid, se presentaron, pero para junio las perspectivas habían cambiado: terminaron trabajando junto a Claudio Gómez-Perretta en la Oficina Regional de Proyectos, dependiente de Obras Públicas. Curiosamente, el ejercicio propuesto por Perretta para valorar su capacidad técnica consistió en el paso de la Autopista del Mediterráneo por encima de la dársena del Puerto y frente a los barrios marítimos.
} 


\section{EL PLAN GENERAL DE VALENCIA Y SU COMARCA ADAPTADO A LA SOLUCIÓN SUR}

\subsection{El área metropolitana como referente}

Para comprender el giro que se dio en el planeamiento de la Gran Valencia a comienzos de los años sesenta, hay que remitirse al documento que llevó a cabo la revisión del Plan de Madrid de 1946: el Plan General de Ordenación Urbana del Área Metropolitana de Madrid, fechado en 1961, editado en 1962 y aprobado por ley específica de 2 de diciembre de 1963.

Era la primera vez que aparecía el concepto de área metropolitana, aunque sólo fuera en su denominación. Se trataba de un término novedoso en la bibliografía urbanística española, que más bien se había importado de los Estados Unidos. Como ha señalado Terán ${ }^{37}$, el vacío teórico en nuestro país era tal, que en la práctica el nuevo plan supuso una mera continuidad ideológica con los planteamientos anteriores (políticas de descongestión, núcleos periféricos, etc.), a pesar de la constatación de su fracaso. Un nuevo acto de fe en la doctrina urbana tradicional, sin la necesaria profundización en la realidad regional de Madrid.

Ese vacío aludido permite traer a colación el momento en que García-Ordóñez regresa de su viaje urbanístico por los Estados Unidos, en marzo de 1960. Después de haberse puesto en contacto en Nueva York con la Subdirección de Vivienda, Construcción y Planificación de las Naciones Unidas, obtuvo de Gran Valencia la petición de envío de unas recientes publicaciones urbanísticas de las que tuvo conocimiento allíis.

No consta la recepción de los referidos libros, aunque su conocimiento por parte de García-Ordóñez hace suponer que Gran Valencia, en lo que respecta a formación teórica, estaba supuestamente preparada para los nuevos retos de la planificación comarcal que se estaba abordando.

37 Véase al respecto TERÁN TROYANO, Fernando de (1982). Planeamiento urbano en la España contemporánea. 1900-1980. Madrid: Alianza. El libro profundiza en el fracaso del modelo urbanístico, al constatar -entre otras circunstancias- la absorción del primer anillo verde previsto para la periferia de Madrid.

38 Carta de 22 de marzo de 1960 del Secretario de Gran Valencia a la Subdirección de Vivienda, Construcción y Planificación de las Naciones Unidas. En ella se nombra a García-Ordóñez como nuestro Arquitecto planeador consultor, y se expresa la voluntad de corresponder al interés mostrado por esa entidad en mantener contacto directo con organizaciones españolas de planeamiento urbano: con mucho gusto le transmitiremos nuestros trabajos y experiencias, deseando recibir de ese Organismo instrucción y experiencias a la vez. El listado de los libros solicitados es bastante elocuente a la hora de conocer los referentes teóricos del momento:

Tendencias actuales de la planificación regional (Rodwin)

Tendencias que influyen actualmente en la Planificación regional (Ginsburg)

La planificación regional en Europa (Ginsburg)

El concepto de región planificable. La evolución de una idea en los Estados Unidos (Friedman)

La forma de las ciudades norteamericanas (Sert)

Estructura óptima de la urbanización (Bauer)

Reacciones ante la expansión metropolitana en los Estados Unidos (Gulick)

La creación de comunidades equilibradas y la planificación regional - Aspectos sociales y técnicos (Yu-Tsun-Lu)

Esquema de la planificación regional en Francia a partir de 1944 (Prothin)

La planificación regional en la URSS (Gobierno de la URSS) 
De hecho, en aquel momento la Dirección General de Urbanismo seguía también con interés el ámbito científico norteamericano, en el que destacaban la definición y análisis de las áreas metropolitanas. Especial relevancia tendría la investigación del profesor Kingsley Davis, del Instituto de Estudios Internacionales de Berkeley, sobre la delimitación de dichas áreas en todo el mundo (a la de Valencia se le asignaban quince municipios) ${ }^{39}$. En 1965, el Ministerio de la Vivienda editaría una publicación referida al ámbito español en los que, con datos de 1960, aplicaría los principios establecidos por Davis a las ciudades españolas. En esa publicación, revisada dos años más tarde en su segunda edición, el Área Metropolitana de Valencia se aumentaba hasta 31 términos municipales, uno más que los contemplados por la Gran Valencia.

En cuanto a la capital de España, un nuevo ente había nacido de la revisión del planeamiento madrileño, conscientes de la envergadura de la tarea urbanística. Con el nombre de COPLACO se había creado un órgano gestor con financiación propia la Comisión de Planeamiento y Coordinación del Área Metropolitana de Madrid-, encargado de supervisar la nueva unidad territorial que aglutinaba a las unidades administrativas municipales.

El urbanismo metropolitano de la Villa y Corte siempre había ido por delante de las provincias, tanto desde el punto de vista cronológico como de la aplicación práctica de los principios ordenadores, hasta el punto de que se puede afirmar que Madrid experimentaba y la periferia depuraba los errores cometidos. En el caso de Valencia, como se verá, parece que se importaron más bien los principales defectos, sin dotar a la Corporación Administrativa de la necesaria remodelación que el planteamiento metropolitano requería (para la capital se redefinió el ámbito metropolitano de ordenación -el Área Metropolitana de Madrid-, actualizando el número de municipios implicados ${ }^{40}$ ).

Por citar un ejemplo especialmente llamativo, Gran Valencia nunca llegó a recibir, ni de lejos, medios económicos como los que se le consignaron a COPLACO (en palabras de Antonio García Heredia, Arquitecto Jefe de Gran Valencia desde mayo de 1978, esa entidad sí que estaba bien organizada, incluso con un presupuesto propio ${ }^{41}$ ). Incluso antes de la creación de este ente, puede palparse la tensión existente al respecto en una carta que el Secretario de la Corporación, Rafael Ariño, enviaba a Bidagor en julio de 1960, como contestación a un oficio del Ministerio de la Vivienda:

Contestando a su comunicación, para dar cumplimiento al informe que reclama la Secretaría General Técnica del Ministerio de la Vivienda, referente a las previsiones de inversión pública de dicho Departamento para el año 1961, tengo el honor de manifestarle que la Corporación Administrativa Gran Valencia no goza de

\footnotetext{
39 Puede consultarse ANGELUCCI, Suzanne R. (1959). The world's metropolitan areas. Berkeley: Institute of International Studies, University of California Press (versión en español: Las áreas metropolitanas del mundo, Compañía Editorial Continental S.A. México, 1961).

40 La Ley 121/1963, de 2 de diciembre, en su artículo 20, daba la lista de municipios incluidos: Madrid, Alcobendas, San Sebastián de los Reyes, Paracuellos del Jarama, Getafe, Leganés, Alcorcón, Villaviciosa de Odón, Boadilla del Monte, Pozuelo de Alarcón, Majadahonda, Villanueva del Pardillo, Villanueva de la Cañada, Torrejón de Ardoz, San Fernando de Henares, Coslada, Ribas de Jarama, Brunete, Mejorada del Campo, Velilla de San Antonio, Pinto y Colmenar Viejo. Las Rozas, como ya se ha dicho, se incorporó al año siguiente.

${ }^{41}$ Entrevista con el autor (14 de diciembre de 2011).
} 
ninguna ayuda estatal ni percibe del Estado cantidad por ningún concepto, pues sus ingresos proceden exclusivamente de los consignados en el Presupuesto ordinario que anualmente se forma para cubrir sus atenciones ordinarias, cuyo Presupuesto, en su parte de ingresos, se nutre casi exclusivamente con las aportaciones que realizan los Ayuntamientos, en virtud de un reparto que se efectúa entre los mismos.

(...) No obstante, creemos que este asunto nos da motivo para significar de nuevo ante el Gobierno los deseos varias veces manifestados por la Corporación Gran Valencia, de gozar en el terreno económico del mismo trato favorable de que disfrutan las entidades similares a Gran Valencia que vienen existiendo en Barcelona y Madrid. ${ }^{42}$

Como se puede suponer, no hubo ninguna respuesta favorable desde el Ministerio en lo referente a la cuestión económica. Por ello, ante el gran crecimiento de población que estaba experimentando la comarca, puede situarse en este punto el verdadero comienzo de la descoordinación metropolitana de la Gran Valencia, al menos en cuanto a los servicios urbanos se refiere. Ante la pasividad oficial, la iniciativa privada empezó a proponer medidas para solucionar, entre otros, los problemas originados por los servicios regulares de viajeros que ya por entonces se daban en la comarca.

Se conserva, por ejemplo, un escrito de 30 de octubre de 1959 dirigido al Ministerio de Obras Públicas en el que varios particulares, dada la densidad de tráfico de los Servicios Públicos de Transporte en la Ciudad de Valencia, han considerado oportuna la construcción y explotación de dos Estaciones de Autobuses destinadas a la concentración de llegadas y salidas de dichos vehículos, los cuales se establecerán en las zonas Norte y Sur de la Ciudad, en terrenos cuyo emplazamiento y superficie someteremos a la aprobación de esa Dirección General. ${ }^{43}$

El procedimiento se alargó, pues se presentaron nuevos concursantes como el Sindicato Provincial de Transportes y Comunicaciones de Valencia, pero el episodio no deja de ser elocuente. La Corporación Administrativa Gran Valencia, a pesar de ostentar claras atribuciones legales -a tenor de la Base $5^{a} \mathrm{~g}$ ) de la Ley de 18 de diciembre de 1946, y del artículo $10 \mathrm{~g}$ ) del texto articulado de 14 de octubre de 1949-, no ejerció nunca sus competencias en materia de transporte colectivo de viajeros $^{44}$.

\footnotetext{
42 Escrito de 12 de julio de 1960, con registro de salida 1563, de Gran Valencia al Director General de Urbanismo. En ella también se daba cuenta de la labor que en aquel momento desarrollaba la Oficina Técnica: estudios encaminados a la formación de Polígonos para situar en ellos zonas residenciales, habiendo elegido terrenos de secano y otros lindantes con la autopista en proyecto de Valencia a Sagunto.

43 Escrito con registro de entrada 31 de octubre de 1959 en el Ministerio de Obras Públicas. Archivo General del Ministerio de Fomento.

44 El texto decía literalmente: Autorizar el establecimiento y explotación de servicios de transportes colectivos, salvo lo reservado a la competencia de los Ayuntamientos por la Ley Municipal y el Reglamento de Obras y Servicios Municipales y las facultades que competen al Ministerio de Obras Públicas.

En un escrito de 10 de noviembre de 1976 dirigido al Presidente del Consejo General de Gran Valencia, la Dirección General de Transportes Terrestres abundaba en este sentido: Descartadas las excepciones que el propio precepto acota, relativas en primer lugar a los transportes urbanos propiamente tales, y en segundo término a los interurbanos estatales, resulta evidentemente que las facultades de
} 
Tiempo después, el propio Presidente del Consejo General llegó a dejar por escrito que la histórica dejación de deberes de la Gran Valencia en este tema estuvo motivada muy posiblemente por el respeto a la competencia de los Ayuntamientos y a las facultades que competen al Ministerio de Obras Públicas ${ }^{45}$. En cualquier caso, el propio Ministerio ratificó la falta de responsabilidad por parte del ente supramunicipal, que a la larga originaría numerosos problemas judiciales con las concesiones de líneas metropolitanas.

Volviendo a la ordenación urbanística, la tarea de la Oficina Técnica durante estos años, a la espera de la tramitación del Plan General y de la dotación económica para las obras de desvío del cauce, no estuvo centrada en un único campo, dedicándose a perfeccionar el planeamiento comarcal que parecía iba a ser ratificado. Así ocurrió, por ejemplo, con la modificación de las Ordenanzas reguladoras de la edificación: un informe del Arquitecto Jefe de la Oficina Técnica de Gran Valencia, de 12 de marzo de 1960, alertaba de que las Bases Generales de las Ordenanzas (que formaban parte del Plan General de Ordenación Urbana de 1946), regían en aquellos pueblos que no tenían aprobado su Proyecto Parcial correspondiente.

Considerando que la solución más económica para la construcción de viviendas, compatible con la Ley de viviendas de Renta Limitada, era la de cuatro o cinco plantas, la situación resultaba a todas luces perjudicial para los pueblos. A tal efecto, se optó por modificar el contenido de los artículos $3^{\circ}$ y $4^{\circ}$ de la Ordenanza aplicable a los Poblados de Cintura, con el fin de poder autorizar mayores alturas en los edificios ${ }^{46}$.

El 6 de agosto se publicó la modificación en el Boletín Oficial de la Provincia, no formulándose alegación alguna, por lo que en septiembre el Presidente de la Comisión Ejecutiva elevó la propuesta a la Dirección General de Urbanismo para obtener la aprobación ministerial definitiva. Un año y medio más tarde, el 10 de mayo de 1962, Pedro Bidagor contestó a Gran Valencia adjuntando un informe emitido por la Sección de Planeamiento (Muñoz Monasterio participó en él) que

autorización de servicios de transporte colectivo se refieren a los transportes regulados, de modo peculiar y específico, por la propia Ley: aquellos que, como facultad preferente, puede gestionar el Ayuntamiento de Valencia, fuera de su término municipal y dentro de la zona afectada por la Ordenación Urbanística Comarcal, para cuyo establecimiento y explotación se requiere, en consecuencia, la superior autorización o aprobación de ese Consejo.

45 Escrito de 31 de mayo de 1976 dirigido al Director General de Transportes Terrestres, Ministerio de Obras Públicas. En ese momento, ostentaba la Presidencia del Consejo General el Gobernador Civil Enrique Oltra Moltó.

${ }^{46}$ La redacción definitiva propuesta inicialmente, dentro del capítulo XIV de las Bases generales de ordenanzas, decía así:

Artículo 30. - Se clasifican las calles en cinco categorías:

1 a. - Calles de anchura mayor o igual de 16 metros.

2a.- " " " " 10 metros

3a.- " " " " " 8 metros

$4 a^{-}-"$ " " " " 6 metros

5a.- " " " " menor de 6 metros

Artículo 40. - Se permitirá la construcción de planta baja y cinco pisos en las calles de $1^{a}$ categoría, con una altura máxima a cornisa de 18 metros; planta baja y cuatro pisos en las de $2^{a}$ categoría, con una altura máxima de 15 metros; planta baja y tres pisos en las de $3 a$ categoría, con una altura máxima de 12 metros; planta baja y dos pisos en las de $4^{a}$ categoría, con una altura máxima de 9 metros; y planta baja y un piso en la de $5^{a}$ categoría, con una altura máxima a cornisa de 6 metros. 
modificaba la redacción, corriendo la escala del artículo $4^{\circ}$ un lugar para que las alturas de los edificios fuesen sensiblemente iguales que los anchos de las calles.

El proyecto de modificación parcial de Ordenanza municipal de Valencia fue finalmente aprobado por la Dirección General de Urbanismo el 10 de octubre de 1962. Recuérdese este hecho cuando se hable de la densidad propuesta por el Plan de 1966, y de todo el debate previo a su aprobación.

El Ayuntamiento, por su parte, encargó durante esas semanas, sin contar con Gran Valencia, el desarrollo de un plan de aprovechamiento turístico en El Saler a la sociedad TEVASA (Terrenos de Valencia S.A.). Dos meses antes, ésta, con la colaboración del Banco Urquijo y de la empresa Estudios y Proyectos Técnicos Industriales S.A., había solicitado la debida autorización para la redacción de un plan de urbanización de la Dehesa de la Albufera, comprometiéndose TEVASA a concurrir al oportuno concurso de ejecución, en el que disfrutaría del derecho de tanteo. El 26 de octubre de 1962, la corporación municipal le dio autorización para que, en el plazo de un año, realizase los oportunos estudios y elaborase un Plan de Ordenación del Monte de la Dehesa.

A tal fin, el arquitecto Julio Cano Lasso, en colaboración con los también madrileños Vicente Temes González de Riancho y Luis Felipe Vivanco Bergamín, presentó pocos meses más tarde su proyecto de ordenación urbanística, siendo expuesto en el salón de fiestas municipal el 16 de diciembre de $1963^{47}$.

A pesar del gran peso comarcal que suponía esta inmensa ordenación de todo el frente litoral Sur del municipio (871 ha de suelo, con más de 10 kilómetros de playa: el origen de toda una gran megalópolis mediterránea ${ }^{48}$ ), Gran Valencia permaneció ajena a su tramitación, o, al menos, su Oficina Técnica no tuvo oportunidad de pronunciarse.

Sorprendente cuanto menos, pues la urbanización de esa zona residencial al Sur de la comarca tenía prevista una capacidad para 40.000 habitantes (con una absorción máxima de hasta 100.000 personas en la zona de esparcimiento popular). El turismo de sol y playa comenzaba a ser una realidad en España, asociado a la imagen de progreso y apertura a las divisas extranjeras, y Valencia aspiraba a crear el mejor complejo turístico de la península.

El plano de relación con la ciudad puede servir de buen reflejo documental de la incidencia de este plan parcial en ordenación supramunicipal. Aun siendo posterior a la ordenación de Gran Valencia de 1959, curiosamente no recoge lo previsto en su plano VIII. Plan comarcal. En cambio, parece referir con más fidelidad los esquemas de 1958 (que era el único documento que había recibido ratificación en la Dirección General de Urbanismo). Sin embargo, no deja de ser interesante comparar la magnitud de la nueva ordenación turística proyectada con respecto a la comarca,

\footnotetext{
47 A la inauguración acude personalmente el entonces Ministro de Información y Turismo, Manuel Fraga Iribarne. Puede consultarse la completísima tesis, todavía sin publicar, ROQUETTE RODRÍGUEZVILLAMIL, Juan Luis (2011). "La arquitectura de Julio Cano Lasso". Director: Juan Miguel Otxotorena Elizegui. Universidad de Navarra, Escuela Técnica Superior de Arquitectura. Julio Cano Lasso era, además, compañero de promoción, en la Escuela de Arquitectura de Madrid, de Antonio Gómez Llopis, y había participado junto a Alejandro Blond, en 1953, en el concurso para la sede de la Delegación de Hacienda en la capital valenciana.

48 Véase "Ordenación turística de la Dehesa de la Albufera y Playas de El Saler". La Gran Megalópolis Mediterránea. Arquitectura. Mayo 1964, no 65 (separata).
} 
aspecto que en los esquemas de la Comisión Técnica Especial sólo había quedado introducido con un simbólico círculo amarillo.

La Oficina Técnica de Gran Valencia sí que intervino, en cambio, durante estos años previos a la revisión del plan metropolitano, en la ordenación de diferentes zonas de la comarca, incluido algún sector del término municipal de Valencia. Así puede apreciarse, por ejemplo, en los trabajos del Polígono I-C -así llamado por su cercanía al Proyecto Parcial no I, Zona S.O.- y del Sector Burjasot, Benimamet, Paterna, Godella y Rocafort.

Estos dos desarrollos de suelo, uno con carácter de plan parcial y el otro más territorial, constituyeron un claro precedente y una referencia técnica a la hora de analizar cómo se abordó el estudio integral de la comarca. Se hablará a continuación, por su relevancia metropolitana, del segundo de ellos.

\subsection{Plan General del Sector Burjasot, Benimanet, Paterna, Godella y Rocafort (1961).}

Después de la Ordenación de Valencia de 1959, este plan complementario supone el trabajo más representativo de la ordenación comarcal previa al Plan de 1966. Además, la serie de planos de junio de 1961 sobre el Sector Burjasot, Benimamet, Paterna, Godella y Rocafort sirvió para retomar una planificación iniciada diez años atrás en torno a los Proyectos Parciales de Desarrollo no 1 y 2 del Sector BurjasotGodella-Benimamet (Valencia).

Curiosamente, esta ordenación adoptó la categoría de Plan General, emulando el proceder adoptado por García-Ordóñez al acometer la revisión del Plan de Ordenación, inicialmente limitada al casco urbano de la capital. Como se ha visto, todavía no estaba clarificado del todo el mecanismo legal para revisar un plan comarcal que había nacido bajo iniciativa ministerial y al que con posterioridad se le había asignado como tutor una entidad supramunicipal totalmente singular.

Inicialmente se optó, pues, por la vía fácil de trocear el territorio en distintos sectores y encargar a la Oficina Técnica de Gran Valencia el estudio parcial de los mismos. De hecho, en la propia Memoria, los arquitectos de Gran Valencia dejaron claras sus intenciones: actualizar, en esta zona, el Plan General de Ordenación Urbana de Valencia y su Comarca, aprobado por el Gobierno en 27 de julio de 1946.

En julio de 1960, Monasterio había mostrado los planos de un estudio formulado por la Oficina Técnica para la creación de un importante núcleo residencial en dicha zona, con el objeto de establecer allí un gran polígono a modo de ciudad-satélite ${ }^{49}$. Las autoridades de la Corporación Administrativa, sumamente complacidas, instaron a que se completasen los trabajos sobre este nuevo núcleo urbano del que se encuentran precedentes en el contemporáneo escrito a la Dirección General de Urbanismo antes recogido, donde se hablaba de los terrenos de secano como ideales para la formación de Polígonos para zonas residenciales.

No cabe duda de que, si bien es posible que García-Ordóñez pudiera haberse desvinculado ya de Gran Valencia, esta documentación suponía la continuidad

\footnotetext{
${ }^{49}$ Acta 67 del Consejo General de Gran Valencia, de 22 de julio de 1960.
} 
natural de los trabajos a escala comarcal que tanto él como Monasterio habían iniciado en 1959.

El Consejo General acababa de aprobar definitivamente en 1961 el Proyecto Parcial de Ordenación Urbana de Rocafort, redactado por Gran Valencia. Fue un buen punto de partida para todo aquel estudio tan ambicioso, si bien a los pocos meses toda otra referencia a esta ciudad satélite quedó sustituida en las actas por los trabajos de redacción de la Adaptación del Plan.

Los planos del Plan General del Sector Burjasot, Benimamet, Paterna, Godella y Rocafort llevan por fecha el mes de junio de 1961, y van firmados por Víctor Bueso y Antonio Gómez Llopis (como venía siendo habitual, Lleó no intervenía en el planeamiento de los poblados de la comarca). Se distribuyen en cuatro colecciones:

- Red Viaria (IV)

- Sistema de espacios libres (V)

- Zonificación (VI), y

- Organización (VII)

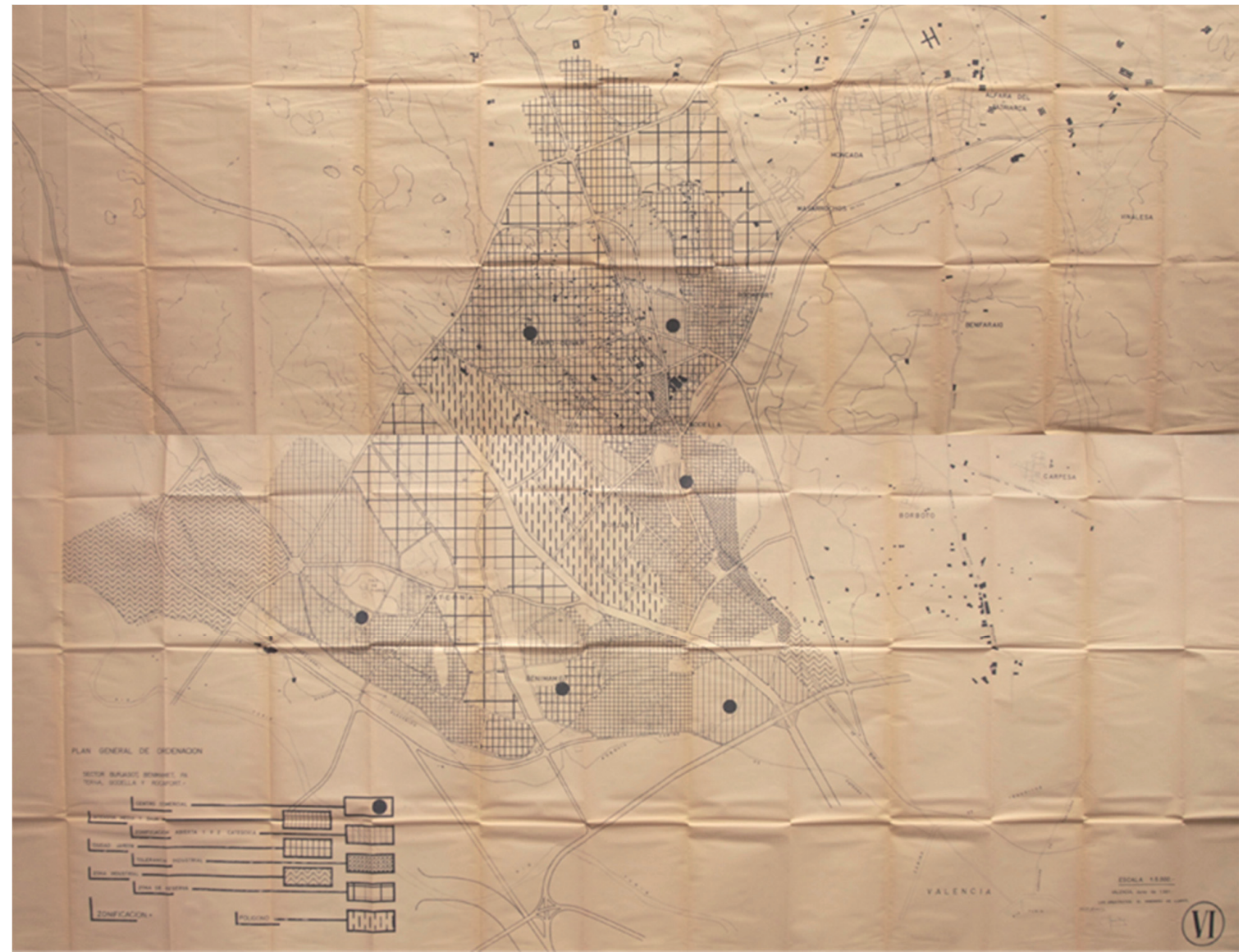

Figura 8. Montaje de las dos hojas correspondientes al Plano de Zonificación (VI) del Plan General del Sector Burjasot, Benimamet, Paterna, Godella y Rocafort, de junio de 1961

Fuente: Elaboración propia a partir de originales en papel del Archivo Histórico de la Generalitat Valenciana 
La documentación del plan se completaba con la Memoria Descriptiva, unas nuevas Normas Urbanísticas (un proyecto de bases generales para las ordenanzas reguladoras de la edificación), y un Estudio Económico-financiero con Programa de actuación. La Memoria y el Estudio están fechados un año más tarde que los planos, en junio de 1962. Se trataba del proyecto mejor documentado hasta la fecha de todos los que habían acometido los técnicos de Gran Valencia, puesto que en cada colección -dada la escala utilizada, 1:5.000- hubo que realizar dos hojas de gran formato.

Entre septiembre y noviembre de 1961, la Comisión Ejecutiva aprobó el Plan General de estos cinco poblados, con las condiciones de incluir algunas zonas de tolerancia industrial, que el plano de zonificación (VI) apenas trataba (una estrecha franja al Este de Burjasot, junto a la acequia de Moncada, y un pequeño sector cercano al núcleo urbano de Godella). Además, se terminó pidiendo un nuevo estudio que tuviera en cuenta el reciente polígono proyectado por la Gerencia de Urbanización ${ }^{50}$, y los nuevos anchos de los accesos aprobados por Obras Públicas (la nueva avenida continuación de Fernando el Católico pasó a tener ahora los preceptivos $82 \mathrm{~m}$ ).

Con respecto a la red viaria, se mantenía un esquema continuista con las previsiones de García-Ordóñez para la capital. Teniendo en mente la Solución Sur, Bueso y Llopis variaron los viarios, teniendo esta zona unas mejores comunicaciones (...). Se justificaba este rediseño para transformar este sector en una auténtica ciudad satélite de Valencia capital. Entre otras mejoras, se preveía una nueva vía de desvío de la travesía de Paterna que fuera a parar a la nueva zona de industria al Oeste del sector (el polígono Fuente del Jarro).

Finalmente, el 13 de diciembre de 1962, el Consejo General aprobó el Plan en su forma última (tras reclamaciones de Burjasot, Paterna y Godella), incluyendo el barrio de Santa Bárbara a propuesta de la Oficina Técnica, y acordó elevarlo a la Dirección General de Urbanismo, hecho que tuvo lugar en febrero de 1963. La zonificación de este sector supuso un claro precedente para lo determinado por la futura Adaptación del Plan (redactada, como se verá, a finales de 1963). El parecido es manifiesto, como no podía ser de otra forma, siendo la red viaria -y la inclusión de más suelo urbano- la diferencia fundamental entre ambas propuestas.

La zona Intensiva se adaptaba en su conjunto a las zonas existentes, mientras que la de Edificación abierta volvía a hacer su aparición en este ámbito, tras las experiencias fallidas de los Sectores A y B: la mayor se establece en Paterna, junto al actual núcleo y la futura zona industrial, para servicio de ésta. Otro núcleo importante de edificación abierta se proyecta en Burjasot, donde ya se estableció en el Proyecto parcial, a la embocadura con la prolongación de la Avenida de Fernando el Católico. Otro núcleo extenso se ubica entre Campo-Olivar y Rocafort.

La zonificación de Ciudad-Jardín se establece en tres zonas, en todas las cuales existe ya un núcleo ya construido de Ciudad-Jardín, a saber: Campo-Olivar, Rocafort y Benimamet. Santa Bárbara se incluirá después. Además, llama la

\footnotetext{
50 La Gerencia de Urbanización, recién creada en 1959, se estaba dedicando a preparar suelo a gran escala, tanto residencial como industrial, con el fin de ofrecer parcelas edificables a colectivos diversos (comunidades de propietarios, cooperativas, etc.). Puede consultarse, por ejemplo, la publicación MINISTERIO DE LA VIVIENDA (1965), Gerencia de Urbanización 1959/1964. Madrid.
} 
atención la disposición de seis centros comerciales, de los cuales no se da justificación ni en cuanto a su número ni situación.

Resulta significativo, por citar otro de los aspectos estudiados, cómo se afronta el sistema de espacios libres (V), diferenciando entre su titularidad privada o pública, o señalando explícitamente los cementerios. También la profusión de dotaciones indicadas en el plano de Organización (VII), en el que se distinguen ayuntamientos, mercados, iglesias, mataderos, establecimientos militares, espectáculos, etc.

El Plan de Etapas presenta, además, la primera muestra de desmedida confianza en el planeamiento, típica de ese período de resurgir económico: sin ningún reparo, se afirma que la realización del Plan General necesitará un período de tiempo de cincuenta años, para después pasar a dividir en etapas de diez años los cinco momentos en que habrá de llevarse a cabo. El caso es que a día de hoy se tiene la oportunidad de contemplar en qué medida sus cálculos fueron acertados. Como se verá enseguida, la Adaptación del Plan continuará con este discurso de optimismo planificador, proyectando sus previsiones de manera desmedida hasta bien entrado el siglo XXI.

\subsection{La primera redacción de la Adaptación (1963).}

Como se ha visto en el capítulo anterior, la resolución del Consejo General de agosto de 1961, y la aprobación del Plan Sur, por Ley de 23 de diciembre de 1961, sirvieron de excusa para alterar el curso de la tramitación de la Adaptación del Plan General diseñada por Gran Valencia y que había promovido el propio Ayuntamiento. Aunque inicialmente se restringió al ámbito de la capital, ya se ha visto que hubo desde un principio voluntad de extenderlo a toda la Comarca, según las orientaciones de 1958 de la Comisión Técnica Especial.

Sin embargo, la salida de García-Ordóñez y la referencia del contemporáneo nuevo planeamiento metropolitano de Madrid, hicieron que la nueva Adaptación tomara un nuevo sesgo, potenciando el crecimiento urbano hasta límites difícilmente imaginables pocos años atrás.

En 1962, tras 3 años de crecimiento económico que certificaban el éxito del Plan de Estabilización, y con un Plan General de Desarrollo de la Economía Española en ciernes (anunciada ya en la exposición de motivos de la Ley de Bases de Ordenación del Crédito y la Banca, de 14 de abril), la contención planificadora dio paso a un moderado optimismo: el Ayuntamiento de Valencia -y no la Oficina Técnica metropolitana- decidió dar un giro a su política urbanística, desprotegiendo la Zona de huerta, de uso y edificación controlada (así consignada en 1959) para permitir una expansión urbana sin precedentes. Esos terrenos, según la Corporación municipal, no necesitaban protección, pues su alto rendimiento agrícola impediría por sí mismo la promoción de viviendas dado el elevado precio del suelo.

Al optimismo económico siguió una euforia acorde con el sentir común a toda la clase política del país, en la que los técnicos de Gran Valencia -los mismos que habían trabajado y apoyado el Plan General de 1959- se vieron primeramente inmersos, y, por qué no decirlo, arrastrados muchas veces en contra sus 
planteamientos originales ${ }^{51}$. La Presidencia de la Comisión Ejecutiva tenía suficiente autoridad como para imponer su criterio a la Oficina Técnica, y el precedente de García-Ordóñez no resultaba para nada tranquilizador ${ }^{52}$.

El 22 de febrero de 1963, Adolfo Rincón de Arellano dirigió un escrito al Ministro de la Vivienda en el que -refiriéndose a la Adaptación del Plan General de Ordenación de Valencia a la Solución Sur- exponía que éste había de acometerse a la mayor brevedad, lo cual puede llevarse a cabo por la Oficina Técnica de esta Corporación Gran Valencia, pero para imprimir la debida celeridad a tan importante trabajo, es necesario que el personal de la misma trabaje en horas extraordinarias, $y$, al propio tiempo, que tome parte en el mismo personal técnico ajeno a dicha Oficina.

El escrito continuaba, puesto que Gran Valencia carece de la debida consignación en sus presupuestos para estos gastos de carácter extraordinario, solicitando del Ministerio una subvención de doscientas mil pesetas, según la estimación para cubrir exclusivamente el pago de personal y material requerido para estos trabajos.

Se ha dicho que el Plan de 1966 no contenía estudios previos y que su cartografía (procedente del Servicio Cartográfico del Ejército) carecía del más mínimo rigor $^{53}$. Sería más exacto apuntar que lo que no poseía la Oficina Técnica era presupuesto propio alguno para afrontar empresa de tal envergadura. Por no hablar de la tramitación tan atormentada que venía retrasando la necesaria Adaptación del Plan General a la Solución Sur, y que exigía la máxima urgencia en su resolución.

En cualquier caso, no es justo tachar de imprecisa la labor de recogida previa de datos, si se tiene en cuenta lo ya adelantado por la Comisión Técnica Especial y la revisión del Plan de 1959. Eso sí, con varios años de distancia en un período en el que la comarca comenzaba a experimentar un gran crecimiento, circunstancia que, sin duda, favoreció la distorsión de las previsiones iniciales.

Finalmente, se pudo contar con la subvención solicitada, aprobada por Bidagor el 13 de mayo de 1963 con la condición de realizarse los trabajos bajo la supervisión de la Dirección General de Urbanismo. Existe una relación detallada de

\footnotetext{
${ }^{51}$ En este sentido se manifiesta el arquitecto Antonio Gómez Gil, hijo de Antonio Gómez Llopis, en las repetidas entrevistas mantenidas con el autor.

52 Adolfo Rincón de Arellano (1910-2006) ejerció sus funciones como Alcalde con una autoridad hasta entonces desconocida. Durante la Guerra Civil había sido Jefe Provincial de la Falange por Valencia, y más tarde Presidente de la Diputación Provincial de 1943 a 1949, momento en el que pasa a ser Procurador en Cortes. Con buenos contactos políticos, permaneció en el cargo hasta que la remodelación gubernamental de 1969 -con la salida de Manuel Fraga Iribarne (uno de sus principales mentores) y la entrada de Vicente Mortes Alfonso como Ministro de la Vivienda- le sirvió de excusa para presentar su dimisión. En realidad, tal y como se describe en otra sección de la tesis doctoral que sirve de fuente a este artículo -aquí no incluida-, Rincón de Arellano llevó al límite su postura dominante sobre la Corporación Administrativa Gran Valencia al proponer incluso la anulación de competencias del ente supramunicipal en 1968. El Gobernador Civil, quien no había sido consultado, no recibió muy bien tal petición: no es aventurado suponer que este episodio tuviera relación directa con la dimisión fulminante del Alcalde, la misma semana en que Antonio Rueda emitía su informe para el Ministro de la Vivienda. Por muy pocas semanas, se le privó incluso de la inauguración de las obras del cauce nuevo. Véase SELVA ROYO, Juan Ramón (2014), 29+1. La ordenación urbanística..., ob. cit.

53 Así lo indica Ma Blanca Blanquer Prats en CONSELLERÍA D'OBRES PÚBLIQUES, URBANISME I TRANSPORTS (1986). La Gran Valencia, Trayectoria de un Plan General. Ed. COPUT-Generalitat Valenciana.
} 
los gastos, producidos con cargo a la indicada subvención, que permite hacerse una idea de las cuantías empleadas: más de la mitad (113.950 ptas.) fueron a parar a la Nómina de remuneración al personal, mientras que el resto se dedicó en exclusiva a gastos de producción (copias de planos, material de escritorio y oficina, fotografías, reportajes gráficos, etc.). No sobró ni una peseta.

Consta, por poner un ejemplo, que cada uno de los tres Arquitectos cobró dos anticipos de honorarios de 3.000 ptas., en agosto y diciembre de 1963, con cargo a la subvención concedida. Pero junto a ellos, otros quince profesionales también se incluyeron como personal con pagos a satisfacer (con distintas cuantías), dando lugar a unos totales de 45.500 y 49.500 ptas. en los dos montantes de anticipos. En la relación de los técnicos figuraban, entre otros, Antonio Gasull Giménez, Julio Bellot Senent (Arquitecto Mayor de Valencia, que había pasado a formar parte de la Comisión Ejecutiva y del Consejo General de Gran Valencia el 2 de junio de 1961), Jesús y Francisco Ribes Bustos, José Mayol Hernández, José Correa Sanz, Ramón Giménez Ruiz, José Hoyos Monsell, Enrique León Murcia y Álvaro Ansuátegui Alday.

Con respecto a la cartografía del plano topográfico, perfectamente apreciable en el primer plano de la serie (limpio de cualquier otra indicación), hay que hacer alguna aclaración. No tenía sentido hacer uso de la base catastral de 1929-44, limitada al ámbito de la capital y unos pocos municipios colindantes más, tal y como se había acudido a ella con los trabajos del Plan de 1959 (recuérdese que éste fue un plan inicialmente restringido al Ayuntamiento de Valencia). Tampoco cabía pensarse encargar al Instituto Geográfico un nuevo levantamiento, pues no se disponía de tiempo -quince años había llevado levantar el anterior- ni de fondos suficientes.

Desde la Oficina Técnica se estaba en comunicación con la Jefatura de Detall del Servicio Geográfico del Ejército de la III Región Militar, como lo prueba la correspondencia conservada. En esas cartas se solicitan planos (como el del polígono de Paterna a escala 1:10.000, con curvas de nivel a $5 \mathrm{~m}$, requerido en abril de 1960), o diversas ampliaciones de fotogramas (utilizando la maquinaria de la que no se disponía en la Corporación).

Finalmente, para la confección de la base gráfica de los planos, sólo se abonaron 298,60 ptas. al Servicio Geográfico, lo que hace pensar que la colaboración se redujo a la adquisición de las hojas -quince escasos planos topográficos- de la Cartografía Militar de España relativas a los términos de Gran Valencia ${ }^{54}$. Se puede comparar la información topográfica del ya citado plano 1 del Plan, con estas hojas, también a escala 1:10.000 (que condicionaron el formato), editadas por el Ejército entre 1959 y 1962.

Esta información, aun no siendo de origen catastral, no creo que pueda tacharse de poco rigurosa, pues durante años fue utilizada por los arquitectos valencianos

\footnotetext{
${ }^{54}$ El Servicio Geográfico del Ejército había emprendido una campaña topográfica en 1959, consistente en una Cartografía Militar de España a escala $1: 10.000$ y con equidistancia de curvas de nivel de $5 \mathrm{~m}$ (Depósito Legal M. 12.418-1959). Las hojas correspondientes al ámbito requerido por Gran Valencia se levantaron y editaron entre 1960 y 1962: se trataba de las hojas 696-III (4 cuadrantes), 696-II (cuadrantes N.O. y S.O.), 722-IV (4 cuadrantes), 722-I (cuadrantes N.O. y S.O.), 722-III (cuadrantes N.O. y N.E.) y 722-II (cuadrante N.O.). En total, quince planos topográficos. Posteriormente, todas las hojas editadas -incluidas las planchas- fueron destruidas por el Ejército, no pudiendo adquirirse en la actualidad de manera oficial.
} 
ante la escasa actualización de los planos del catastro. Tendrían que pasar algunos años, además, para que se hiciera de nuevo un levantamiento topográfico de una precisión comparable, basado en la restitución a partir de fotografías aéreas ${ }^{55}$. En todo caso, podría ser tachada de poco práctica dado el formato tan grande que originó.
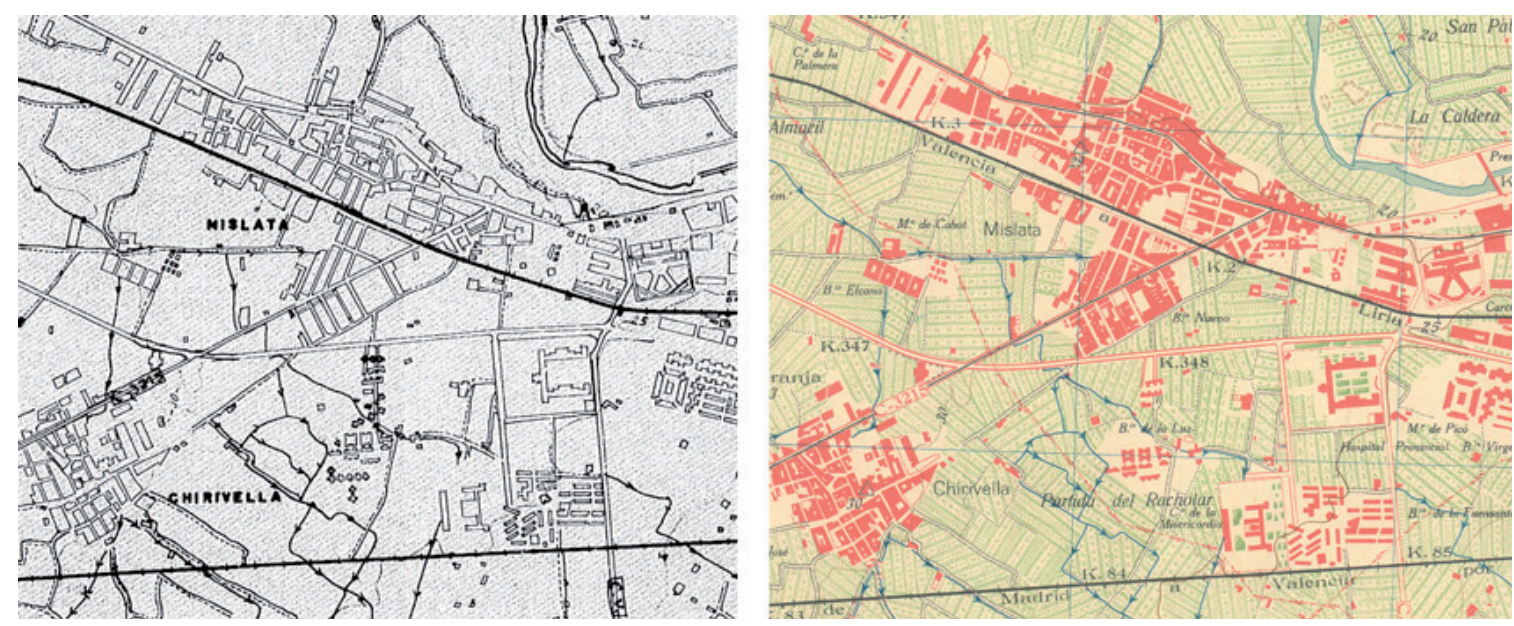

Figura 9. Comparativa entre fragmentos del Plano 1 de la Adaptación del Plan y de la hoja 722-IV N.E. de la Cartografía Militar de España, que evidencia el origen gráfico de toda la información usada por la Gran Valencia. El redibujo es evidente: hasta las cotas de nivel están grafiadas en el mismo lugar (únicamente se ha suprimido la información relativa al tipo de terreno: cultivo, secano, etc. y se han vaciado los sombreados de la edificación)

Fuente: Archivo de Arquitectura y Urbanismo de la ETSAV

La Oficina Técnica acometió durante la segunda mitad de 1963 la labor gráfica de ordenación de la comarca con el criterio de ofrecer una solución definitiva a los problemas de la ciudad. De seguro que Mauro Lleó, como Arquitecto Jefe, tras haber vivido dos riadas catastróficas en menos de diez años, valoraría la oportunidad histórica que se le presentaba para resolver de una vez por todas el urbanismo de la comarca. Catorce años después de su colaboración en los Albergues para Damnificados en Nazaret (Valencia) y Chirivella, y de participar-como funcionario de Regiones Devastadas- en los polígonos promovidos a raíz de la riada olvidada, interviniendo en el Plan 5.000 viviendas para Valencia, llegaba la hora de plantear el desarrollo futuro de la ciudad a cuarenta años vista (el Estudio económico-financiero llegó incluso a contemplar como horizonte el año 2040). Además de las fuertes premisas políticas y de la oportunidad personal, también recibió indicaciones precisas desde la Jefatura de Obras Públicas de Valencia, referentes, entre otros aspectos, a las secciones viarias, sobre todo en el ancho de los accesos a la ciudad $^{56}$. Más adelante, Lleó refrendaría también el trabajo de la Red Arterial, realizado en paralelo por la Oficina Regional de Proyectos.

55 Claudio Gómez-Perretta, al frente de la Oficina Regional de Proyectos (dependiente del Ministerio de Obras Públicas), coordinó durante los años 1964-67 una restitución propia para ser utilizada en la Red Arterial de Valencia. Los aparatos de restitución y el personal encargado se ubicaban en sus oficinas de Valencia.

56 El Servicio la Dirección General de Carreteras, según Orden Circular de fecha 7 de febrero de 1961, había fijado como sección transversal mínima en zona urbana urbanizable la de $80 \mathrm{~m}$, distribuidos de la siguiente forma: 


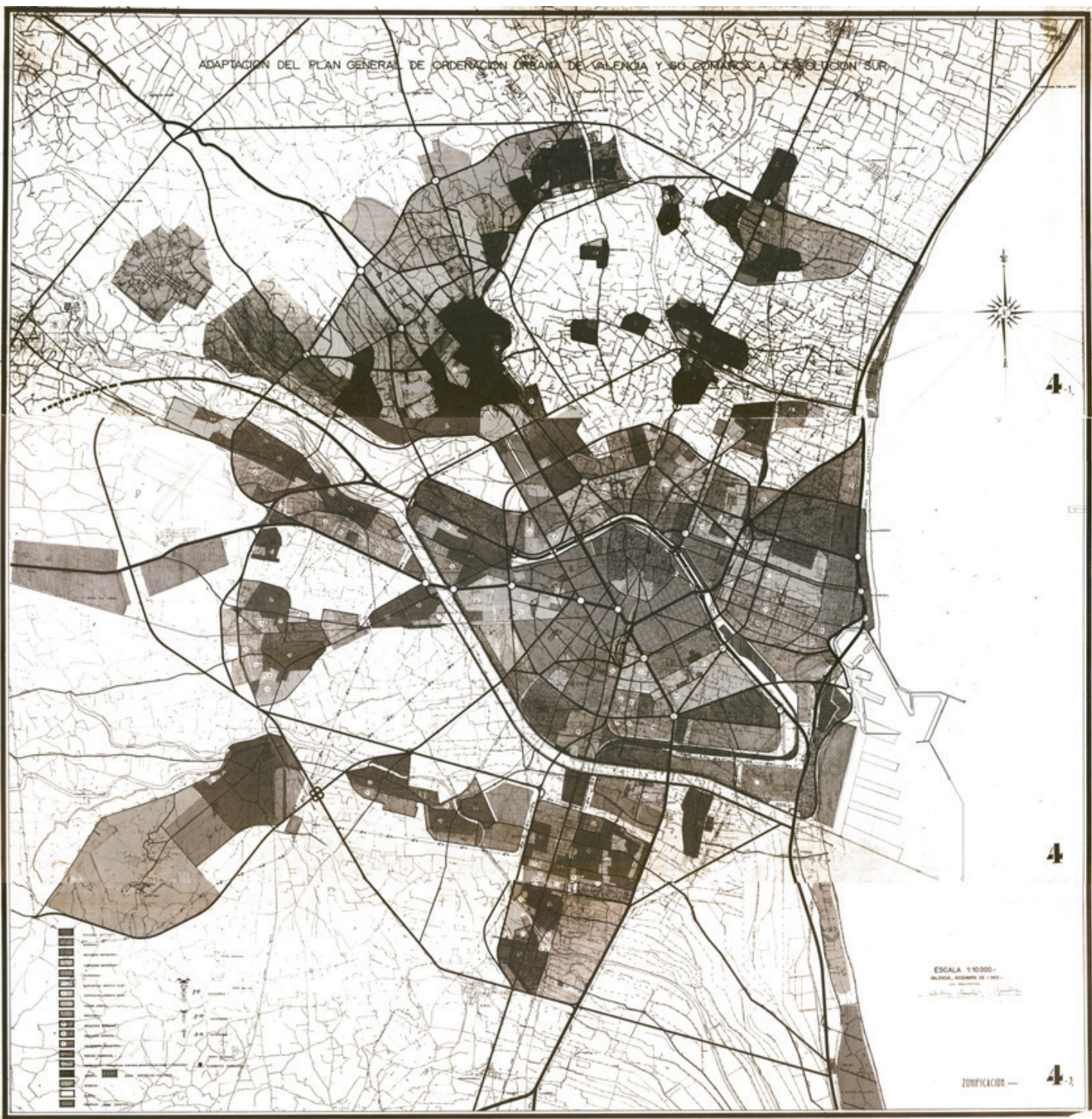

Figura 10. Montaje de las hojas del Plano 4. Zonificación, a escala 1:10.000, de la Adaptación del Plan General de Ordenación Urbana de Valencia y su Comarca a la Solución Sur. Fechadas en diciembre de 1963: las aquí reproducidas son originales firmados por los tres arquitectos de la Oficina Técnica de Gran Valencia, que refundieron algunas de las reclamaciones de los Ayuntamientos aceptadas con posterioridad al sellado de los originales por la Dirección General de Urbanismo.

Fuente: Elaboración propia a partir de originales del Archivo profesional de Antonio Gómez Llopis

Tras un año y medio de trabajo (y gracias a la subvención concedida por el Ministerio), los planos de la nueva Adaptación del Plan General de Ordenación

$\begin{array}{lll}\text { Aceras y plantaciones: } & 2 \times 8 & 16 \mathrm{~m} \\ \text { Calzadas de servicios: } & 2 \times 9 & 18 \mathrm{~m} \\ \text { Zona verde de separación y reserva: } & 2 \times 10 & 20 \mathrm{~m} \\ \text { Calzada de circulación rápida: } & 2 \times 8 & 16 \mathrm{~m} \\ \text { Mediana de separación: } & & 10 \mathrm{~m}\end{array}$

Finalmente Gran Valencia fijó un ancho de $82 \mathrm{~m}$. 
Urbana de Valencia y su Comarca a la Solución Sur -el único plan metropolitano que redactará la Oficina Técnica de Gran Valencia durante toda su existencia- fueron fechados en diciembre de 1963. Sobre los originales en vegetal con la información topográfica, se dibujó a tinta el contenido, superponiendo las oportunas tramas (según el uso corriente de la época), para obtener la copia final en papel, que era posteriormente firmada. Se trata de una colección de 10 unidades temáticas, divididas cada una de ellas -en razón de la enorme extensión afectada a la escala elegida, 1:10.000- en tres hojas correspondientes a la zona Norte, centro y Sur de la comarca. Algunos planos (los numerados del 2 al 5) se completaron también con una cuarta hoja relativa a la zona de la Albufera a la misma escala, pero sin continuidad de formato con las tres primeras ${ }^{57}$. El único plano que no es de la escala ya mencionada, como advierte la Memoria, es el de Relación con la Comarca, que por la extensión que abarca se redactó a 1:25.000.

El plano más difundido, sin duda, es el número 4, correspondiente a la Zonificación. Es cierto que las tramas empleadas a esa escala hacen muy difícil la correcta interpretación de algunas zonas donde se apelmazan las sombras, hasta tal punto que en los archivos del Ayuntamiento se encuentran varios expedientes sobre petición de información -por parte de particulares-, como aclaración de lo grafiado. Se reproduce en el Anexo de esta investigación ${ }^{58}$, por primera vez, el juego de hojas originales del plano de Zonificación, selladas por la Dirección General de Urbanismo, que se conserva en el Archivo de Planeamiento del Ayuntamiento de Valencia (tanto las tres hojas apaisadas, una de ellas fraccionada en tres pliegos, como la cuarta hoja correspondiente a la Albufera).

Una última precisión para diferenciar las abundantes copias o reproducciones de este plano 4: en muchos de ellos aparece una variante en el linde Oeste de Catarroja (una de las reclamaciones posteriores de los Ayuntamientos, que fue aceptada), lo que permite afinar la datación -a pesar de tener indicado diciembre de 1963- de la fecha de la copia. Tal es el caso del plano, excelentemente conservado, que se ha reproducido arriba, y cuya digitalización permitiría hoy, sin duda, una lectura más precisa de la zonificación del Plan $^{59}$. No aparecen, sin embargo, otras modificaciones fácilmente reconocibles, como la ampliación de suelo industrial en Torrente, o la reasignación de usos en Paiporta (que otras copias posteriores, igualmente sin valor normativo, sí que las recogerán).

\footnotetext{
57 En el Archivo de Planeamiento del Ayuntamiento de Valencia sólo se encuentran, curiosamente, las hojas del plano 4, selladas y firmadas por la Dirección General de Urbanismo. No se conserva ningún otro plano, ni siquiera sin diligenciar. Sin embargo, he localizado hojas selladas del resto de planos junto con vegetales originales- en el Archivo Histórico de la Generalitat Valenciana, sección Gran Valencia. De todas formas, las fuentes más valiosas para la obtención de la documentación me han venido de los microfilms conservados en el Archivo de Arquitectura y Urbanismo de la ETSAV, y del Archivo personal de Antonio Gómez, y en ningún caso estaban diligenciados.

58 Se trata de la tesis doctoral que sirve de marco a este artículo. Puede consultarse SELVA ROYO, Juan Ramón (2014), 29+1. La ordenación urbanística..., ob. cit.

59 Es cierto que la lectura y precisión de la trama deja mucho que desear, aunque en esos años, la importancia de la visión del urbanista estaba centrada más bien en la gran escala, confiando el detalle al desarrollo de los planes parciales. Varios años más tarde, en 1979 la Corporación Administrativa Gran Valencia efectuó (mediante encargo a la empresa PRODEIN) una transcripción y actualización del todavía vigente Plan General de ordenación de Valencia y su comarca, en 15 hojas a escala 1:10.000, con el fin de poner al día las actuaciones realizadas durante esos años, facilitar la comprensión de la zonificación y servir de documento informativo para la posterior revisión del plan. De todas formas, nunca llegó a ser aprobado, no teniendo más valor que el documental.
} 


\subsection{Cesiones y compromisos:hacia la versión definitiva.}

En septiembre de 1964 ya estuvo listo el Proyecto de Adaptación del Plan, formulado por la Oficina Técnica de Gran Valencia. Manuel Muñoz Monasterio, como arquitecto director de dicha oficina, compareció ante la Comisión Ejecutiva para informar detalladamente sobre las directrices que se habían seguido en el mismo, en orden a la delimitación de la comarca a base de situar en ella dos millones de habitantes, indicando las distintas zonas en que ha sido dividida, dando a unas carácter residencial y a otras carácter industrial, especificando igualmente la red viaria que se proyecta y las zonas verdes que se establecen. Especificó también lo referente a las ordenanzas que habrían de regir, distintas en cada una de las zonas, para lo que se preveía unificarlas por razón de zonas. Por último, señaló que en lo posible y en lugares adecuados se han situado zonas de Ciudad Jardín en la comarca, y se establecen también zonas de edificación abierta por considerarlas de utilidad y conveniencia60.

La vigencia de la estructura administrativa se manifestó como un buen argumento para el alcalde Rincón de Arellano, quien, como Presidente de la Comisión Ejecutiva, tomó las riendas de la tramitación del Plan. Así, por ejemplo, cuando Monasterio sugirió la conveniencia de informar a todos los alcaldes de la comarca -pues a todos afectaba el nuevo plan-, Rincón se amparó en lo previsto en el Decreto de 1949 para que bastara la decisión de la Corporación. Ya se le informaría con posterioridad al resto de corporaciones locales (como de hecho sucedió, presentando reclamaciones en el período posterior de exposición pública) ${ }^{61}$.

Todavía en fase de estudio, desde la Comisión Ejecutiva se requirieron explicaciones al equipo redactor respecto a las debidas proporciones en el señalamiento de zonas verdes (que se consideraban escasas), y sobre la densidad de población a primera vista excesiva que resultaría de la aplicación del plan (para lo que se pedía un nuevo estudio de las ordenanzas en lo referente a las alturas y partes interiores).

Muñoz Monasterio confirmó que no se alcanzaba el $10 \%$ de zonas verdes señalado, pero que se sobrepasaría ampliamente con posterioridad al incluir las de los polígonos y los respectivos proyectos parciales, confiando un aspecto tan controvertido a su ejecución por retales. A su vez, también coincidió en señalar la densidad prevista como superior a la de otras grandes ciudades españolas, aunque otorgaba la última palabra al criterio de alturas con respecto al ancho de calles que definitivamente se fijase en las Ordenanzas. La parte documental, pues, no estaba lista aún en octubre (la Memoria lleva fecha de noviembre de 1964), requiriéndose un nuevo estudio del proyecto en ese sentido. Tras las oportunas aclaraciones, el estudio de planificación -la documentación gráfica-, sin embargo, se consideró por todos en extremo acertado.

A la hora de hablar de la Memoria, hay que hacer notar un aspecto que hasta ahora no se había descubierto. Y es que gran parte de la misma -sobre todo los párrafos referentes a la red viaria y su relación con las unidades vecinales, terrenos

\footnotetext{
60 Acta de la Comisión Ejecutiva de Gran Valencia, en Sesión del 24 de septiembre de 1964.

61 No obstante, consta una convocatoria a todos los alcaldes afectados, realizada por el Secretario de Gran Valencia, pero cumpliendo órdenes del Alcalde de Valencia, el 9 de noviembre de 1964.
} 
de huerta y centros comerciales- están tomados literalmente del Plan de Adaptación redactado por Fernando M. García-Ordóñez en marzo de 1959, cinco años antes ${ }^{62}$. Resulta cuanto menos llamativo, puesto que muchos de estos aspectos se habían desvirtuado totalmente (gran parte de la huerta que se intentaba proteger se había calificado ahora como suelo urbano). La malla triangulada original, además, que estructuraba los proyectos parciales de desarrollo mediante los accesos y las circunvalaciones, se había sustituido por una enmarañada red de carreteras que abarcaba todo el territorio comarcal.

Muchos de los aspectos previstos hacía un lustro, que habían encontrado su justificación en los planos realizados por García-Ordóñez, perdieron aquí su sentido convirtiéndose en papel mojado: las cinturas verdes que habían de envolver los barrios, borrando de la ciudad esa tendencia a convertirse en una mancha indefinida de construcciones, eran ahora un brindis al sol; de los Polígonos de edificación impuesta, a desarrollar sobre los terrenos expropiados (desvinculados del dominio público original), se omitió el correspondiente a la Plaza de Castilla; y respecto de los centros representativos de la ciudad, la diferenciación se volvió más compleja aun recogiendo las mismas descripciones (se definía, sin embargo, el gran centro cívico situado entre las uniones de las dos Grandes Vías y los Tránsitos, concretando los enlaces viarios).

No comparto en todos sus puntos, por tanto, la tesis de la continuidad con el planeamiento de 1946, que ha sido defendida por varios autores ${ }^{63}$. Es cierto que los argumentos teóricos del urbanismo de la época repiten los consabidos mantra de la limitación del crecimiento de la ciudad y la descentralización en núcleos satélites, cada vez más lejanos de la realidad urbana. Pero si hay que hablar de continuidad con el modelo radiocéntrico, habría que hacer notar antes los planteamientos de García-Ordóñez de 1959 (salvando las importantes distancias que su nueva red viaria plantea con respecto al Plan de Accesos de 1952), más próximos, sin duda, a la contenida metrópolis pensada por Valentín-Gamazo.

El caso es que creo que es legítimo hablar de una cierta ruptura -y desgarradora en cierta medida- entre lo planificado en 1959 y lo propuesto a finales de 1963, sobre todo en cuanto a la desorbitada cantidad de suelo ordenado, a la estructura viaria concebida como una omnipresente malla territorial de confusa jerarquización, y a la absorción indiscriminada de la huerta. Por supuesto, la Adaptación muestra en su texto el respeto a los criterios generales de ordenación del Plan anterior y a los planes parciales vigentes, pero su información gráfica lo desmiente (de hecho, ya García-Ordóñez, en su plano I de Ordenación de Valencia, había acometido una traumática actualización de muchos de los polígonos aprobados hasta la fecha, con motivo del nuevo cauce proyectado). Ahora, la escala

\footnotetext{
62 Puede consultarse este extremo en el Anexo de la tesis donde se han resaltado en color los párrafos copiados en el documento normativo definitivo del Plan, anotando las diferencias principales y sus motivos directos.

63 Por ejemplo, en CONSELLERÍA D'OBRES PÚBLIQUES, URBANISME I TRANSPORTS, La Gran Valencia..., ob. cit. se afirma que "la desviación del cauce del Turia (...) supone la introducción de nuevas variables relevantes que posibilitan, en la situación urbanística de 1960, adoptar un nuevo modelo de ordenación o, al menos, variar sustancialmente el existente. Sin embargo, el Plan de 1966 no planteó estas posibilidades, optando por la línea de la continuidad."
} 
de actuación se ampliará considerablemente, incluyendo en suelo urbano muchas de las obras ejecutadas al margen del planeamiento ${ }^{64}$.

En enero de 1965, el Proyecto de Adaptación se sometió de nuevo a examen de la Comisión Ejecutiva, una vez introducidas en él las modificaciones acordadas cuatro meses antes (incluida la de delimitar sobre plano la zona histórico-artística). Pero ahora será el ingeniero Claudio Gómez-Perreta quien proponga algunas modificaciones respecto a la red viaria, debido a los proyectos recientemente aprobados por la oficina de su cargo (la Oficina Regional de Proyectos, de la Jefatura de Obras Públicas de Valencia) ${ }^{65}$.

Monasterio hizo notar también que las zonas verdes, tras las indicaciones políticas, se habían transformado en zonas deportivo-culturales, aspecto que ahora se puede comprobar claramente al comparar los dos montajes de los planos 5 (Zonas verdes) incluidos en el Anexo: en la reproducción fotográfica, ligada a los planos originales de 1963, se aprecian muchos sectores así zonificados que luego quedarán reconvertidos en zonas compatibles con equipamientos (el gran triángulo del acceso desde Barcelona, donde hoy se encuentran la Universidad Politécnica y el Campus de los Naranjos; la zona situada en la salida del eje Este-Oeste de circulación rápida, a la altura de Mislata; o el amplio sector de La Punta, junto al complejo ferroviario de la Fuente de San Luis).

Las hojas definitivas 5.2 y 5.3 selladas por la Dirección General de Urbanismo dan fe de ello, ratificando el carácter periférico de las zonas verdes, bajo cuya trama se incluían también -sorprendentemente- los diversos cementerios de la comarca. Se había suprimido, además, la zona de ampliación del Cementerio General, quedando como principales zonas verdes ámbitos residuales junto a vías de ferrocarril e instalaciones portuarias.

De cualquier forma, ante las modificaciones efectuadas (viarias y de zonificación), el proyecto regresó a la Oficina Técnica, para su actualización. Se puede observar que la nueva Zona Deportiva-Cultural tiene -en el plano sellado- un sombreado propio en la leyenda, pero situado fuera de la columna única, lo que prueba su posterior añadido. De hecho, la leyenda final en el plano 5.3 reestructuró su diseño originario, manteniendo la trama ajedrezada para las zonas verdes pero reelaborando los iconos para las categorías de los centros comerciales (de dos

64 Un ejemplo paradigmático de estos conjuntos urbanos construidos al margen del planeamiento vigente lo constituye la Ciudad del Artista Fallero, una actuación residencial de casi 100.000 metros cuadrados, ubicado en el sector de Benicalap y redactado en junio 1963 por el propio Manuel Muñoz Monasterio (junto con los también arquitectos Carlos Sobrini, Emilio G. de Castro y G. González). Tras constituirse la sociedad promotora en julio de ese año, el Pleno municipal aprobó la inclusión de esta iniciativa privada sobre suelo de huerta en lo que habría de ser el Plan Parcial no 24 . Se comenzó a construir el 17 de marzo de 1965. El proyecto incluía 1.200 viviendas, naves para los artistas falleros, bajos comerciales y una iglesia. En septiembre de 1965, los arquitectos Antonio Gómez Llopis y Víctor Bueso, por la Oficina Técnica de Gran Valencia, elaboraron un Proyecto de modificación del Plano Parcial no 24 redactado por el Ayuntamiento de Valencia, con el objeto de introducir algunas modificaciones viarias: en octubre de 1966, el Ayuntamiento concedió la aprobación inicial al Plan Parcial.

65 Dependiente de la Dirección General de Carreteras y Caminos Vecinales, del Ministerio de Obras Públicas. Recuérdese lo dispuesto en el Decreto de 14 de octubre de 1949 sobre la Ley de ordenación de Valencia y su comarca, artículo 10, letra e), sobre el requisito de que los planos que afectasen a obras y permisos dependientes del Ministerio de Obras Públicas, habían de ser aprobados por dicho Departamento (la Jefatura de Obras Públicas). 
pasaron a tres, ahora señaladas mediante caduceos de distintos tamaños) y añadiendo una estrella de seis puntas para los elementos singulares ${ }^{66}$.
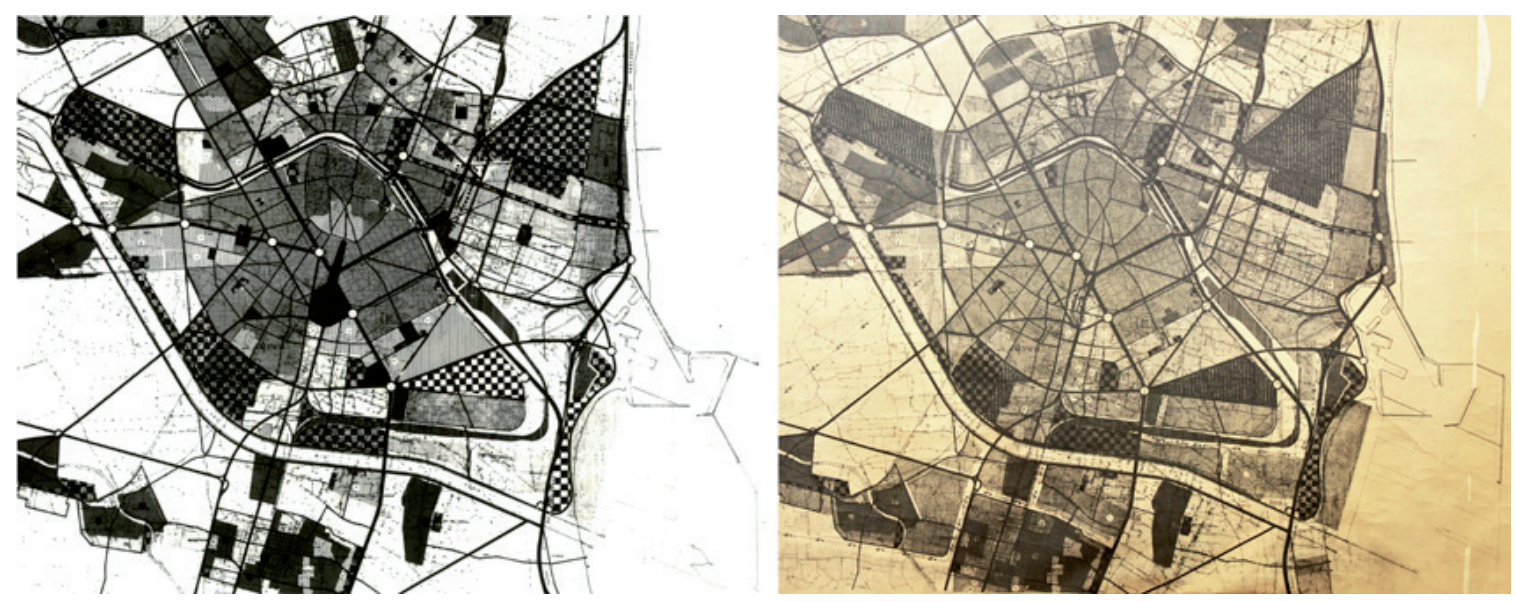

Figura 11. Comparación de la primera versión del Plano 5.2 Zonas Verdes, de la Adaptación del Plan (diciembre de 1963) con el aprobado finalmente en 1966: gran parte de las reservas de esparcimiento quedaron convertidas a lo largo de la tramitación en Zona Deportivo-cultural.

Fuente: Archivo de Planeamiento del Ayuntamiento de Valencia y Archivo Histórico de la Generalitat Valenciana.

Ya sólo quedaba por darle una redacción definitiva a las ordenanzas (Mauro Lleó también había advertido que no eran aceptables tal y como estaban redactadas), pero, como la aprobación de todo el Plan quedaba a expensas de este asunto -no tenía sentido aprobar los planos sin ordenanzas-, se decidió nombrar una comisión que auxiliase a la Oficina Técnica para su rápida redacción. La integraron Claudio Gómez-Perretta, Juan Galvañ, Joaquín Olcina ${ }^{67}$, Julio Bellot, Salvador Pascual y José Fuenmayor.

Finalmente, el Consejo General aprobó tanto las Normas Urbanísticas como el resto de documentación y planos en su sesión de 16 de julio de 1965, decidiendo la exposición pública de la totalidad del Proyecto del Plan General en la forma que determinaba la vigente Ley del Suelo de 1956.

Las bases de Ordenanzas quedaron simplificadas con la redacción final, fruto de la reducción de las zonas a establecer: de quince tipos contemplados en 1946, se pasó a doce calificaciones, unificando en la Zona de Extensión las anteriormente denominadas zonas de Ensanche, Transición de Ensanche, Ensanches Futuros y Núcleos Periféricos. Esta medida acabó por fomentar la uniformidad del continuo edificado, no diferenciando las características peculiares de cada barrio, y propiciando un aumento generalizado de la volumetría.

\footnotetext{
66 La composición de la leyenda final es similar a la del Plano 4 Zonificación, con la salvedad de la desaparición del ajedrezado en éste último (queda sólo un sombreado denso para señalar las zonas verdes). El caduceo aludía al dios romano del comercio, Mercurio. El plano 5.3 sellado por la DGU carece, por cierto, de la firma de Antonio Gómez Llopis.

67 Joaquín Olcina Doménech había sido nombrado, por Pedro Bidagor, Delegado del Ministerio de la Vivienda en la provincia de Valencia el 24 de junio de 1964, en sustitución del arquitecto Enrique Pecourt Betés. De esta forma, se integraba como representante de la Dirección General de Urbanismo en la Corporación Administrativa Gran Valencia.
} 
Además, la Zona de Ciudad Jardín como alternativa de menor densidad quedó restringida a los municipios de las zonas Suroeste y Noroeste, reforzando la tendencia de implantación de la segunda residencia en los espolones de secano. La gran protagonista de las calificaciones será, sin duda, la Edificación Abierta, de carácter totalmente residencial, a la que se concede un mayor aprovechamiento que en el Plan anterior ${ }^{68}$, y que va a ser la principal encargada de absorber la huerta colindante con los núcleos urbanos.

Coincido con muchos autores en lo poco que estas ordenanzas ayudaron a equilibrar la comarca, fomentando la densificación y permitiendo la mancha gris edificada. Lo cierto es que, al ser redactadas en último lugar, las Normas Urbanísticas tuvieron que responder tanto al desmesurado ansia de urbanización del Ayuntamiento de Valencia (ya previsto por la documentación gráfica), como a las nuevas alturas y coeficientes aprobados en 1962, promovidos por la Corporación Administrativa -bajo la iniciativa de los alcaldes miembros de la Comisión Ejecutiva- para igualar los aprovechamientos de los pueblos de la cintura con la capital.

Con la norma no 36 se introdujo, además, otro aspecto controvertido permitiendo la construcción de edificios singulares -amparando así la excepción de las normas establecidas en el Plan General de Ordenación y en las Ordenanzas aplicables- cuando se dieran determinadas circunstancias. Pero hay que decir que, inicialmente, el borrador de este artículo contemplaba un texto más elaborado. Así, el punto $2^{\circ} \mathrm{a}$ ), sobre los casos de manzanas completas de un único propietario (en caso de no estar previsto el edificio en el Plan Parcial), se completaba con la frase podrá aumentarse la altura en una planta más de las autorizadas en las Ordenanzas, por cada tres metros de profundidad o anchura que por todo el perímetro de la manzana ceda el propietario o propietarios del solar para vía pública. De esta forma se intentó en un principio controlar la singularidad y obtener a cambio un cierto beneficio para el ciudadano.

Igualmente, el punto $2^{\circ} \mathrm{b}$ ), referente a los chaflanes en calles de más de quince metros, parece que -a tenor de las anotaciones sobre el borrador- fue rechazado por la Oficina Técnica en su redacción final, siendo introducido a última hora para ampliar las posibilidades de aplicación en el caso de constituir una importante y muy calificada mejora del conjunto armónico de la plaza y sector correspondiente. Nada se dice, además, sobre qué se entiende por conjunto armónico ${ }^{69}$.

En una tentativa de control más minucioso, se incluyó en el borrador un punto 30 sobre cómo había de tramitarse el expediente sobre autorización de estos

68 En realidad, la Ordenanza Especial no 9 de 1955 (referida a las Zonas de Edificación Abierta), no asignaba ninguna edificabilidad concreta al suelo así calificado (debiendo atenerse a lo especificado en los planos): quedaban limitadas las alturas por la forma de las parcelas y la distancia entre los bloques. Sin embargo, los artículos de 1965 -aun manteniendo limitaciones internas (la altura de la edificación será función del espacio entre bloques paralelos, siendo la altura máxima igual a la separación)- asignan dos categorías con distinto aprovechamiento: 3,5 y $5 \mathrm{~m}^{3} / \mathrm{m}^{2}$.

69 Además, existió un tercer caso, el c), finalmente no incluido en el texto definitivo, que decía: "Se podrá autorizar un edificio singular con mayor altura de la normal en un solar, cuando el propietario ordene la futura construcción sin superar el volumen total que la Ordenanza determina para la parcela, siempre que el elemento de mayor altura quede separado de los edificios colindantes, $y$, tanto las paredes medianeras de éstos como la totalidad de la fachada del futuro edificio, se decore con materiales nobles de construcción. Precisará que concurran también relevantes motivos urbanísticos y sociales para conceder la autorización". 
edificios singulares: tras la petición del interesado se abría un período de información pública que acababa con la emisión de sendos informes por parte del ayuntamiento respectivo y la Oficina Técnica de Gran Valencia; si finalmente el Consejo General otorgaba la calificación de edificio singular (siempre sin que pudiera vincular precedente alguno), todavía pendía la aprobación definitiva de la Comisión Central de Urbanismo, tras lo que el ayuntamiento expedía la licencia de obra nueva, exigiendo -claro está- el arbitrio sobre aumento de volumen de edificación que establece el artículo 187 de la Ley del Suelo. Estas precauciones fueron incluidas en el texto definitivo como una norma independiente, la $37 \mathrm{a}$.

A lo que no se alude en ningún momento es a qué se refería la mente del legislador cuando hablaba de edificio singular, puesto que en otro borrador sobre la ordenanza de aparcamiento se consideraban como tales los de carácter administrativo, bancarios, espectáculos, hoteles o colectivos, sanitarios, etc., quedando fuera de esta relación los destinados a vivienda privada.

Los proyectos aprobados por la Oficina Regional de Proyectos referidos por Claudio Gómez-Perretta, y que según el Decreto de 1949 habían de ser vinculantes para las modificaciones del Plan (se confería la última palabra al Ministerio de Obras Públicas en todo lo que fuera de su competencia), no eran otros que los incluidos en la Red Arterial de Valencia. Poco podía hacer aquí la Oficina Técnica de Gran Valencia, integrada en una Corporación cuyo articulado le colocaba a merced de los proyectos aprobados por un Ministerio ajeno, y de tanto peso en el contexto de crecimiento de las infraestructuras en la España de la década de los 60.

El 20 de marzo de 1965 se había fechado el Anteproyecto para el acondicionamiento del Camino de Tránsitos. Sin embargo, el juego completo de planos de la Red Arterial (en cuya programación se incluía a aquél como el primero de los anteproyectos), no sería aprobado hasta un año después. Los planos definitivos fueron fechados el 28 de febrero de 1966: se trataba de una colección de 122 planos de $84 \times 59 \mathrm{~cm}$, dibujados a una tinta (la mayoría de ellos a escala 1:2.000), elaborados por la Oficina Regional de Proyectos.

En cuanto al diseño concreto del viario, llaman la atención la profusión de vías de servicio, clotoides y curvas de desaceleración con que se invade a la ciudad. Se tomaron como referencia infraestructuras de ciudades de Estados Unidos -país visitado a tal efecto por Domingo Amat García-Morato, uno de los técnicos de la Oficina Regional de Proyectos, que regresó más partidario que nunca de su aplicación-, buscando en la experiencia americana el método que solucionase definitivamente el colapso circulatorio.

Quizá lo más interesante sea la serie inicial de 6 planos de Ordenación Urbana a escala 1:20.000, que contiene un resumen de lo planificado -todavía sin vigenciapor la Oficina Técnica de Gran Valencia. Venía a ser una transcripción del Plano 8, de Relación con la Comarca, elaborado por el quipo de Lleó.

La complementaba, sin embargo, otra serie también de 6 hojas a la misma escala, denominada Esquema General, donde se superponía a los planos de ordenación la nueva red viaria propuesta. Puede apreciarse así, el gran peso de que se dotaba a las infraestructuras viarias en la ordenación comarcal, disponiendo un gran número de circunvalaciones y accesos radiales, y cómo ésta quedaba en gran 
medida desvirtuada por las nuevas barreras, tan extrañas a aquella malla triangulada de 1959.

En aquel momento, toda esta confianza ilimitada en la disposición indiscriminada de viario se veía como una gran oportunidad, facilitada principalmente por la posibilidad de aprovechamiento máximo del cauce pendiente de desalojo. El tráfico se erigía en aquellos años como el gran problema por solucionar en las ciudades: me consta que Mauro Lleó, que no redactó la Red Arterial pero sí la recibió como necesaria, se mostró partidario de ello, animado por el parecer positivo de otros muchos técnicos extranjeros con los que tuvo ocasión de compartir sus impresiones ${ }^{70}$.

Posteriormente, se editó a color una publicación resumen, en formato reducido, con la misma información original de la Red Arterial, si bien ahora mucho más manejable y visualmente más atractiva. Sin embargo, este intento de divulgación en busca de la aceptación popular se mostró inútil, al publicarse de manera no oficial, en el número de septiembre de 1968 de la revista madrileña La Gaceta Ilustrada, una perspectiva del destino propuesto para el antiguo cauce del Turia.

Este dibujo incluía, además de la autopista, un singular metropolitano aéreo, quizá como sustitución del subterráneo inicialmente previsto por García-Ordóñez. Las necesidades de movilidad se estaban llevando a un extremo nunca visto, introduciendo novedosos modos de transporte al modo de las referencias norteamericanas y japonesas, entonces tan de moda ${ }^{71}$. En cualquier caso, esta ilustración contribuyó decisivamente a desatar la posterior contestación ciudadana, dando al traste con uno de los pilares de la Adaptación del Plan a la Solución Sur.

Mención aparte merece también aquí el trabajo de información cartográfica que llevó a cabo la Oficina Regional de Proyectos a partir de la restitución fotográfica. Resulta significativo que estos medios tan avanzados estuvieran a disposición de una oficina dependiente del Ministerio de Obras Públicas, y no en la Dirección General de Urbanismo (o en la Corporación Administrativa encargada de la coordinación urbanística metropolitana). El caso es que la base que se pudo utilizar en la Red Arterial de Valencia contenía la información más actualizada en aquel momento.

El Plan de Etapas, grafiado en el Plano 6, y acompañado por las previsiones del Estudio Económico-Financiero (fechado en noviembre de 1964), también requiere un comentario para completar así el repaso a la documentación del Plan. La Oficina Técnica estableció cuatro etapas para el desarrollo de lo planificado, con diferente sombreado en el plano pero sin correspondencia directa con la documentación escrita, pues en el estudio se analizaban las superficies necesarias para ser urbanizadas -tanto de zonas residenciales como industriales- en ocho períodos (uno por década, alcanzando hasta el año 2040).

\footnotetext{
70 Así me lo comunicaron, en sendas entrevistas, tanto su viuda, Dña. Pilar García-Ontiveros, como el arquitecto Juan Calduch, colaborador suyo a comienzos de los ochenta en la inspección técnica provincial por parte del Ministerio de la Vivienda.

71 Las referencias cercanas eran algunas propuestas que se estaban haciendo para la Avenida del Generalísimo en Madrid, en las que se incluían monocarriles del tipo Alweg, como los instalados en 1959 en Seattle (Estados Unidos). La empresa japonesa Hitachi compró poco después la patente, construyendo varios de estos transportes en Tokyo y Osaka. Se trataba de vehículos de control automático manejados a velocidad constante desde un puesto de control.
} 

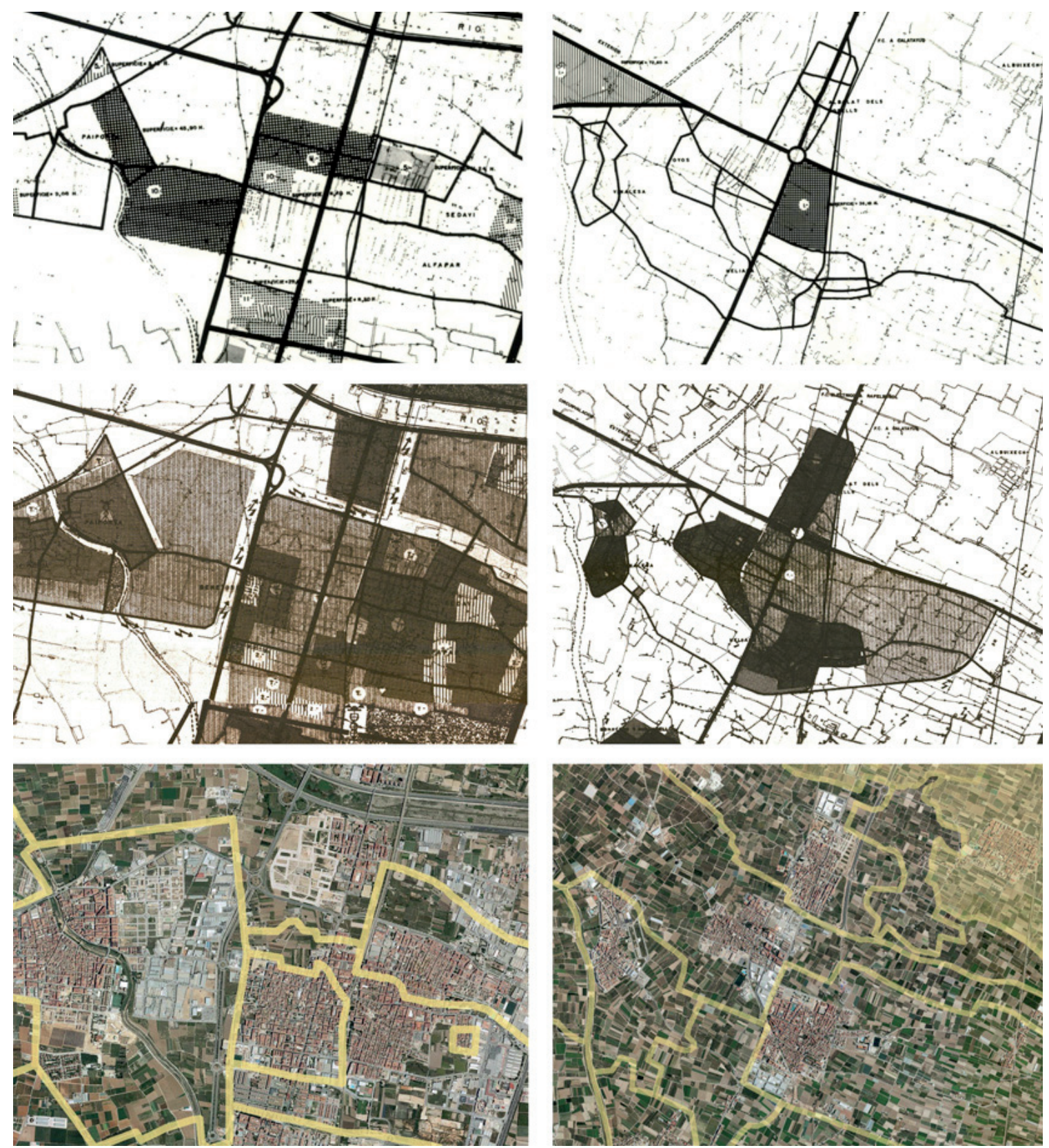

Figura 12. Se muestran, a modo de ejemplo, dos columnas con la comparación gráfica entre lo previsto por el plano 6 (Plan de Etapas) de la Adaptación del Plan a la Solución Sur, con lo grafiado en el plano 4 (Zonificación) y la realidad construida en 2008, más allá de los cuarenta años que planteaba la Oficina Técnica de Gran Valencia como horizonte de aplicación. En los primeros fragmentos, el sombreado oscuro corresponde a la Etapa I, la más urgente en cuanto a realización en 1963. Los dos sectores comparados son los núcleos al Sur del nuevo cauce, en torno a Benetúser (izquierda), y la unidad prevista para Meliana, Foyos y Albalat dels Sorells (derecha). En ambos se aprecia la no ejecución de lo previsto (salvo en la zona industrial colindante con Paiporta): a pesar de la prioridad concedida, ni la industria planificada entre los términos de Benetúser y Valencia, ni la zona de tolerancia industrial que había de favorecer la unidad urbana propuesta para el Norte de la comarca, fueron finalmente desarrolladas.

Fuente: Elaboración propia sobre originales del Archivo de Planeamiento del Ayuntamiento de Valencia, Archivo de Antonio Gómez y ortofotos del ICV 
Parece que la intención de este último documento era la de obtener, tras las estimaciones de crecimiento poblacional, el coste de urbanización necesario para afrontar la financiación con datos objetivos. A continuación me fijaré, sin embargo, en el aspecto estructurante del territorio.

La Etapa I contemplaba una urbanización de 510,83 Ha (de las cuales 194,81 eran para suelo industrial), para un crecimiento de 108.076 habitantes, aproximadamente la mitad de lo previsto hasta el año 1970. Se trataba, pues, de sectores de urgente realización ${ }^{72}$ : zonas en suelo consolidado de la capital, como los Polígonos de Castilla y Vara de Cuart (industrial), o el Plan Parcial no 11; el Polígono de Ademuz, desarrollado por la Gerencia de Urbanización; y otros núcleos que equilibrarían las necesidades industriales de la comarca, como la zona de tolerancia industrial entre Meliana y Foyos, la que había de rodear a Benetúser, o el polígono entre Chirivella y la unidad Alacuás-Aldaya.

En la segunda etapa, el Plan adoptó una postura más ambiciosa, urbanizando $642,41 \mathrm{Ha}$, de las cuales 134,29 correspondían a industria y el resto a residencial (76,22 a vivienda de lujo, 177,84 a vivienda tipo medio y 254,06 a vivienda modesta). Era preciso, pues, preparar suelo para 33.788 nuevas viviendas. Las zonas incluidas se correspondían con el crecimiento de la mayor parte de los poblados de la comarca. En Valencia, se apuntaba al Polígono de Campanar, al de la Fuente de San Luis y al veterano Barrio Residencial Burjasot-Benimamet, entre otros; mientras que en la periferia destacaban la franja de edificación abierta prevista al Oeste de Rocafort, y el Polígono industrial de Fuente del Jarro.

Las Etapas III y IV eran más modestas, previendo la urbanización de 348,20 y $277,25 \mathrm{Ha}$ respectivamente (sin embargo, el suelo industrial seguía siendo comparable a los períodos anteriores: 124,20 y 78,80 Ha). Para el final se dejaron, por ejemplo, la zona de edificación abierta y tolerancia industrial situada junto al nuevo acceso Sur a la capital (zona de Malilla), la zona de extensión de Torrente y la ciudad-jardín en el sector Norte de Godella.

Como ya se ha dicho, las 1.778,69 Ha previstas por el Plan de Etapas en su parte gráfica no se corresponden con las necesidades apuntadas hasta mitad del siglo XXI en la documentación escrita (2.860 Ha para suelo residencial y 782,80 para zona industrial), por lo que hay que estimar que las primeras se refieren al horizonte del año 2000, pues, tal y como dice la Memoria, la Adaptación se realiza con las previsiones de un futuro de cuarenta años.

A finales de 1965 se habían recibido ya, por parte de Gran Valencia, escritos de alegación al Plan por parte de particulares y de los ayuntamientos afectados ${ }^{73}$. El 30 de diciembre, el Consejo General adoptó los acuerdos para aceptar o rechazar dichas reclamaciones: se acordó, además, elevar a la Dirección General de Urbanismo el Proyecto aprobado para obtener la definitiva aprobación ministerial,

\footnotetext{
72 El Estudio Económico-Financiero planteaba un crecimiento hasta 1970 de 220.000 habitantes, siendo necesario alojamiento para 198.000. Precisaba la cifra de 528 Ha necesarias de suelo residencial, 144 de zona industrial y 73,92 de zonas verdes.

${ }^{73}$ La exposición al público de los planos y documentos correspondientes fue anunciada en el Boletín Oficial de la Provincia el 12 de agosto de 1965, disponiendo los interesados de un mes para formular sus alegaciones. Pasado el período de información pública, se abrió otro período de un mes para dar audiencia a las corporaciones locales a cuyo territorio afectaba el Plan, cosa que se hizo saber a los respectivos alcaldes por medio de oficio.
} 
debiendo acompañar a dicho proyecto las reclamaciones presentadas con los informes emitidos por la Oficina Técnica, consignando en cada una el acuerdo del Consejo General y ordenando que aquellas reclamaciones que hayan sido aceptadas por el Consejo se acompañen de un plano esquemático de la modificación introducida para mayor claridad.

Las reclamaciones que fueron aceptadas y que así lo precisaban se reflejaron en una serie de once planos de pequeño formato que Mauro Lleó firmó en enero de 1966 y se adjuntaron al expediente.

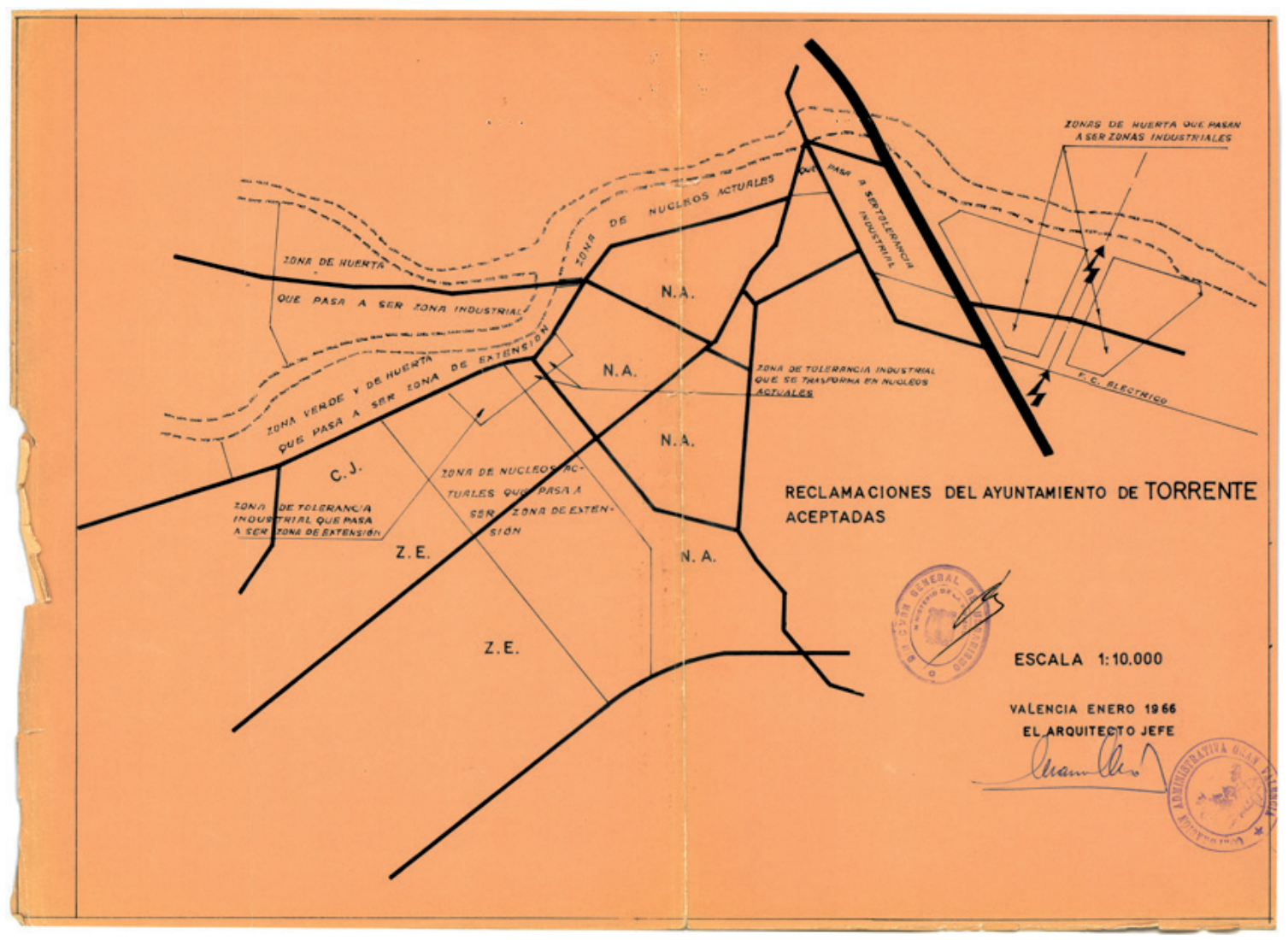

Figura 13. Plano con las reclamaciones del Ayuntamiento de Torrente aceptadas por la Oficina Técnica de la Gran Valencia en enero de 1966.

Fuente: AArchivo de Planeamiento del Ayuntamiento de Valencia

Además, se incluyeron muchos informes técnicos que no iban acompañados de documentación gráfica (relativos a Alfafar, Masanasa, Manises y Benetúser). En la práctica, casi todas las cuestiones planteadas por los ayuntamientos fueron atendidas, versando la mayor parte de las veces sobre zonas verdes que pasaban a calificarse como suelo industrial (salvo en Foyos, que modificó la calificación en sentido inverso), polígonos industriales que se ampliaban, o petición de pasarelas para conectar sectores urbanos divididos por la gran cantidad de viario previsto.

De esta forma, las corporaciones locales intensificaron la ocupación de huerta que había planteado la Oficina Técnica, suprimiendo zonas verdes, ciudad-jardín o 
deportivo-culturales por otras de mayor aprovechamiento. Así lo plantearon los ayuntamientos de Alboraya, Alfafar, Bonrepós, Cuart de Poblet, Meliana, Mislata, Paiporta, Sedaví y Torrente, entre otros. El Consejo General no quiso hacer acepción de municipios, y concedió la mayoría de solicitudes. Los informes técnicos, además, se mostraron favorables en todas las cuestiones viarias (desviación de carreteras, puentes, etc.), muchas de las cuales eran inapreciables a la escala de 1:10.000 utilizada.

El 21 de enero de 1966 se remitió la información (Planos, Memoria, Normas Urbanísticas, Estudio Económico y reclamaciones aceptadas) a Madrid. La Dirección General de Urbanismo dio su visto bueno, recibiendo plena sanción administrativa en el único artículo del Decreto 1988/1966, de 30 de junio, por el que se aprobaba la revisión y adaptación al Plan Sur del Plan General de Ordenación de Valencia y su Comarca (BOE 27/07/66).

Tras estas disposiciones, junto a la serie de diez planos de gran formato elaborados meses atrás (aunque conservaban la fecha de diciembre de 1963) cobraron plena validez normativa los planos esquemáticos firmados por el Arquitecto Jefe de la Oficina Técnica y los informes de los cuatro municipios sin documentación gráfica, que también recibieron el sellado y firma del Ministerio de la Vivienda (el 6 de marzo de 1967, el propio Bidagor ratificaba en un informe dirigido al Presidente de la Comisión Ejecutiva la correcta tramitación de la Adaptación), con lo que no fueron incluidos en una nueva versión de los planos. La documentación oficial se encontró, al final de su larga historia administrativa, dispersa entre planos e informes muy variados.

Con posterioridad, sí que se elaboraron por parte de la Oficina Técnica numerosos planos refundidos con las nuevas zonificaciones reclamadas por los municipios. Por supuesto, se trataba de copias no selladas, pero sirvieron como instrumento de trabajo para todas las corporaciones afectadas ${ }^{74}$. Así se encargó al equipo de Lleó desde el Consejo General en septiembre de 1966. En esa misma sesión se ordenó formular un informe clasificando, para cada uno de los ayuntamientos, los planes parciales en los grupos siguientes:

A) Planes parciales, debidamente aprobados, que estén en su totalidad de acuerdo con el plan general revisado.

B) Planes parciales, debidamente aprobados, que resulten afectados en pequeña parte por el plan general.

C) Planes parciales, debidamente aprobados, que resulten sustancialmente afectados por el plan general.

D)Planes parciales en tramitación, distinguiéndolos en las tres clases indicadas

E) Parte del plan revisado que no ha sido desarrollada en planes parciales.

A continuación, se encargó a la Oficina Técnica que determinara los plazos para la adaptación o nueva redacción de los distintos planeamientos. El nuevo Plan General

\footnotetext{
74 Se pueden distinguir claramente de los primeros planos, entre otros detalles, por la inclusión de las dos grandes zonas de huerta que pasaron a ser zonas industriales en la zona Este del término de Torrente, entre el ferrocarril eléctrico y el barranco de Chiva (por cierto, un suelo industrial que nunca se llegó a ejecutar).
} 
comenzó, pues, su andadura pendiente de su concreción por medio de los correspondientes planes parciales, una tarea en la que los arquitectos de la Corporación Administrativa participaron desde la primera línea, al menos en los sectores donde Gran Valencia había intervenido directamente con anterioridad.

\section{CONCLUSIONES}

La aprobación de la Adaptación del Plan General de Valencia, en el verano de 1966, significó de hecho el respaldo oficial a los planteamientos de desarrollo a gran escala en la comarca de Valencia, muestra de la entonces enorme confianza depositada en la economía española y el desarrollo asociado a ella. Así se entiende, por ejemplo, que sus redactores contemplaran sin inmutarse el número de viviendas que sería necesario construir en el período 2040-2050, o que desbordados ante el crecimiento descontrolado de la ciudad- confiaran la disposición y mantenimiento de las zonas verdes a cada uno de los proyectos parciales de desarrollo.
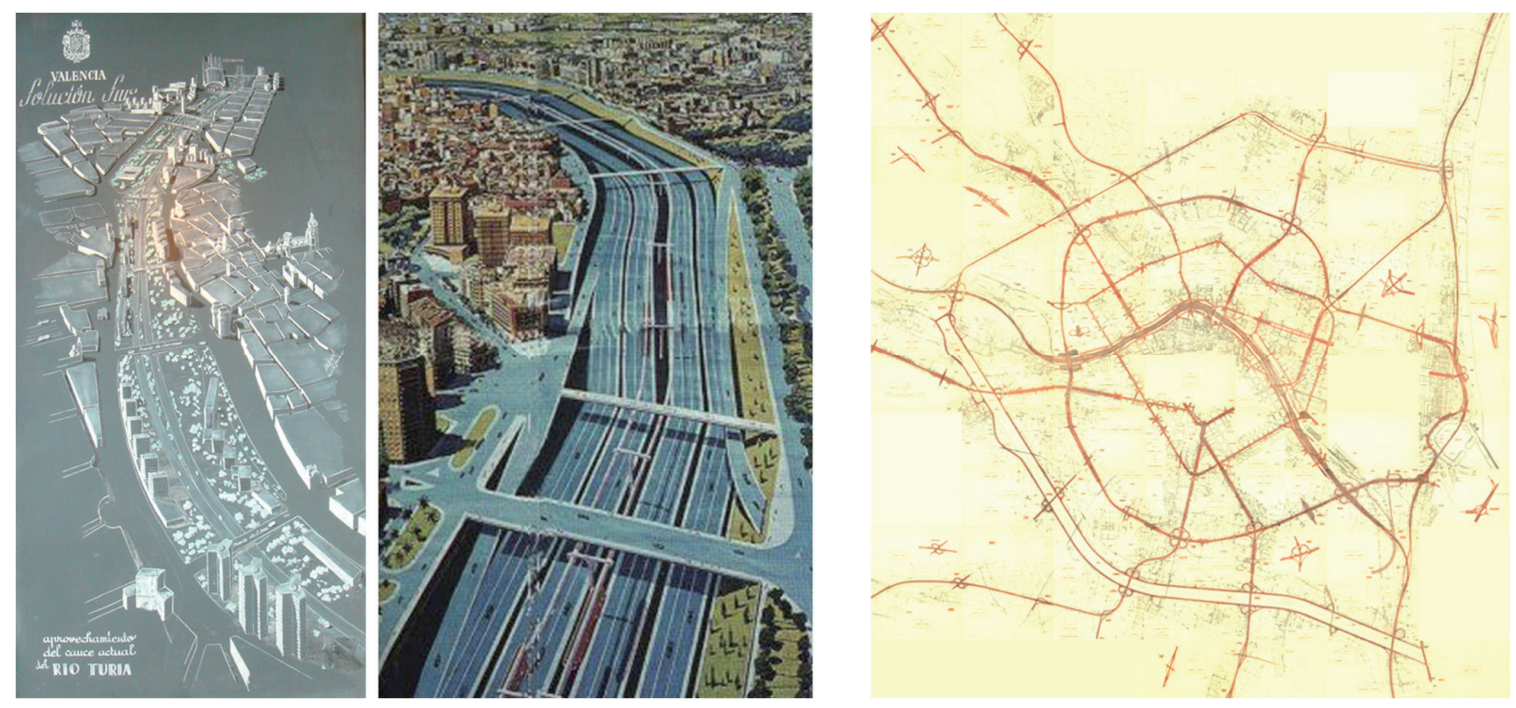

Figura 14. Perspectivas desde puntos de vista opuestos sobre la urbanización de los terrenos desalojados por el cauce: una relacionada con la maqueta elaborada por la Comisión Técnica Especial en 1958 (izquierda) y otra derivada de la Red Arterial de Valencia, publicada en 1968 en La Gaceta Ilustrada. A la derecha, montaje de 70 de las 100 hojas a escala 1:2.000 de que se componía la publicación divulgadora de la Red Arterial de Valencia, de febrero de 1966.

Fuente: Elaboración propia a partir de originales del Archivo de Planeamiento del Ayuntamiento de Valencia

Durante los años de tramitación de la Adaptación del Plan General a la Solución Sur, la doctrina urbanística en relación con las áreas metropolitanas se había ido consolidando. Buena muestra de ello es el ciclo de conferencias que el Instituto de Estudios de Administración Local organizó en Madrid durante el curso 1965-66. En él intervinieron destacados protagonistas del urbanismo español contemporáneo, como los ya citados Emilio Larrodera López, Gabriel Alomar Esteve y Fernando de Terán Troyano. 
El nuevo concepto urbano supramunicipal, acuñado con la denominación área metropolitana, concentró directamente la atención de varias intervenciones ${ }^{75}$. La Red Arterial de Valencia, que en ese momento estaba siendo redactada por la Oficina Regional de Proyectos, parece incluso responder a una de las primeras premisas que apuntó Larrodera en su conferencia para la solución de los problemas metropolitanos: las urgentes necesidades de transporte mediante vías de comunicación rápidas. Grandes vías rápidas aproximándose al centro, pero sin cruzarlo, al menos en superficie, enlazándose entre sí en zonas marginales con vías de circunvalación, para comunicar no sólo a las diferentes comunidades entre sí, sino a su vez a todas ellas con el centro del conjunto mediante la elección de nudos de comunicaciones, verdaderos centros neuromotores de las agrupaciones satélites.

El conferenciante continuaba: estos nudos o centros deben estar exentos de toda posibilidad de próxima edificación de cualquier carácter, con excepción de aquellos servicios necesarios para auxilio y ayuda de la circulación. Es claro, por tanto, que la selección de estos puntos clave de la malla viaria del área metropolitana es de gran importancia y su defensa imprescindible ${ }^{76}$.

Así, toda la prioridad concedida a las infraestructuras viarias -lo que hoy en día resulta uno de los aspectos menos respetuosos de aquel Plan General-, se contemplaba entonces como un sacrificio necesario, e incluso como una conquista urbana, pues adelantarse al crecimiento ingente que estaba por venir permitía solucionar hoy los problemas del futuro (las rectificaciones a posteriori tendrían una trascendencia económica que las volverían irrealizables).

Larrodera acuñó incluso el binomio red arterial en uno de sus epígrafes. En función de la geografía, la situación de los núcleos exteriores y su incorporación o adaptación al área metropolitana (y dando por supuesto la existencia de vías de circunvalación del núcleo central), la red radial se orientaría en una o varias direcciones, podrá ser una teoría completa circular de radios o, por el contrario, limitarse a una única vía radial importante. Esta nueva malla del área metropolitana recibió incluso una analogía orgánica, pues se definía como red circulatoria y sistema nervioso a la par.

Esta pretensión de validez científica universal, propia de un método contrastado por las experiencias norteamericanas, vino a desfigurar las propuestas viarias directamente relacionadas con la Solución Sur, generando tres niveles de anillos circulatorios (Camino de Tránsitos, Ronda Exterior y Circunvalación interior) junto con varios radios, y todo ello atravesado por las generosamente dimensionadas autopistas Madrid-Levante y la de Enlace Sur.

Manteniendo el debate en un plano terminológico, se llegó a establecer tácitamente la oposición conurbación/área metropolitana. La conurbación sería el

\footnotetext{
75 Se trata de El planeamiento en las áreas metropolitanas, de Larrodera, y Las áreas metropolitanas en España y en el extranjero, de Luis Jordana de Pozas. El propio Larrodera citaba a la Dirección General de Urbanismo a la hora de definir el criterio para la inclusión de ciudades españolas en este grupo: un tope mínimo de 100.000 habitantes para el conjunto, 50.000 habitantes para el Municipio polo, y (...) unos límites mínimos a la densidad -100 habitantes por hectárea-, al crecimiento demográfico -15 por cien en los últimos treinta años (...)- y, por último, una continuidad territorial.

76 Puede consultarse el texto completo en LARRODERA LÓPEZ, Emilio (1967). "El planeamiento en las áreas metropolitanas", conferencia incluida en Problemas del urbanismo moderno, Instituto de Estudios de Administración Local. Madrid.
} 
resultado de un crecimiento descontrolado de la ciudad central, que absorbe y fagocita los pequeños núcleos-satélite de su periferia. En cambio, el área metropolitana respondía al modelo equilibrado entre todos los núcleos urbanos contiguos, con un criterio limitador de mínimos basado en la población total.

El cambio de denominación no respondía, pues, a nuevos fundamentos teóricos del urbanismo. Aunque no se reconociera abiertamente, en el fondo todo parecía tratarse de una cuestión cuantitativa: las principales ciudades españolas estaban creciendo desmesuradamente, como resultado, entre otros factores, de un creciente éxodo rural. Pero el referente seguía siendo esa imagen canónica de la ciudad orgánica -ahora más grande y más compleja-, con sus barriadas autosuficientes rodeadas de cinturones verdes.

Incluso los numerosos intercambios técnicos que mantenían desde hacía años los urbanistas españoles -fruto de la apertura cultural que experimentó el paíscorroboraban el enfoque adoptado. Al estar tan atrasados con respecto a otras ciudades con mayor grado de urbanización, se tenía conciencia de llegar a tiempo para resolver los enormes problemas que estaban despuntando. Las grandes infraestructuras, junto a una adecuada y ambiciosa planificación basada en criterios técnicos, salvarían la ciudad.

Volviendo a la ciudad de Valencia, el nuevo enfoque -vamos a llamarlo asídesarrollista propició, como se ha visto, un planeamiento comarcal que pasó de ordenar 6.800 a 13.240 hectáreas (un aumento de casi un $95 \%$ con respecto al Plan de 1946), con una previsión de 40 años vista y un fortísimo incremento de suelo industrial y residencial, cifrado en unas 3.700 y 2.800 hectáreas, respectivamente (un $75 \%$ y un $170 \%$ más que el suelo así calificado en el anterior Plan).

Se pasó a ocupar, ya fuera con suelo urbano o reserva urbana (según la denominación utilizada por la Ley del Suelo de 1956) un 31\% del total del área de Gran Valencia, pero sin definir ni aclarar si el alcance territorial de la misma -el Área Metropolitana de Valencia- era el adecuado o necesitaba de una renovación. Las infraestructuras corregirían las carencias que pudieran derivarse de lo inapropiado de una entidad administrativa que iba camino de cumplir veinte años. Y entre todas ellas, entre las grandes inversiones previstas para la Valencia del futuro, la principal era -sin duda- el desvío del río Turia.

La construcción del nuevo cauce adquirió unas dimensiones hasta el momento no igualadas en la obra civil (se excavaron $11.173 .000 \mathrm{~m}^{3}$ de tierra y se ejecutaron más de $420.000 \mathrm{~m}^{3}$ de hormigón armado, además de $71 \mathrm{~km}$ de acequias), con la diferencia fundamental con respecto a la red arterial de que éste sí recibió una financiación adecuada, y año tras año se fue convirtiendo en una realidad.

En resumen, el Plan General de Valencia y su Comarca de 1966 supuso el mejor manifiesto de la mente planificadora de su tiempo: un ambicioso documento que extrapoló los anteriores postulados fundamentándose en una confianza ciega en el desarrollo económico y la capacidad de las infraestructuras para resolver los problemas urbanos. El resultado fue la propia pérdida de referencias organicistas, una planificación a gran escala que desvirtuó las bases en que pretendía apoyarse. 


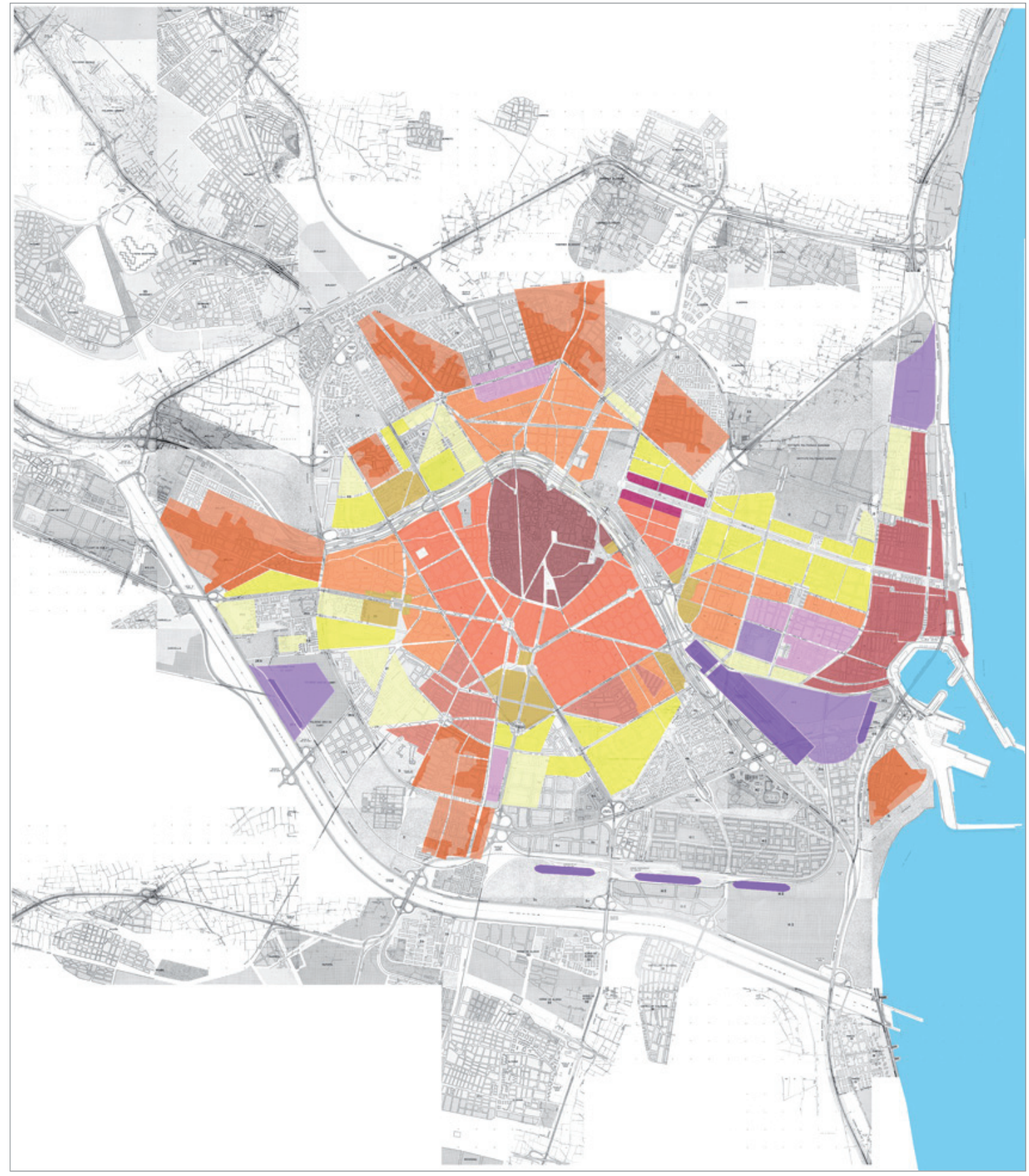

Figura 15. Superposición de dos concepciones opuestas de la ciudad central, que permite comparar la proyectada por García-Ordóñez en 1959 (en color) con la prevista por el planeamiento en 1974 (en gris, al fondo).

Fuente: Elaboración propia a partir del Plano III de la Ordenación de Valencia (Archivo Histórico Municipal del Ayuntamiento de Valencia), sobre montaje de las hojas de información urbanística del informe PREVASA (Archivo de Arquitectura y Urbanismo de la ETSAV). 
Sin embargo, no hay que caer en el error de entenderlo como un documento monolítico, fruto de una reflexión teórica unívoca. Como se ha podido comprobar, su accidentada tramitación lo convirtió en un plan lleno de compromisos, en la que la oportunidad política y el clima cultural de euforia desvirtuaron los planteamientos iniciales nacidos de la Comisión Técnica Especial. La incierta posición de la Gran Valencia -en una década en que el Ayuntamiento de la capital adquirió un protagonismo excesivo- no ayudó precisamente a la defensa de los criterios técnicos, quedando muchas veces sus arquitectos condicionados por decisiones ajenas a su voluntad.

Los interesantes trabajos aquí presentados -el Plan General de Valencia de García-Ordóñez (1959), el Plan General del Sector Burjasot, Benimamet, Paterna, Godella y Rocafort (1961), o la redacción previa de la Adaptación del Plan (1963)compensan el enfoque negativo que hasta hoy pesa sobre los arquitectos responsables del documento definitivo ${ }^{77}$. Una intrahistoria compleja para un momento convulso, que en cualquier caso merece la pena sacar a la luz. Dejar atrás los relatos mitificantes, más propios del conocimiento posmoderno que de un riguroso análisis científico, nos ayudará a reconstruir adecuadamente nuestra historia reciente y, por qué no decirlo, aprender de los errores cometidos.

\section{ARCHIVOS CONSULTADOS}

Archivo Histórico de la Generalitat Valenciana

Archivo de Planeamiento del Ayuntamiento de Valencia

Archivo Histórico Municipal del Ayuntamiento de Valencia - Palacio de Cervelló

Archivo de Arquitectura y Urbanismo de la ETSAV

Archivo de Urbanismo del Colegio Territorial de Arquitectos de Valencia

Archivo Histórico del Colegio Territorial de Arquitectos de Valencia

Archivo General de la Administración (AGA). Alcalá de Henares, Madrid

Archivo General del Ministerio de Fomento. Madrid

Archivo Central del Ministerio de Vivienda, Ministerio de Fomento. Madrid

Archivo profesional de Mauro Lleó Serret

Archivo profesional de Víctor Bueso Bellot

Archivo profesional de Antonio Gómez Llopis

Archivo personal de Fernando Martínez García-Ordóñez

Archivo personal de Antonio García Heredia

Hemeroteca Municipal de Valencia

Biblioteca del Colegio Territorial de Arquitectos de Valencia

77 Se puede consultar la totalidad de la documentación original, incluida la del Plan General definitivamente aprobado en 1966, en el Anexo de SELVA ROYO, Juan Ramón (2014), 29+1. La ordenación urbanística..., ob. cit. 


\section{BIBLIOGRAFÍA}

ANGELUCCI, Suzanne R. (1959). The world's metropolitan areas. Berkeley: Institute of International Studies, University of California Press (versión en español: Las áreas metropolitanas del mundo, Compañía Editorial Continental S.A. México, 1961).

BIDAGOR LASARTE, Pedro (1967). "Situación general del urbanismo en España", en Revista de Derecho Urbanístico, no 4. Madrid.

CONSELLERÍA D'OBRES PÚBLIQUES, URBANISME I TRANSPORTS (1986). La Gran Valencia, Trayectoria de un Plan General. Valencia: COPUT-Generalitat Valenciana.

DELEGACión DEL GOBIERNO (1958). Valencia - Ordenación Técnica de la Ciudad y su Comarca. Valencia.

GAJA DÍAZ, Fernando; BOIRA MAIQUES, Josep Vicent (1994). "Planeamiento y realidad urbana en la ciudad de Valencia (1939-1989)", en Cuadernos de Geografía, no 55 . Valencia: Universidad de Valencia. 1994.

GARCÍA HEREDIA, Antonio (2008), "Principio y fin del área metropolitana de Valencia. De la autarquía a la democracia", en Historia de la ciudad V. Tradición y progreso. Valencia: ÍCARO (Colegio Territorial de Arquitectos de Valencia).

GARCÍA-ORDÓÑEZ, Fernando M. (1958). "Un plan regional: nueva Valencia". Nuestro Tiempo, no 45, Pamplona.

- (1959) "La renovación urbana en Valencia", en Boletín Informativo y cultural del Ateneo Mercantil. Valencia.

- (2006) "Memorias profesionales", sin publicar. Valencia.

GIMÉNEZ BALDRÉS, Enrique (1996). Parcelaciones Residenciales Suburbanas. La formación de la periferia metropolitana de Valencia. Valencia: Generalitat Valenciana, COACV y Universidad Politécnica de Valencia.

LARRODERA LÓPEZ, Emilio (1967). "El planeamiento en las áreas metropolitanas", en Problemas del urbanismo moderno, Instituto de Estudios de Administración Local. Madrid.

LARRODERA LÓPEZ, Emilio; GARCÍA ORDÓÑEZ, Fernando (1962), "Planes Generales con aplicación al Plan General de Valencia", Sesión de estudio para el $1^{\text {er }}$ Congreso Nacional de Urbanismo 'La Gestión Urbanística', Barcelona, 1959. Madrid: Ministerio de la Vivienda, Secretaría General Técnica.

LLEÓ SERRET, Mauro (1971). "El arte y el planeamiento urbano. La preocupación artística en los núcleos urbanos a través de la prehistoria y la historia", discurso de ingreso en la Real Academia de Bellas Artes de San Carlos de Valencia, en Archivo de Arte Valenciano no 42. Valencia.

LLOPIS ALONSO, Amando (2010), "El Jardín del Turia: otros tiempos, otros proyectos, otras imágenes", en Historia de la ciudad VI. Proyecto y complejidad. Valencia: ÍCARO (Colegio Territorial de Arquitectos de Valencia). 
MINISTERIO DE LA VIVIENDA (1965). Gerencia de Urbanización 1959/1964. Madrid.

PEÑÍN IBÁÑEZ, Alberto (1978). Valencia 1874-1959. Ciudad, arquitectura y arquitectos. Valencia: Escuela Técnica Superior de Arquitectura de Valencia.

PÉREZ IGUALADA, Javier (2012). "La ciudad de la edificación abierta. Valencia 1946-1988". Director: Luis Alonso de Armiño. Valencia: Universidad Politécnica de Valencia, Departamento de Urbanismo ETSAV.

ROQUETTE RODRÍGUEZ-VILLAMIL, Juan Luis (2011). "La arquitectura de Julio Cano Lasso". Director: Juan Miguel Otxotorena Elizegui. Pamplona: Universidad de Navarra, Escuela Técnica Superior de Arquitectura.

SELVA ROYO, Juan Ramón (2007), "Fernando Martínez García-Ordóñez. Trayectoria profesional", en ViA Arquitectura. Premios 2005-2006. Valencia: Colegio Oficial de Arquitectos de la Comunidad Valenciana.

- (2013) FMGO, Fernando M. García-Ordóñez, Arquitecto. 1954-1983. Disponible en internet (formato ibooks): <https://itunes.apple.com/es/book/fmgo/id626795424?mt=11>.

TERÁN TROYANO, Fernando de (1982). Planeamiento urbano en la España contemporánea. 1900-1980. Madrid: Alianza. 
LOS CUADERNOS DE INVESTIGACIÓN URBANÍSTICA publicados por el Departamento de Urbanística y Ordenación del Territorio desde el año 1993, difunden bimensualmente aquellos trabajos de investigación realizados en el área del Urbanismo, la Ordenación Territorial, el Medio Ambiente, la Planificación Sostenible y el Paisaje, que por sus características, muchas veces de investigación básica, tienen difícil salida en las revistas profesionales. Su objetivo es la difusión de estos trabajos, en el convencimiento de que es necesario potenciar el uso de este idioma entre el mundo científico para conseguir alcanzar ámbitos de difusión a los que, de otra forma, no se podría acceder.

Su formato no es el convencional de una revista de este tipo, con artículos de diferentes autores que, en realidad, abordan aspectos parciales de cada trabajo, muy adecuados para la difusión y el conocimiento rápido de los mismos, pero que no pueden profundizar demasiado debido a su limitada extensión, sino que se trata de amplios informes de la investigación realizada que ocupan la totalidad de cada número. Esto permite, sobre todo a aquellos investigadores que se inician, el tener accesibles los aspectos más relevantes del trabajo y conocer con bastante precisión el proceso de elaboración de los mismos.

La realización material de los Cuadernos de Investigación Urbanística está a cargo del Departamento de Urbanística y Ordenación del Territorio de la Escuela Técnica Superior de Arquitectura de Madrid, garantizándose el respeto de la propiedad intelectual, pues el registro es siempre en su totalidad propiedad del autor. Está permitida su reproducción parcial en las condiciones establecidas por la legislación sobre propiedad intelectual citando autor, previa petición de permiso al mismo.

\section{NORMAS DE PUBLICACIÓN}

Las condiciones para el envío de originales se pueden consultar en la página web:

http://www.aq.upm.es/Departamentos/Urbanismo/publicaciones/ciurpublicar.html

\section{FORMATO DE LAS REFERENCIAS}

Monografías: APELLIDOS (S), Nombre (Año de edición). Título del libro (No de edición). Ciudad de edición: Editorial [Traducción castellano, (Año de edición), Título de la traducción, No de la edición. Ciudad de edición: editorial].

Partes de monografías: APELLIDOS (S), Nombre (Año de edición). "Título de capítulo". En: Responsabilidad de la obra completa, Título de la obra (No de edición). Ciudad de edición: Editorial.

Artículos de publicaciones en serie: APELLIDOS(S), Nombre (Año de publicación). "Título del artículo", Título de la publicación, Localización en el documento fuente: volumen, número, páginas.

Asimismo, se recuerda que el autor tendrá derecho a tres ejemplares gratuitos.

\section{CONSULTA DE NÚMEROS ANTERIORES/ACCESS TO PREVIOUS WORKS}

La colección completa se puede consultar en color y en formato pdf en siguiente página web:

The entire publication is available in pdf format and full colour in the following web page:

http://www.aq.upm.es/Departamentos/Urbanismo/publicaciones/ciurnumeros.html

\section{ÚLTIMOS NÚMEROS PUBLICADOS:}

96 Irina Tumini: "The urban microclimate in open space. Case studies in Madrid", 78 páginas, Septiembre 2014.

95 Luz Elena Cornejo Ganga: "Categorías de análisis de un modelo de planificación turística sustentable", 96 páginas, Julio 2014.

94 Mattia Bertin: "Cittá al limite. Per una trattazione urbanística del disastro", 78 páginas, Mayo 2014.

93 Luis Alberto Salinas Arreortúa: "Transformaciones urbanas en el contexto neoliberal", 74 páginas, Marzo 2014.

92 Pedro Fidalgo: "Aportaciones para la definición de elementos visuales determinantes del paisaje", 92 páginas, Enero 2014. 


\title{
PROGRAMA OFICIAL DE POSGRADO EN ARQUITECTURA
MASTER PLANEAMIENTO URBANO Y TERRITORIAL

\author{
PREINSCRIPCIÓN DEL 15 DE MARZO AL 27 DE JUNIO DE 2014 \\ COORDINADORA DEL MÁSTER: Ester Higueras García \\ PERIODO DE DOCENCIA: Septiembre 2014 -Junio 2015 \\ MODALIDAD: Presencial y tiempo completo \\ NUMERO DE PLAZAS: 40 plazas \\ CREDITOS: 60 ECTS
}

\begin{abstract}
El Máster se centra en la comprensión, análisis, diagnóstico y solución de los problemas y la identificación de las dinámicas urbanas y territoriales en curso, atendiendo a las dos dimensiones fundamentales del fenómeno urbano actual: por un lado, el proceso de globalización y, por otro lado, las exigencias que impone la sostenibilidad territorial, económica y social. Estos objetivos obligan a insistir en aspectos relacionados con las nuevas actividades económicas, el medio físico y natural, el compromiso con la producción de un espacio social caracterizado por la vida cívica y la relación entre ecología y ciudad, sin olvidar los problemas recurrentes del suelo, la vivienda, el transporte y la calidad de vida. Estos fines se resumen en la construcción de un espacio social y económico eficiente, equilibrado y sostenible. En ese sentido la viabilidad económica de los grandes despliegues urbanos y su metabolismo se confrontan con modelos más maduros, de forma que al estudio de las técnicas habituales de planificación y gestión se añaden otras nuevas orientaciones que tratan de responder a las demandas de complejidad y sostenibilidad en el ámbito urbano.
\end{abstract}

El programa propuesto consta de un Máster con dos especialidades:

- Especialidad de Planeamiento Urbanístico (Profesional)

- Especialidad de Estudios Urbanos (Investigación Académica)

Se trata de 31 asignaturas agrupadas en tres módulos:

MÓDULO A. Formación en Urbanismo.

MÓDULO B. Formación en Estudios Urbanos e Investigación.

MÓDULO C. Formación en Planeamiento.

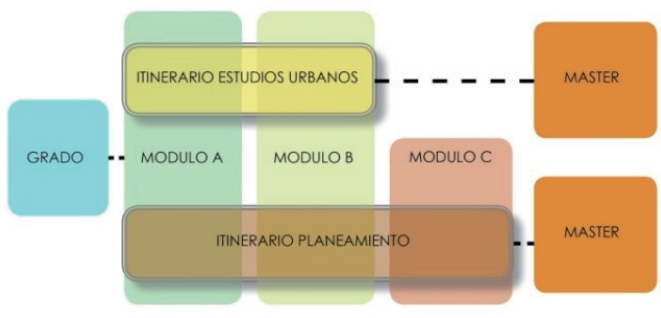

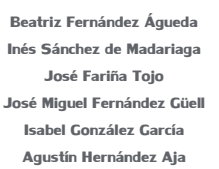

Agustín Hernández Aja

\section{PROFESORADO:}

Ester Higueras García

Francisco José Lamiquiz

Julio Pozueta

Fernando Roch Peña

elipe Colavidas

osé María Ezquiaga
Llanos Masiá

Javier Ruiz Sánchez

Carlos Verdaguer

Enrique Villa Polo

Carmen Andrés Mateo

Álvaro Sevilla

ENTIDADES COLABORADORAS:

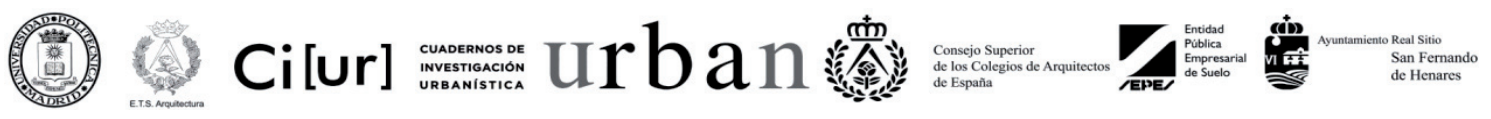

CONTACTO: masterplaneamiento.arquitectura@upm.es

www.aq.upm.es/Departamentos/Urbanismo/masters/index.html 


\section{ALGUNAS DE LAS ACTIVIDADES REALIZADAS DURANTE EL CURSO 2014/15...}
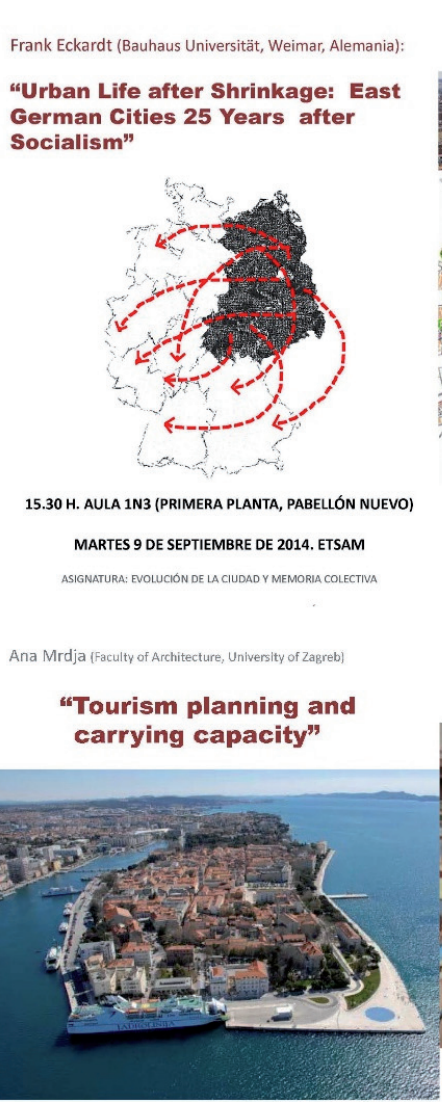

11.30 H. SALA DE GRADOS B (PABELLón ANTIGUO) JUEVES 18 DE SEPTIEMBRE DE 2014. ETSAM ASIG NATURA: SEMI IARIO EN LINEAS DE INVESTIGACIÓN

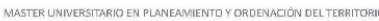

VIERNES 26 DE SEPTIEMBRE DE 2014

MASTER UNIVERSITARIO EN PLANEAMIENTO Y ORDENACIÓN DEL TERRITORIO
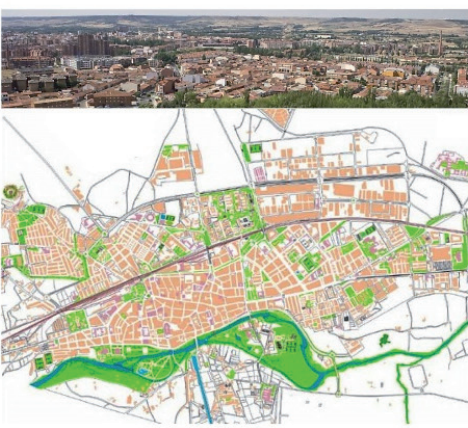

"Visita a la ciudad de Palencia"

RECEPCIÓN EN EL AYUNTAMIENTO Y PASEO POR LA CIUDAD Y SUS BARRIOS

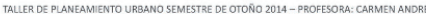

MIÉRCOLES 11 DE FEBRERO DE 2015. ETSAM MASTER UNIVERSTIARIO EN PLANEAMIENTO Y ORDENACIÓN OEL TERRITORIO

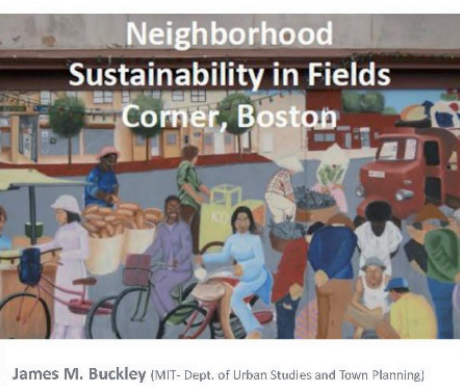

"Urban regeneration in USA"

11.30 H. AULA 1N3 (AULA MÁSTER)

INAUGURACÓN ACADEMICA DEL SEGUNDO SEMESTRE DEL MASTER
Jasé Fariña Tojo (Catedrático UPM, DUyOT)

Luis Felipe Alonso Teixidor (Catedrático "Ad Honorem" UPM, Duyo Ramón López de Lucio fCatedrático "Ad Honarem" UPM, DUyOT,

"El sprawl y su paisaje"

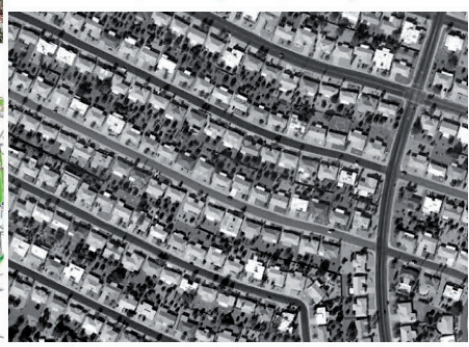

11.30 H. SALA DE GRADOS B (PABELLÓN ANTIGUO)

JUEVES 9 DE OCTUBRE DE 2014. ETSAM

ASIGNATURA: SEMINARRO EN LINEAS DE INVESTIGACION

IMASTER UNNERSTTARIO EN PLANEAMIENTO Y ORDENACIÓN DEL TERRTOPIO

MIÉRCOLES 5 DE NOVIEMBRE DE 2014. ETSAM MASTER UNIVERSTIARIO EN PLANEAMIENTO Y ORDENACIÓN DEL TERRITORIO

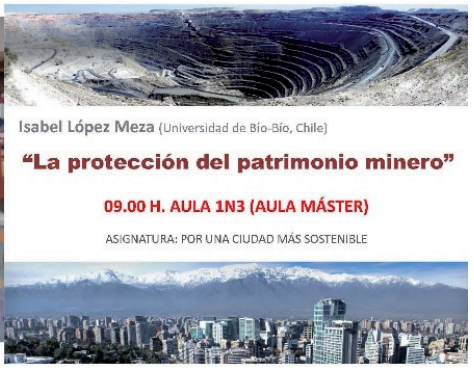

Mario Torres Jofré (Universidad de Chile)

“La ciudad contemporánea. Una perspectiva crítica"

$16.00 \mathrm{H}$. AULA 1N3 (AULA MÁSTER) ASIGNATURA: PROYECTAR LA CIUDAD COMPLEIA

VIERNES 27 DE FEBRERO DE 2015 JUEVES 19 DE MARZO DE 2015 MIÉRCOLES 25 DE MARZO DE 2015

MASTER UNIIERSITARIO EN PLANEAMIENTO Y ORDENACIÓN DEL TERRITORIO MASTER UNIIERSITARIO EN PLANEAMIENTO Y ORDENACIÓN DEL TERRITORIO MASTER UNIVERSITARIO EN PLANEAMIENTO Y ORDENACIÓN DEL TERRITORIO

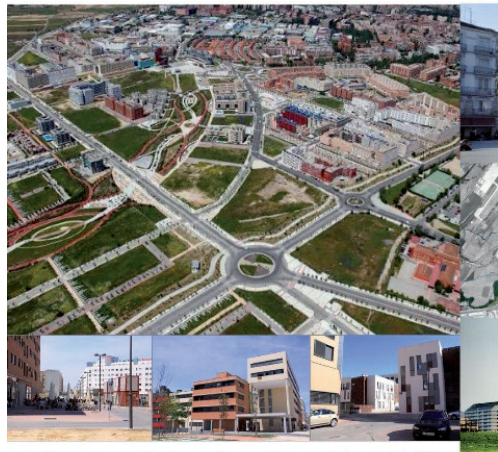

"Visita a Móstoles Sur (Madrid)"

15.30 H. METRO MANUELA MALASAÑA (METROSUR)

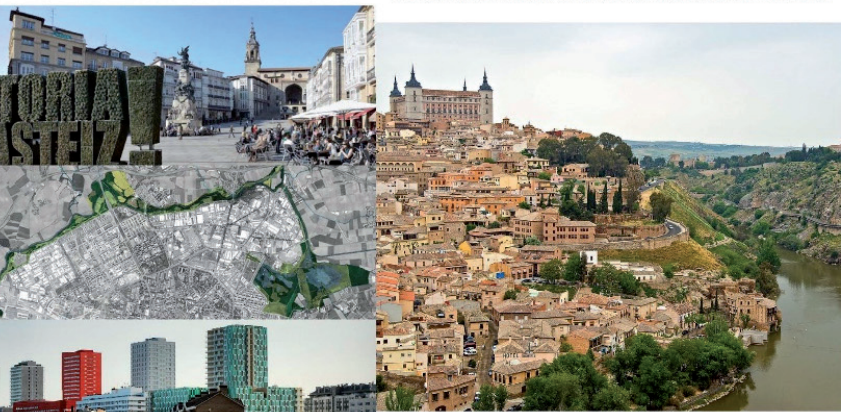

"Visita a Toledo"

16.00 H. PLAZA DE ZOCODOVER (CENTRO)

JOINT WORKSHOP-SPRING 2015 - EVOLVING CITIES

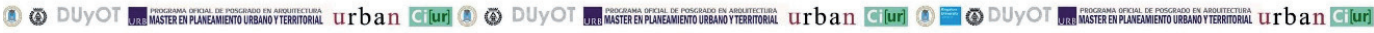


Otros medios divulgativos del Departamento de Urbanística y Ordenación del Territorio:

\section{urbain}

ReVISTA del Departamento de URBanística y ORDENACIÓN del TERRITORIO

ESCUELA TÉCNICA SUPERIOR DE ARQUITECTURA

\section{PRESENTACión SEgUNDA ÉPOCA}

DESDE el año 1997, URBAN ha sido vehículo de expresión de la reflexión urbanística más innovadora en España y lugar de encuentro entre profesionales y académicos de todo el mundo. Durante su primera época la revista ha combinado el interés por los resultados de la investigación con la atención a la práctica profesional, especialmente en el ámbito español y la región madrileña. Sin abandonar dicha vocación de saber aplicado y localizado, la segunda época se centra en el progreso de las políticas urbanas y territoriales y la investigación científica a nivel internacional. Ayer y hoy, nuestro objetivo es contribuir al desarrollo de las técnicas y modelos de ciudad y territorio, desde una perspectiva crítica y conjugando las ventajas de nuestra posición en la encrucijada entre el Norte y el Sur globales, entre Europa, el Mediterráneo y Latinoamérica.

Apoyándose en cuatro vectores de interés -carácter generalista y transversal, espíritu crítico, visión regional de los procesos globales y recuperación de la memoria de la disciplina- la nueva URBAN se propone servir de espacio para un debate en el que la planificación se juegue sus condiciones de posibilidad. Frente a la deriva disciplinar de las últimas décadas, frente al desplazamiento paulatino del lugar social de la planificación urbana y territorial en los modos de gobierno, nos parece urgente replantear el papel que ésta merece en las economías políticas de la producción de espacio.

\section{CONVOCATORIA PARA LA RECEPCIÓN DE ARTÍCULOS: nº6- Teoría urbana. Estados del arte}

Sin una teoría urbana consistente nunca habrá buen urbanismo. Este problemático aforismo podría servir para abrir el debate que la revista Urban se propone albergar en un próximo número especial. La teoría urbana (teoría de la ciudad, teoría del proceso urbanizador) ha presentado una relación histórica compleja con la práctica de la planificación y las políticas de la ciudad y el territorio: anticipación de mundos más o menos felices, re-conocimiento pericial de fenómenos urbanos ya materializados, interpretación crítica que re-imagina el pasado y el presente de la ciudad y el territorio, abriéndolos a un nuevo horizonte... El trabajo teórico es, qué duda cabe, un indicador efectivo de la salud y orientación de la disciplina urbanística pero ¿es también un arma cargada de futuro? ¿Cabe aún idear teorías capaces de cambiar los hechos de un mundo urbano que se presenta cada vez más complejo, abigarrado y ajeno a cualquier indicio de racionalidad? ¿Debe la teoría conformarse, por el contrario, con adoptar una actitud de 'testigo modesto', buscar producciones de sentido en los intersticios de los discursos urbanos dominantes? ¿Qué perspectivas teóricas debemos perseguir, con qué herramientas conceptuales y en qué marcos intelectuales? ¿Cómo debe la teoría pensar su articulación con la práctica? ¿Qué tipo de teoría demanda nuestro mundo urbano en un contexto de crisis global? ¿En qué medida los ensayos por comprender la crisis pueden contribuir a ensanchar el campo teórico del fenómeno urbano?

Este número especial de la revista Urban pretende albergar aportaciones internacionales que exploren sistemática y críticamente los estados del arte en los distintos campos de la teoría urbana y los conecten a las tendencias más amplias de la teoría social contemporánea - de la planificación a la geografía, de la sociología a la historia y más allá, en el horizonte general del conocimiento técnico, las ciencias sociales y las humanidades. Serán especialmente bienvenidas las contribuciones que analicen corrientes actuales de reflexión sobre las intersecciones de ciudad, economía, sociedad, política, cultura, tecnología, naturaleza, medio ambiente, diseño, instituciones... Asimismo se espera que los autores consideren y problematicen la articulación entre teoría y práctica urbanística, recordando que 'la experiencia sin teoría es ciega, pero también que la teoría sin experiencia es un mero juego intelectual’. En definitiva ¿cómo puede contribuir la teoría urbana a cambiar no sólo el conocimiento y discurso sobre la ciudad, sino también los propios procesos que 
la sostienen y transforman? ¿Enfrenta el urbanismo un horizonte de 'miseria de la teoría' o, por el contrario, cabe imaginar un futuro floreciente y un lugar propio para la teoría urbana en el campo más amplio de la teoría social?

Urban mantiene abierta una convocatoria permanente para la remisión de artículos de temática relacionada con los objetivos de la revista: Para más información:

http://www2.aq.upm.es/Departamentos/Urbanismo/institucional/publicaciones/urban/ns/instrucciones-para-autores/

Por último, se recuerda que, aunque La revista URBAN organiza sus números de manera monográfica mediante convocatorias temáticas, simultáneamente, mantiene siempre abierta de forma contínua una convocatoria para artículos de temática libre.

\section{DATOS DE CONTACTO}

Envío de manuscritos y originales a la atención de Álvaro Sevilla Buitrago: urban.arquitectura@upm.es

Página web: http://www.aq.upm.es/Departamentos/Urbanismo/public/urban/info.html

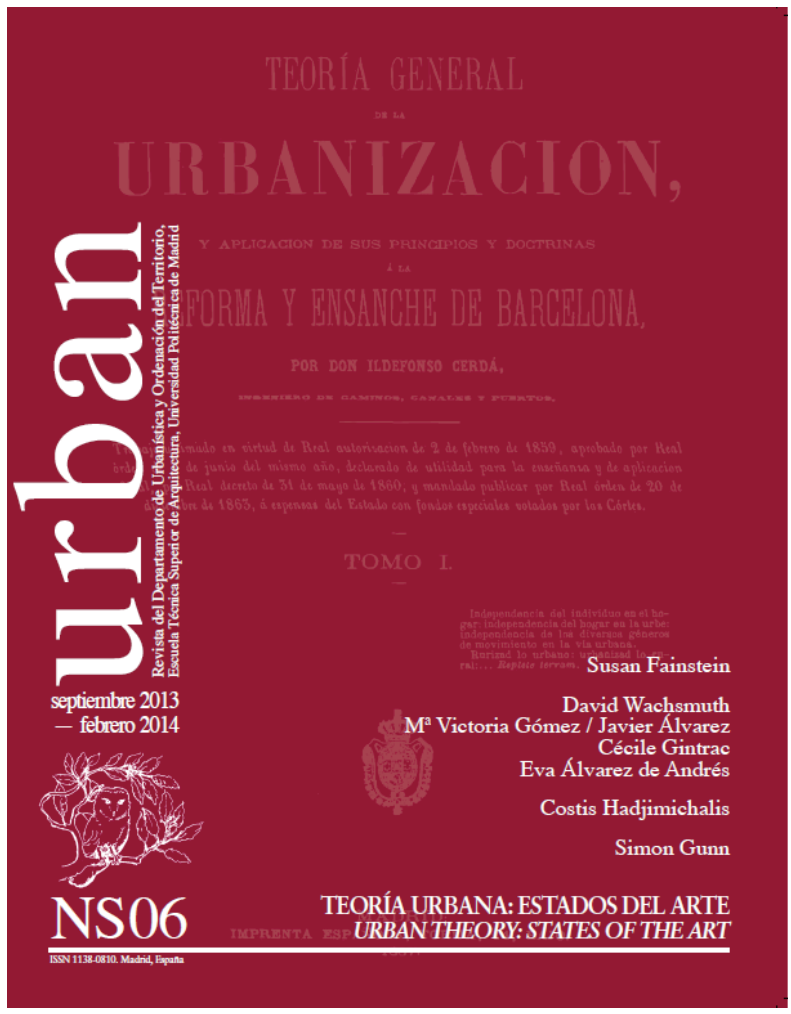

Consulta y pedido de ejemplares: ciur.urbanismo.arquitectura@upm.es

Web del Departamento de Urbanística y ordenación del Territorio:

http://www.aq.upm.es/Departamentos/Urbanismo

Donde figuran todas las actividades docentes, divulgativas y de investigación que se realizan en el Departamento con una actualización permanente de sus contenidos. 